\title{
WestVirginiaUniversity
}

THE RESEARCH REPOSITORY @ WVU

Graduate Theses, Dissertations, and Problem Reports

2009

\section{Capacitive sensor technology for polyethylene pipe fault detection}

Travis W. Kirby

West Virginia University

Follow this and additional works at: https://researchrepository.wvu.edu/etd

\section{Recommended Citation}

Kirby, Travis W., "Capacitive sensor technology for polyethylene pipe fault detection" (2009). Graduate Theses, Dissertations, and Problem Reports. 2764.

https://researchrepository.wvu.edu/etd/2764

This Thesis is protected by copyright and/or related rights. It has been brought to you by the The Research Repository @ WVU with permission from the rights-holder(s). You are free to use this Thesis in any way that is permitted by the copyright and related rights legislation that applies to your use. For other uses you must obtain permission from the rights-holder(s) directly, unless additional rights are indicated by a Creative Commons license in the record and/ or on the work itself. This Thesis has been accepted for inclusion in WVU Graduate Theses, Dissertations, and Problem Reports collection by an authorized administrator of The Research Repository @ WVU. For more information, please contact researchrepository@mail.wvu.edu. 
CAPACITIVE SENSOR TECHNOLOGY FOR POLYETHYLENE PIPE FAULT DETECTION

\author{
by \\ Travis W. Kirby \\ Thesis submitted to the College of Engineering and Mineral Resources \\ at West Virginia University \\ in partial fulfillment of the requirements \\ for the degree of \\ Master of Science \\ in \\ Electrical Engineering
}

Approved by

Roy S. Nutter, Ph.D. Committee Chairperson

Mark Jerabek, Ph.D.

Lawrence Hornak, Ph.D.

Lane Computer Science and Electrical Engineering

Morgantown, West Virginia

2009

Keywords: Capacitive Sensor, Polyethylene Pipe, Fault Detection 


\section{ABSTRACT \\ Capacitive Sensor Technology For Polyethylene Pipe Fault Detection}

\section{Travis W. Kirby}

This work develops a Finite Element Analysis simulation to determine if capacitive sensors can be used to detect defects in polyethylene gas distribution pipes. Currently, there is no in ground detection system to find the defect. Catastrophic results can occur if gas leaks are present and ignite. Finite Element Analysis (FEA) software will be used to simulate how different shapes and sizes of capacitive sensors affect the electric field, which affect capacitance when the dielectric of a material changes. An optimal electrode size and shape was chosen from these simulations, built, and tested at the Battelle Pipeline Safety Research \& Development Program. The sensor was run through multiple tests on a thirteen foot long, six inch diameter polyethylene pipe with a half inch wall thickness where random defects were placed in the pipe. Upon completion of the test, the data was analyzed, and it determined that the capacitive sensor detected all known defects in the polyethylene pipe. 


\section{ACKNOWLEDGEMENTS}

This work would not have been possible without the support and encouragement of my colleague and friends, William Fincham of Parson, and James Spenik and Chris Condon of REM Engineering Services. Their guidance, mentorship, and teachings made it a pleasure and have made many great memories that will last a life time.

I would also like to thank Dr. Roy S. Nutter, my advisor, for giving me the opportunity to work on this project. The opportunity allowed me to expand on my engineering skills, and demonstrate my professionalism that has now grown into more opportunities for my career, both civilian and military. Also to thank Dr. Nutter for his help in the final stages of the report, who has also been abundantly helpful, and has assisted me in numerous ways, including summarizing the contents of documents and providing guidance where needed. 


\section{TABLE OF CONTENTS}

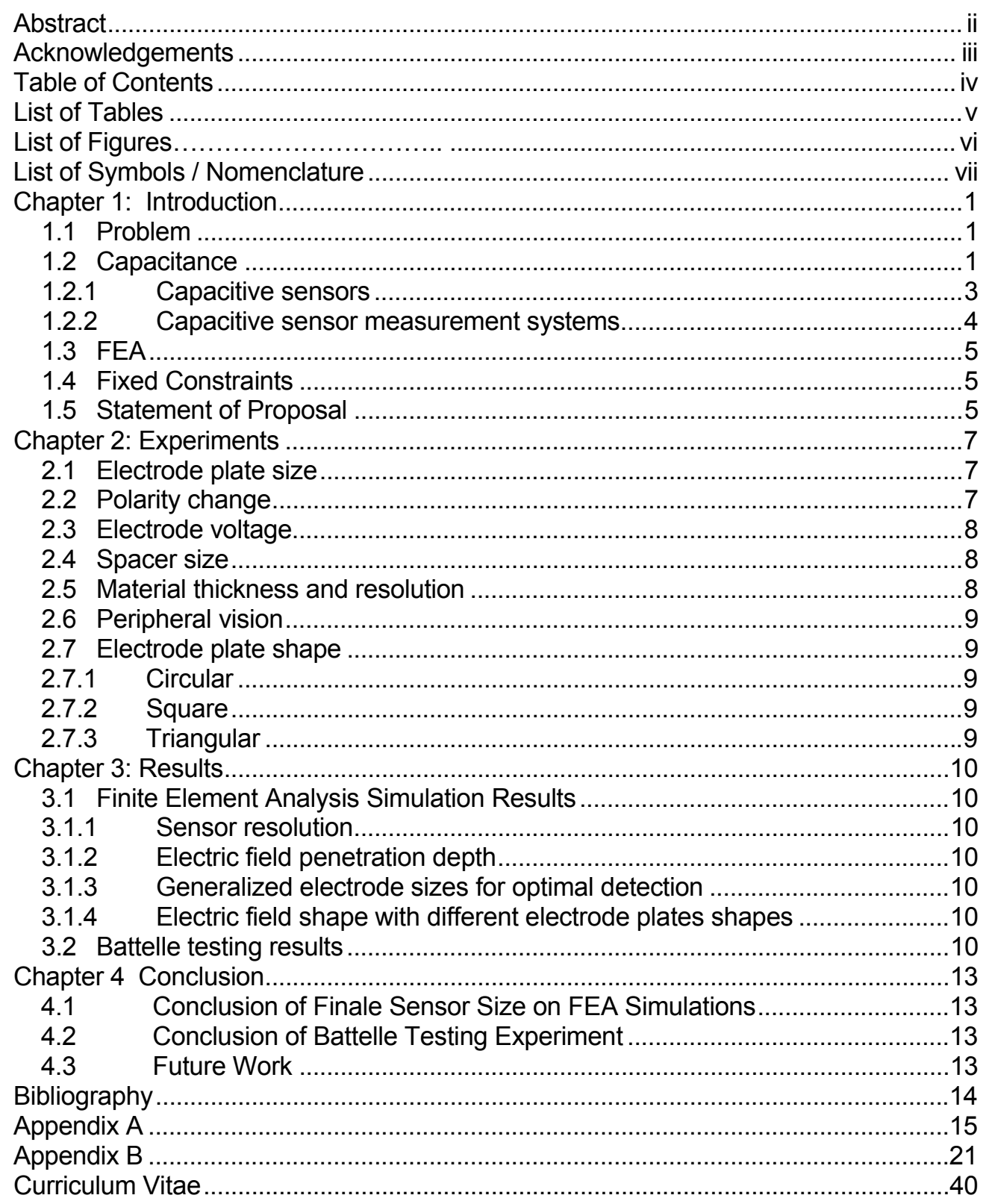




\section{LIST OF TABLES}

Table 1: Guard Electrode Radius vs. Field Intensities ............................................15

Table 2: Active Electrode Radius vs. Field Intensities ............................................15

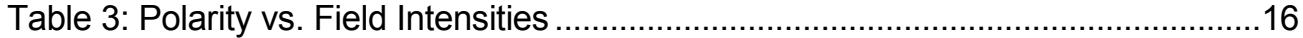

Table 4: Guard Electrode Voltage vs. Field Intensities.............................................16

Table 5: Active Electrode Voltage vs. Field Intensities .............................................17

Table 6: Spacer Size vs. Field Intensities .........................................................17

Table 7: Spacer Size Results vs. Field Intensities Results.......................................18

Table 8: Sensor Specifications ..........................................................................18

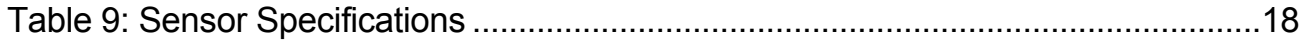

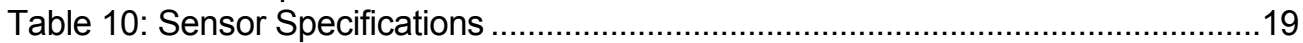

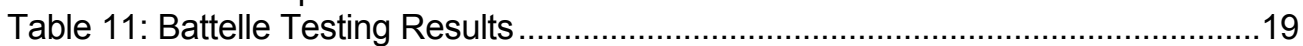




\section{LIST OF FIGURES}

Figure 1. Guard Electrode Radius vs. Field Intensities...........................................21

Figure 2. Active Electrode Radius vs. Field Intensities ............................................21

Figure 3. Plate Sizes Combination vs. Weak Field Intensities (1V) .........................22

Figure 4. Plate Sizes Combination vs. Strong Field Intensities (1V) ..........................22

Figure 5. Plate Sizes Combination vs. Weak Field Intensities (25V) ..........................23

Figure 6. Plate Sizes Combination vs. Strong Field Intensities (25V) ........................23

Figure 7. Plate Sizes Combination vs. Weak Field Intensities (50V) .........................24

Figure 8. Plate Sizes Combination vs. Strong Field Intensities (50V) .........................24

Figure 9. Guard Electrode Voltage vs. Field Intensities...........................................25

Figure 10. Active Electrode Voltage vs. Field Intensities ..........................................25

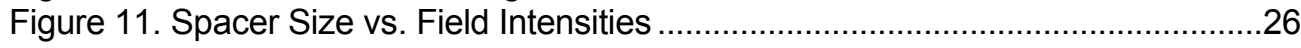

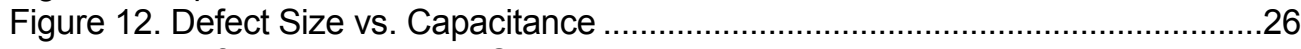

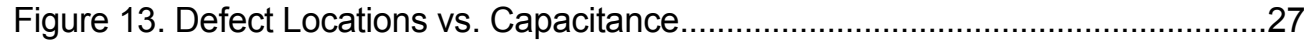

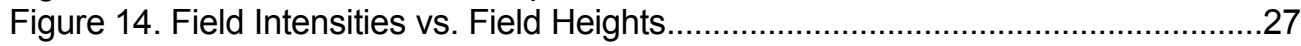

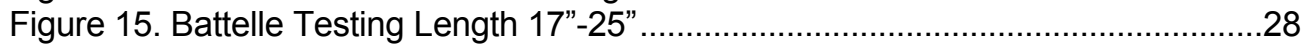

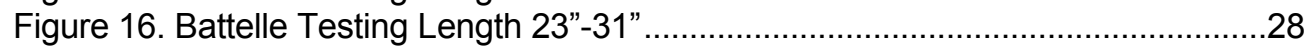

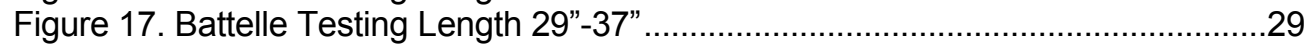

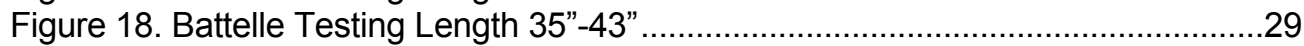

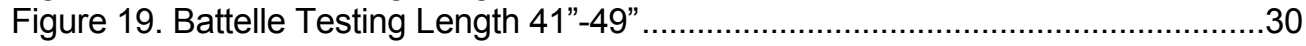

Figure 20. Battelle Testing Length 47"-55"........................................................30

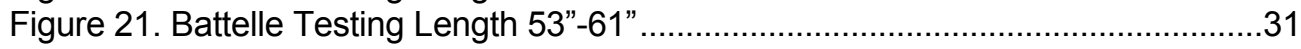

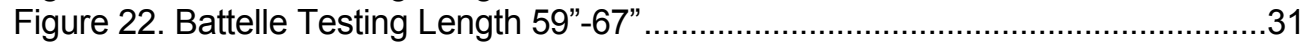

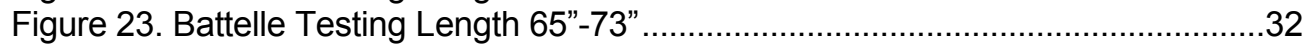

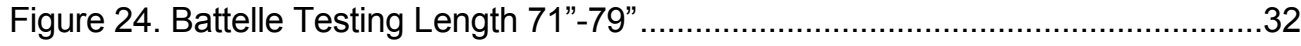

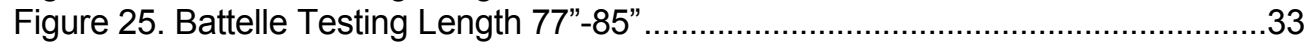

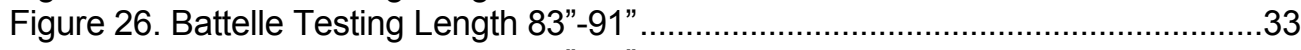

Figure 27. Battelle Testing Length 89"-97"......................................................... 34

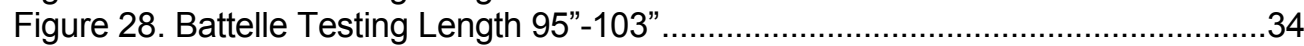

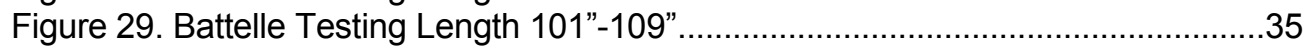

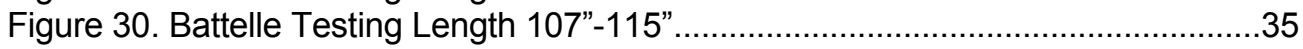

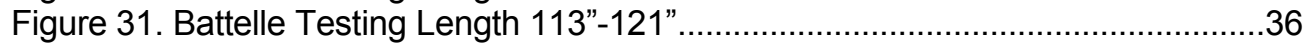

Figure 32. Battelle Testing Length 119"-127".......................................................

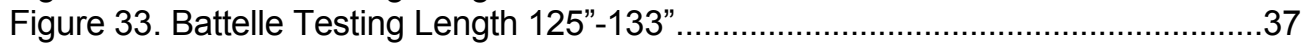

Figure 34. Battelle Testing Length 131"-139"..................................................37

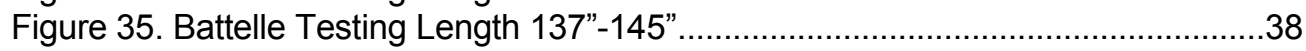

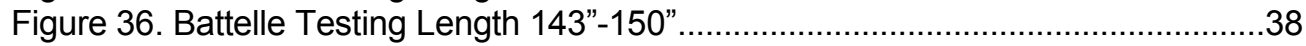




\section{LIST OF SYMBOLS / NOMENCLATURE}

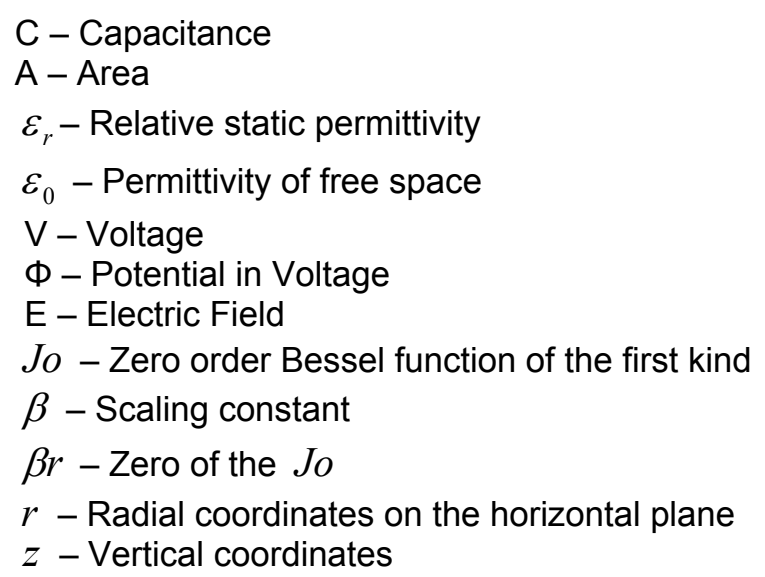

FEA - Finite Element Analysis

NETL - National Energy Technology Laboratory

Capacitance* $^{*}$ Generalized representation for Capacitance

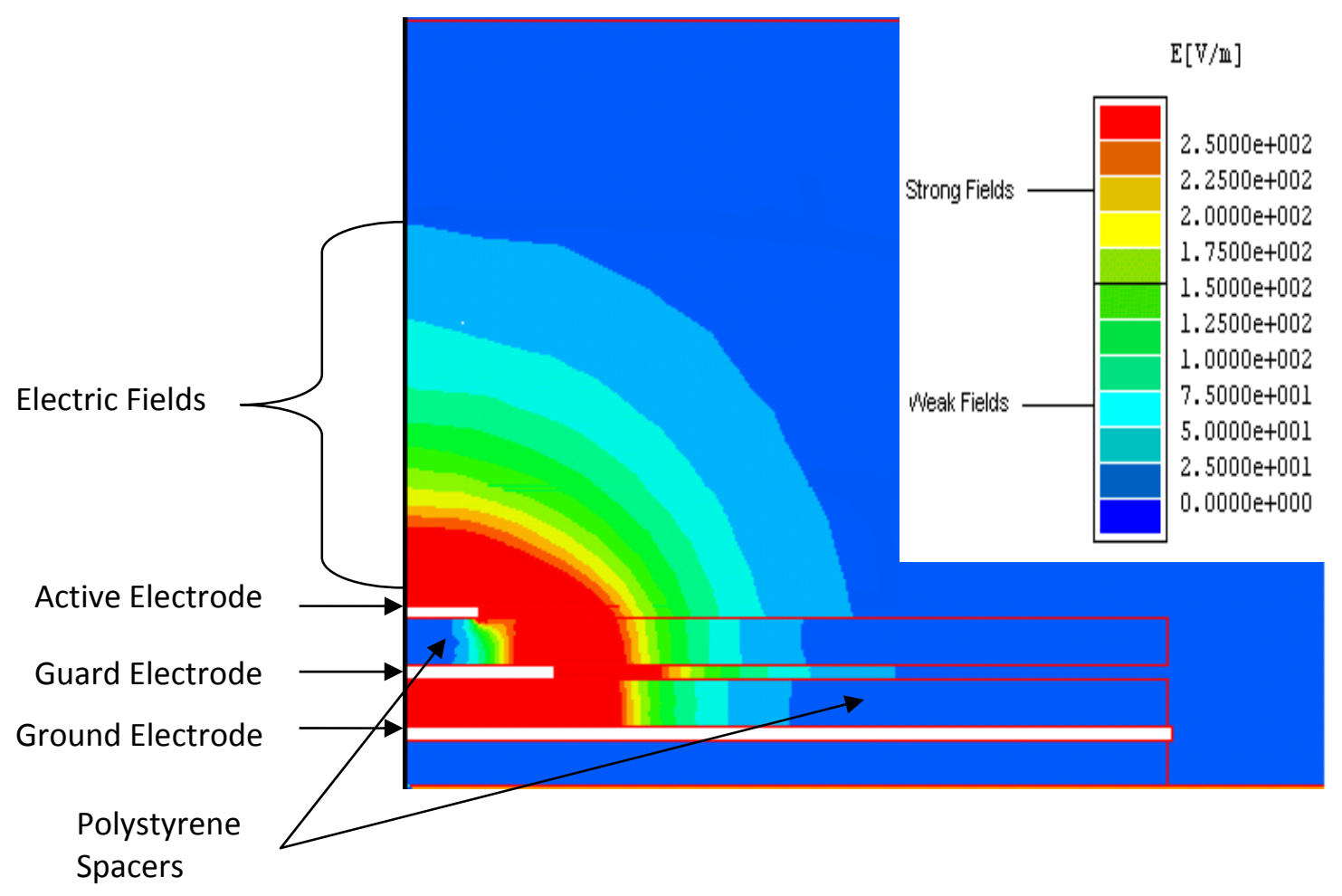




\subsection{Problem}

The leading causes of natural gas explosions are accidents caused by digging near existing pipelines. Most explosions are caused by residential accidents in which the owner does not consult with the gas company to mark properly the location of gas pipes before digging. The results might be catastrophic, costing thousands of dollars in damage as well as the loss of lives. The explosion might also produce a blast wave, causing a domino effect of ruptures in the same gas pipeline or nearby pipelines. To detect potential gas leaks in an area, "gas sniffers" are used to detect the presence of various gases by using a chamber, semiconductor, or electrochemical sensor to detect the amount of gas in the air. However, the operator of the gas sniffer must be present in the area under inspection, and if the presence of gas is detected, this puts the operator in danger. There is currently no in-pipe system that detects defects in polyethylene pipe.

\subsection{Capacitance}

Capacitance describes how the space between two conductors affects an electric field between them. Capacitance is calculated by the geometry of the conductors and the dielectric properties of the material that is between the conductors. The simplest form of showing capacitance is a parallel-plate structure, where two parallel plates both of an area, A are separated by a distance, $d$.

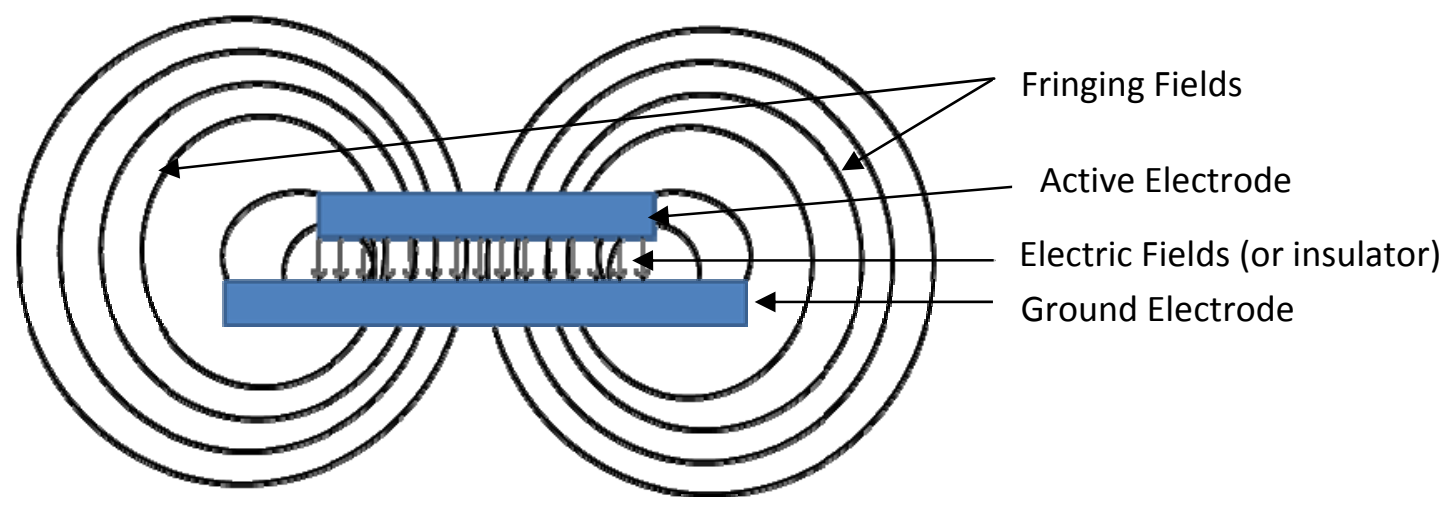

Figure 1: Parallel Plate Capacitor

The equation that results is

$$
C=\frac{\varepsilon_{0} \varepsilon_{r} A}{d}
$$

where

$C$ is the capacitance in farads, $F$

$A$ is the area of each plate

$\varepsilon_{r}$ is the relative static permittivity (also called the dielectric constant)

$\varepsilon_{o}$ is the permittivity of free space where $\varepsilon_{o}=8.854 \times 10-12 \mathrm{~F} / \mathrm{m}$

$\mathrm{d}$ is the separation between the plates 
If the areas of the plates and the distance separating them are constant, this leaves the relative static permittivity as the only variable in the equation. This variable only changes depending on the dielectric constant of the material between the two plates. The dielectric constant is an essential piece of information in capacitor designs. If the material between the electrodes is not homogeneous and consists of two materials with different dielectrics (e.g. polyethylene and air), then this will increase or decrease the capacitance because the relative static permittivity (dielectric constant) is affected. Material with a high dielectric constant will reduce the magnitude of the electric field, thus increasing the capacitance.

The electric field is the force that acts between two charges. In the parallel plate design, an electric field exists between the two plates. "When the plates are close to each other to form a capacitor, the E-field between the plates is constant throughout the interior of the capacitor as long as one is not near the edges of the plates" [9]. "Since the electric field is the negative of the gradient of the potential and the Efield is constant inside a capacitor, the magnitude of the Electric field has a very simple relation to the voltage between the plates and their separation d" [9].

The Electric field between the plates can be expressed as

$$
E=\frac{V}{d}
$$

Where

$E$ is the Electric Field in Newton per coulombs or volts per meter, N/C or V/m

$\mathrm{V}$ is the Voltage in Volts, $\mathrm{V}$

$\mathrm{d}$ is the distance between the plates in meters, $\mathrm{m}$

With fringing fields, the electric field is not constant and decreases in strength as the distance from the plates is increased. Fringing fields are "the electric fields produced by scattered electrons" [4].

The electric fringing field can be best express as: [6]

$$
\Phi(r, z)=J_{o}\left(\beta_{r}\right)\left(c_{1} e^{-\beta z}+c_{2} e^{+\beta z}\right)
$$

where

$J_{0}$ is the zero order Bessel function of the first kind

$\beta$ is the scaling constant

$\beta_{r}$ is the zero of the $J_{0}$

$\Phi$ is the electric potential

$r$ is the radial coordinates on the horizontal plane

$z$ is the vertical coordinates

and the electric field is: [12]

$$
E=-\frac{\partial \Phi}{\partial z}
$$

where

$E$ is the Electric Field in Newton per coulombs or volts per meter, N/C or V/m

$\Phi$ is the electric potential

$z$ is the vertical coordinates 


\subsubsection{Capacitive sensors}

Capacitance sensors detect a change in capacitance when something or someone approaches or touches the sensor. This change in capacitance can be induced by a material with a higher or lower dielectric constant. Depending on the application, the sensor can have multiple electrodes in many different configurations. There are many uses for capacitive sensors depending on what the objective is. For the purposes of this study, the researcher will use a triple plate design with an active electrode, guard electrode, and ground.

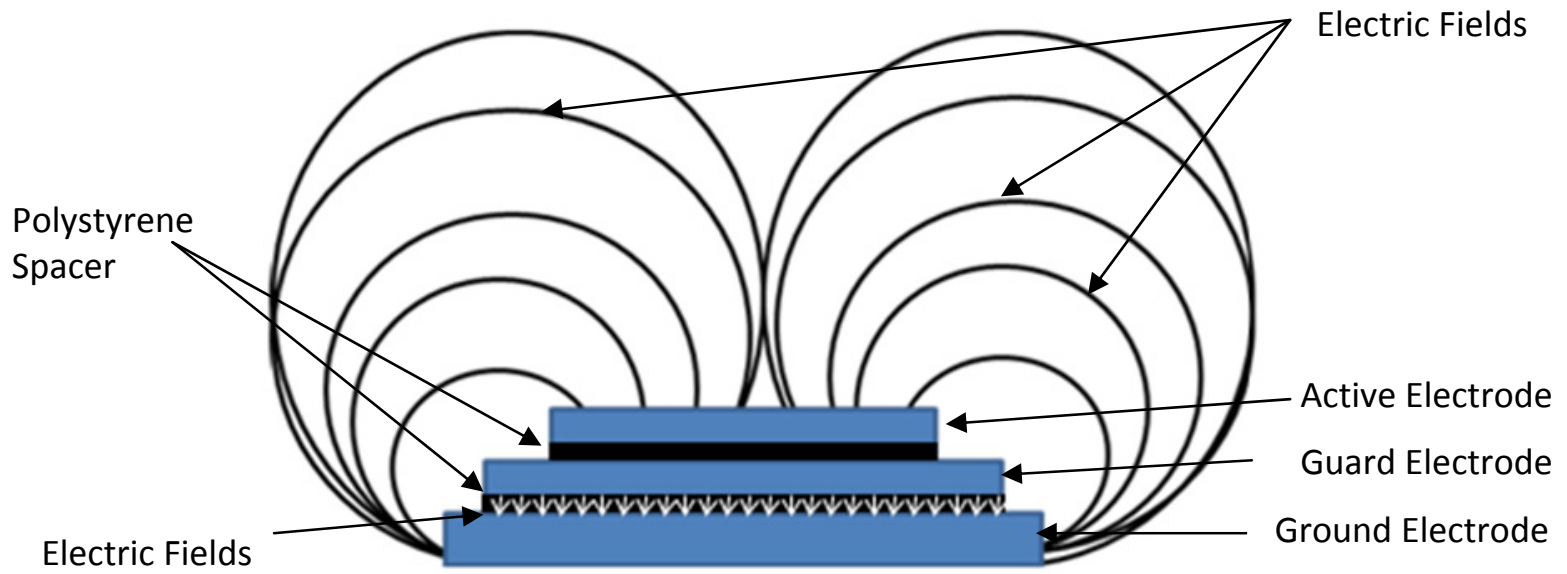

Figure 2: NETL/WVU Triple Plate Capacitive Sensor

By placing a guard electrode in between the active and ground electrode and applying a voltage of the same magnitude and polarity of the active electrode, the electric field of the active electrode are projected outwards.

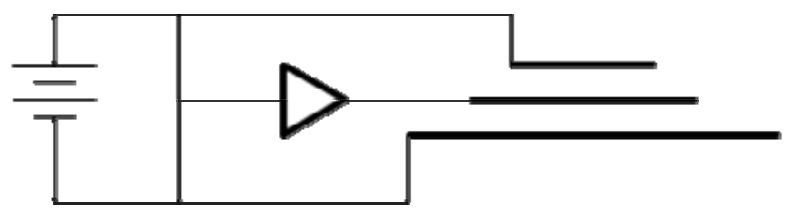

Figure 3: Circuit Design for a Triple Plate Capacitive Sensor

Since a moving charge has an electric field and also a magnetic field, the electric field acts in the same way as magnetic fields in a magnet. As magnets of the same pole are brought closer together, the two magnets will repel. With the triple plate design, the guard electrode will have the same polarity as the active, thus repelling the electric fields of the active and guard away from each other. There will be no electric field between the active and guard electrode plates. 


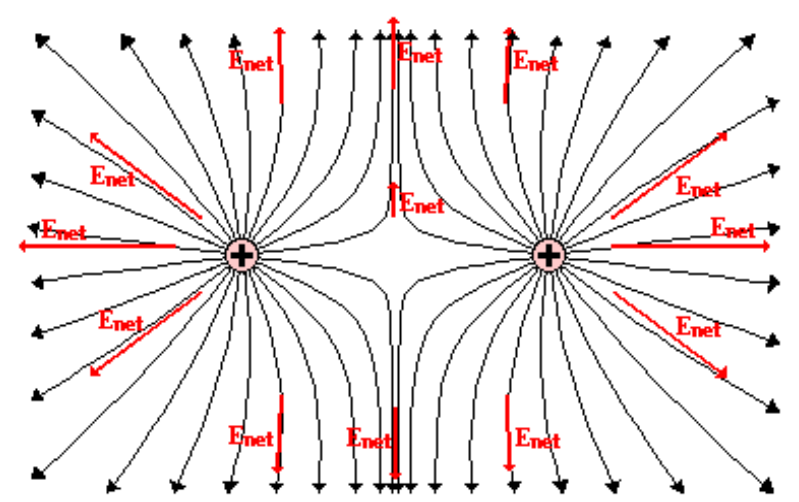

Figure 4: Electric fields with like polarities of two charged points

The electric field of the active electrode can be calculated as a fringing field from equation [4]. The calculations can be solved, however, due to the complexity of calculating fringing fields from equation [4], FEA software will be used that will produce approximations of the electric field and capacitance of the sensor.

\subsubsection{Capacitive sensor measurement systems}

There are three parts to a capacitive sensor measurement system: a probe, driver electronics, and a recorder. The probe detects the change in capacitance. In order to measure these changes, the driver electronics convert the changes in capacitance into voltage changes. Once this conversion takes place, the changes are then sent to a recorder that stores the results so they can be viewed and analyzed.

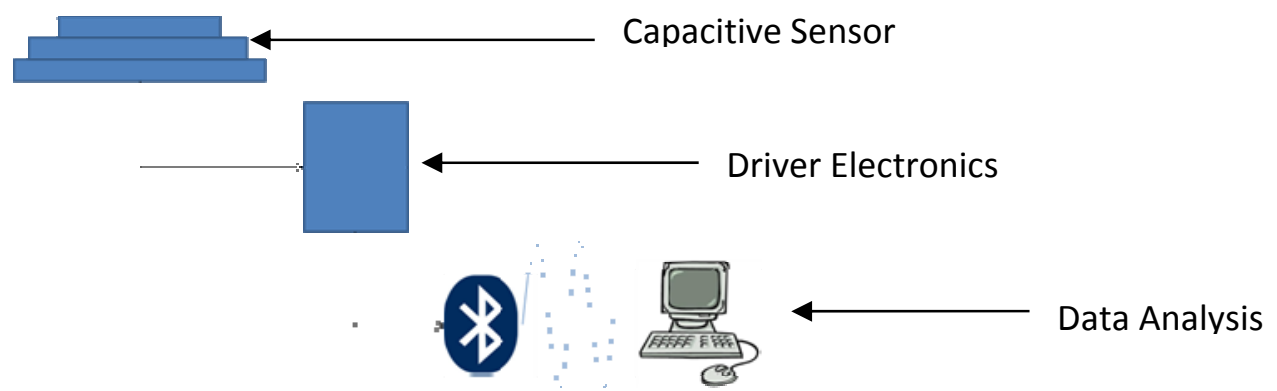

Figure 5: NETL/WVU Capacitive Measurement System

Since the benchmark testing will be conducted on unburied polyethylene pipeline, the capacitive sensor measurement system will use Bluetooth to transmit the data from the driven electronics to an external PC for data analysis. When combined together, the system will be placed on a "pig" that will be sent through the polyethylene pipe.

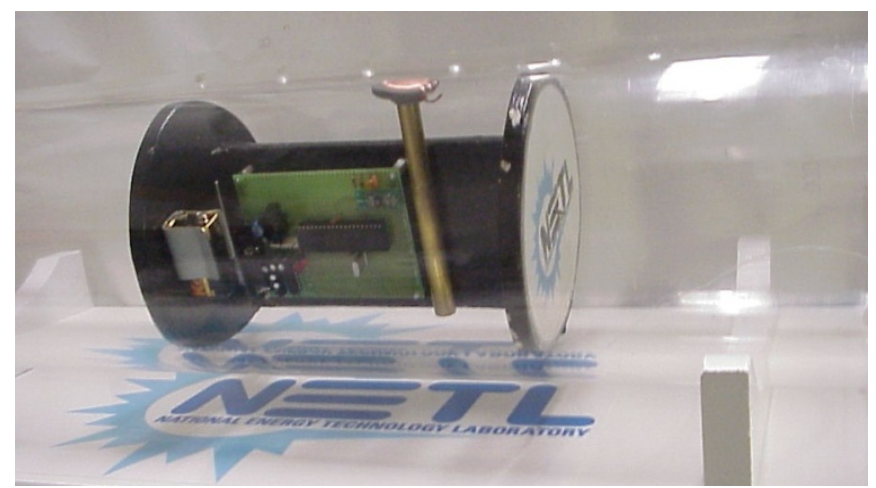

Figure 6: NETL/WVU Capacitive Measurement System Pig 


\subsection{FEA}

FEA software gives the ability to model the sensor for any size and shape and present a polyethylene material to the sensor. The simulation can then be run and based off the constraints for the hardware built to measure capacitance. A determination can be made if the model sensor has the ability to detect the defect.

"The finite element method (FEM) (sometimes referred to as finite element analysis) is a numerical technique for finding approximate solutions of partial differential equations (PDE) as well as of integral equations. The solution approach is based either on eliminating the differential equation completely (steady state problems), or rendering the PDE into an approximating system of ordinary differential equations, which are then numerically integrated using standard techniques such as Euler's method, Runge-Kutta, etc" [2].

"FEA uses a complex system of points called nodes which make a grid called a mesh. This mesh is programmed to contain the material and structural properties which define how the structure will react to certain loading conditions. Nodes are assigned at a certain density throughout the material depending on the anticipated stress levels of a particular area. Regions which will receive large amounts of stress usually have a higher node density than those which experience little or no stress"[7].

\subsection{Fixed Constraints}

A 0.015 in. $^{3}$ defect $(\sim 0.25$ in. $\times 0.25$ in. $\times 0.25$ in.), will be target size of defect that the sensor will be designed for. Although the size of the defect varies in shape and size and does not conform to perfect cubic geometry. The active and reflector will have a potential of 5V. Distance of defect can be at a minimum of $\sim 0.5 \mathrm{in}$. from sensor.

\subsection{Statement of Proposal}

To simulate a capacitive sensor size and shape using Ansoft FEA 2-D and 3-D software to detect size defects greater than or equal to 0.015 cubic inches on the outside of a 6 -inch diameter polyethylene gas pipe with a 0.5 -inch wall thickness. Then, compare sensor simulation with real data collected from NETLbuilt sensor tested at Battelle testing site for pipeline safety. The Battelle testing will consist of a 13 foot, 6 inch diameter, .5 inch wall thickness pipe. Defect will be placed along top of the pipe only, at random locations.

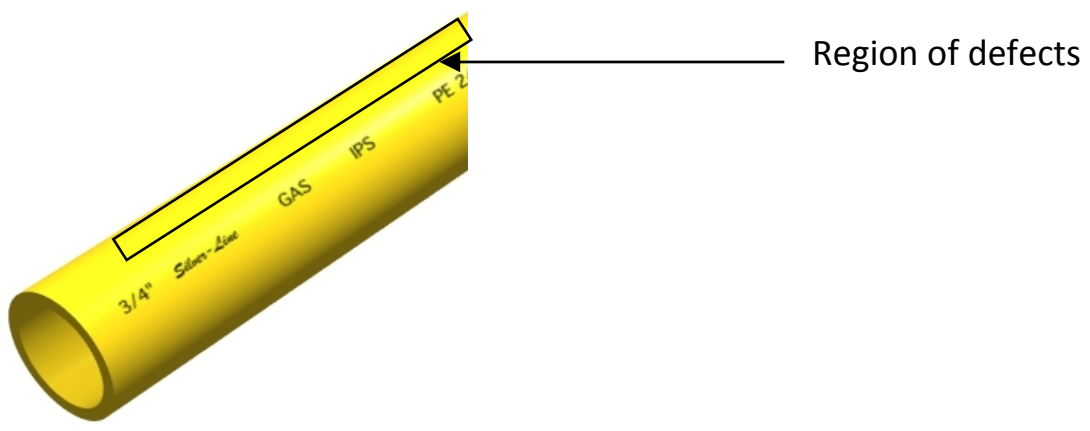

Figure 7: Pipe Defect Location

The sensor will be developed to conform to the curvature of the pipe. 

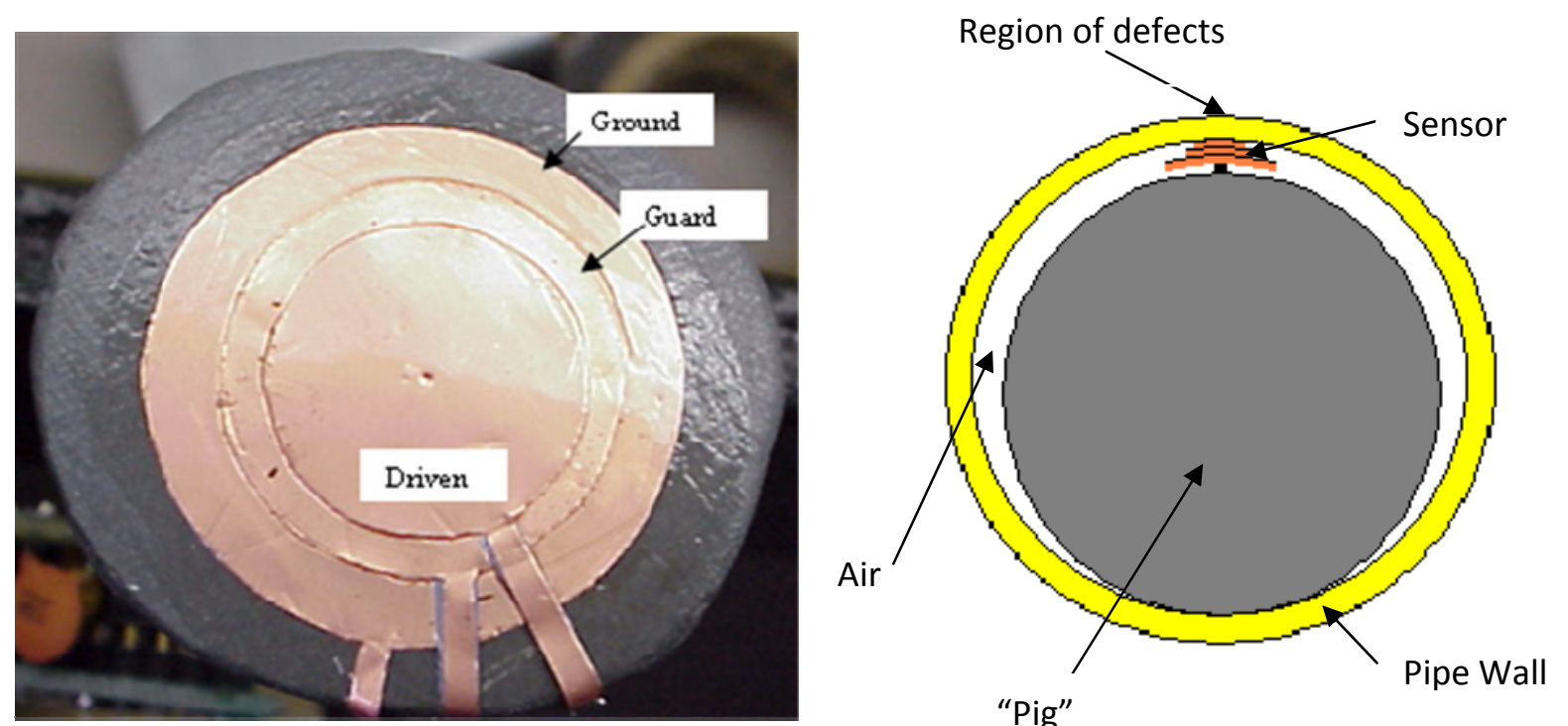

Figure 8: Developed Sensor Head and Side view of Test Stand

Upon completion of the test, NETL results will be compared to the Battelle benchmark data to determine if the capacitive measurement system is capable of detecting defects. 
CHAPTER 2: EXPERIMENTS

\subsection{Electrode plate size}

In Experiment 1, the active and guard electrode sizes are varied to determine how the electric field penetration is affected when presented with a polyethylene material into which a defect is inserted. This causes no change in capacitance when no defect is present and a change in capacitance when the defect is present. The goal is to find the size of the electrodes that will provide the best electric field penetration depth to locate the defect. Simulations are done using FEA software. Specifications for the sensor in this experiment are shown in Appendix A, Tables 1 and 2. The active and guard electrodes are varied in size independently between 0.01 to $0.5 \mathrm{in}$. in increments of $0.05 \mathrm{in}$. The sizes of the electrodes and field intensities are recorded.

Electric field intensities are dependent on distance. The closer to the sensor the field is measured, the stronger the electric field intensity. The further away from the electrode the field is measured, the weaker the electric field intensities will be. The goal is to maximize the distance of both the stronger and weaker electric fields of the electrode. The results gathered show that if either electrode is decreased in size, the height of the weak electric field decreases, and the height of the strong electric field increases (Appendix $\mathrm{B}$, Figures 1 and 2). One observation is that if the guard electrode size is set smaller than the active electrode, the heights of the weak fields are greater in value than if the active electrode is chosen to be the smaller of the two. A smaller active electrode allows for greater height in stronger field intensities than the smaller guard electrode. If a sensor were needed to have better height in the stronger field, then having an active electrode diameter smaller than that of the guard electrode would be the optimal choice.

\subsection{Polarity change}

In Experiment 2, the polarity of the electrodes is changed to determine how the electric field penetration is affected. Data collected from Experiment 1 will be used in comparison with the data collected from Experiment 2 to determine if polarity change improves the electric field intensity. Three different electrode size configurations will be used (Appendix A, Table 3). The polarity of the active electrode is reversed to $-1 \mathrm{~V}$ while the guard electrode potential is held at $1 \mathrm{~V}$ and the ground electrode at $0 \mathrm{~V}$. The electric field intensities are recorded. Next, the guard electrode is given the potential of $-1 \mathrm{~V}$ while the active electrode is given $1 \mathrm{~V}$ potential and the ground electrode, OV potential. The electric field intensities are recorded. Last, the active and guard electrodes are both set at $-1 \mathrm{~V}$ and the ground at $0 \mathrm{~V}$. The electric field intensities are recorded. This test will be conducted again, only with an increased voltage of $+25 \mathrm{~V},-25 \mathrm{~V}$, $+50 \mathrm{~V},-50 \mathrm{~V}$ only to one electrode at a time. Data from all variations of this experiment are then compared. Sensor specifications are located in Appendix A, Table 3.

When the active and guard electrodes have equal polarities and voltages, the weak electric field is projected further when compared to a condition in which the active and guard electrodes have voltages equal in magnitude but opposite in sign. For stronger electric field intensities of $250 \mathrm{~V} / \mathrm{m}$, changing the polarity of the active and guard electrode produces slightly greater intensities. The changes are small, however, and keeping the polarities the same and adjusting the plate sizes would be a more efficient solution.

When increasing the voltage of one electrode plate and changing the polarity, greater penetration depth does occur. This is due to the increased voltage of the electrode. However, as stated before, switching the polarities has some effect on the electric field penetration depth, but keeping the polarities the same and adjusting the active or guard electrode plate sizes could yield equal or better results.

Although a positive charged active electrode and a negative charged guard electrode indicates greater field intensity in some cases, this is only due to the size of the active electrode. If the size of the active electrode were to be increased or if the guard electrode were decreased, then a negative charged active electrode and a positive charged guard electrode would have greater field intensity when an increasing 
voltage is applied to one of the electrodes. This indicates that adjusting the plate size has greater effect on electric field penetration depth than polarity changes.

\subsection{Electrode voltage}

The purpose of Experiment 3 is to determine how varying the electrode voltage affects the electric field penetration depth. The active and guard electrodes are held at a constant size, while only the voltage of the active and guard electrodes are varied independently. The voltages of the electrodes are varied from $1 \mathrm{~V}$ to $50 \mathrm{~V}$ in increments of $5 \mathrm{~V}$. Electric field data is gathered and compared to determine how voltage affects the electric field intensities. Sensor specifications are located in Appendix A, Tables 4 and 5.

The results indicate that increasing voltage will increase the field intensity. This also holds true for increasing the voltage regardless of polarity, also shown in Appendix B Figures 5, 6, 7, and 8.

\subsection{Spacer size}

The purpose of Experiment 4 is to vary the size of the polystyrene spacer thickness and length to determine how the electric field penetration is affected. The polystyrene spacer is tested with both thicknesses half the size and double the size of the original thickness of 0.03 in. The length of the polystyrene spacer matches the electrode that lays on top of that spacer. Electric field intensities are recorded and compared to previous data to determine if the electric field intensities have improved.

FEA analysis shows field intensities above the active electrode are dependent on spacer size between the active and guard electrodes. Increased thickness of the polystyrene spacers causes a reduction in electrical field penetration depth; thinner polystyrene plates increase penetration on average (Appendix A, Tables 6 and 7). Decreasing the diameter of the polystyrene spacers with respect to the diameter of the electrode increases penetration depth of the stronger field intensities but decreases the weaker field intensities (Appendix A, Table 7 and Appendix B, Figure 11). Overall, these changes are minimal, but they can contribute to the overall penetration depth of a sensor.

\subsection{Material thickness and resolution}

The purpose of Experiment 5 is to vary the material thickness to determine how resolution is affected. The sensor is modeled using the values shown in Appendix A, Table 8. In the first test case, the sensor is placed $0.01 \mathrm{in}$. from a polyethylene sample of $0.21 \mathrm{in}$. thick with no defects. A defect of $0.20 \mathrm{in}$. deep is then simulated in the material and increased in length by increments of $0.05 \mathrm{in}$. The capacitance is recorded for each increase of the defect. In the second case, the same constraints are used as in the first case, but the thickness of the polyethylene sample is increased to $0.5 \mathrm{in}$.

FEA analysis shows that a pipe with a thinner wall allows for better resolution. This is because the defect is closer to the sensor where stronger electric fields exist. As the defect is moved away from the sensor or a thicker wall pipe is presented in front of the sensor with the same defect size, then the sensor loses resolution (Appendix B, Figure 12).

\subsection{Peripheral vision}

The purpose of Experiment 6 is to change the location of the defect to determine how far off center the defect can be from the sensor and still be detected. The sensor is modeled using the values shown in Appendix A, Table 9 . The sensor is placed $0.01 \mathrm{in}$. from the $0.5 \mathrm{in}$. thick polyethylene sample with no defect. A defect of 0.25 in. deep by $0.5 \mathrm{in}$. in length is then inserted into the far end of the polyethylene material and moved horizontally towards the sensor by increments of $0.02 \mathrm{in}$. The capacitance is recorded for each increment and analyzed.

The capacitance of the sensor with no defect is 6.91E-12 F and is shown at ND in Figure 13. This is the default value that each increment capacitance value is compared to. The defect's position centered over the sensor is zero. As the defect is moved outward, the capacitance decreases until it is $\sim 0.15 \mathrm{in}$. from 
the center. This is due to the electric fields being strongest on the edges of the electrodes where $\sim 0.15 \mathrm{in}$. is located. From $\sim 0.15$ in., the capacitance increases until $\sim 0.65$ in., where the capacitance is approximately equal to the capacitance at ND, making it seem that no defect is present in the material.

\subsection{Electrode plate shape}

For Experiment 7, 3-D Cartesian coordinates are selected. All sizes are radius values with inches as units of measurement. The boundary/window size is $2.5 \mathrm{in}$. wide and 0.65 in. tall.

The purpose of Experiment 7 is to change the shape of the active electrode to determine how electric field and penetration depth are affected. Three shape geometries (circular, triangular, and square) are modeled in the 3-D FEA software. The surface area of 0.00785 (in. ${ }^{2}$ ) for the active electrodes remains constant. The results are compared to FY2004 experimental data, each shape, and previous 2-D FEA results. Sensor specifications are shown in Appendix A, Table 10.

\subsubsection{Circular}

The circular active electrode produces deepest penetration depth when midrange intensities are considered. The circular electrode has a broader field then the square electrode (Appendix A, Table 10).

\subsubsection{Square}

For the square active electrode the $250 \mathrm{~V} / \mathrm{m}$ value of electrical field intensity occurs furthest away from the active electrode of the three geometries. The square electrode does not have as broad of an electric field. (Appendix A, Table 10).

\subsubsection{Triangular}

Using the triangular active electrode, the $250 \mathrm{~V} / \mathrm{m}$ value was seen closest to the surface of the electrode, and of the three sensor geometries, the $22.5 \mathrm{~V} / \mathrm{m}$ value was seen furthest away (Appendix A, Table 10).

Results of all geometries are compared in Appendix A, Table 10 and Appendix B, Figure 14. The electrical field intensity as a function of distance from active electrode surface for all geometries was essentially equal. Only minute differences were seen; however, since field intensities are strongest at sharp edges and corners, a circular design would be best. 
CHAPTER 3: RESULTS

\subsection{Finite Element Analysis Simulation Results}

\subsubsection{Sensor resolution}

The results indicate that a smaller defect near the sensor head has less effect on large sensors compared to small sensors; however, the small sensor does not penetrate as deeply. As the size of the defect is increased, each sensor has its own threshold where it is able to show a significant change in capacitance. These figures indicate that the value of capacitance as a function of defect size is constant beyond upper and lower threshold values. Thus, the sensor cannot detect those defects. When the active electrode is extremely small compared to the guard, then the change in capacitance with respect to defect size is small.

\subsubsection{Electric field penetration depth}

The reduction in length and thickness of the polystyrene spacers can maximize the penetration depth of the electric field. Since the active electrode is closest to the defect and smaller size electrodes increase the intensity fields closest to the sensor, having the active electrode smaller than the guard allows for better penetration of stronger fields. Higher voltage also increases penetration depth as well as polarity. However, because changing the polarity has little effect on penetration depth, adjusting the electrode plate size, decreasing the spacer size, and/or increasing the voltage itself constitute a more reasonable, effective approach to gaining penetration depth, rather than accommodating hardware to deal with the alternation polarity.

\subsubsection{Generalized electrode sizes for optimal detection}

Active and guard electrode sizes affect the electric field when either or both are changed. Previous experiments conducted on capacitive sensors indicated that having active electrodes smaller then the guard electrode will allow for maximum penetration depth.

\subsubsection{Electric field shape with different electrode plates shapes}

Since different geometric shapes produce slight differences in electric field penetration, any shape electrode may be chosen. However, electric field intensities tend to be strongest on sharp corners and edges. By choosing a circular design, there exist zero corners and only two edges. The circular design also produces a broader range in maximum penetration depth throughout the electric field spectrum.

\subsection{Battelle testing results}

NETLWVU team traveled to Columbus, Ohio to conduct testing of the capacitive sensor. The sensor was constructed to the geometry recommended based off the simulation conducted. The pig was connected to a string that was attached to a spool and controlled by a stepper motor to move the pig through the pipe. Below is the report of the Battelle testing for pipeline safety:

"A demonstration of the sensor was conducted at Battelle's West Jefferson Pipeline Simulation Facility near Columbus, Ohio, as part of an emerging pipeline technologies demonstration. Six groups participated in the demonstration: Oak Ridge National Laboratory (ORNL), The Gas Technology Institute (GTI), The Southwest Research Institute (SwRI), Pacific Northwest National Laboratory (PNNL), Battelle, and the National Energy Technology Laboratory (NETL). This sensor, sponsored by NETL, was the only technology demonstrated concerning plastic pipe; all others investigated metal pipe." [8] 
"Battelle provided the NETL experimenters with a 13-foot long section of 6 -in. nominal diameter polyethylene pipe with a 0.5 -in. wall thickness for a blind test. Battelle placed defects into the outside pipe wall and covered the defects. The experimenters did not know the location of the defects until after all tests were conducted. A calibration hole was provided with known position and characteristics (location $=18$ in., volume $=0.028$ in. $^{3}$, diameter $=0.375$ in., depth $=0.25$ in.)." [8]

"There were nineteen search regions in which defects could have been placed: eleven of the regions contained a defect, eight did not. There were two types of defects: round holes and saw cuts, as shown in Figures 34 and 35 . The probe correctly identified the position of each defect in the regions and gave no false positives. However, one region had two closely spaced defects (Figure 36 ) and the probe identified this as a single defect. Table 5 lists the actual defect positions and the defect position determined by analysis of probe data. The "benchmark" columns represent the actual physical properties of the defects provided by Battelle. The NETL columns represent data from the capacitance probe." [8]

"Ten trials (runs 11-20) were tabulated to determine the positions of the defects in the pipe. The data from these trials are shown in 8-in. sections. A 1-in. overlap is provided between the graphs in case a defect occurs near the end of a section." [8]

"Some difficulties were encountered in determining the exact position of the probe. A stepper motor was used in conjunction with nylon string to propel the sensor. The stepper motor was somewhat underpowered and appeared to stick on occasion. The stepper was aided manually on these occasions. Also, an optical encoder was used to determine position and should have emitted a pulse after every 0.09 -in. movement. Each traverse of the probe covered the same distance through the 13-ft. (142 in.) pipe, and therefore, the number of data points should have been approximately 1577 . However, this was not always the case. On occasion, the number of data points exceeded this number and in other cases it was less. Data were acquired by starting at the furthest position (150 in.) and pulling towards the calibration position (18 in.). The following procedure was used to compensate for the variation in the number of data points." [8]

1. "The distance between data points for each run was calculated assuming the run started at $149 \mathrm{in}$. and ended at $7 \mathrm{in.}$. The start and end positions were dictated by the size of the pig and the probe location on the pig." [8]

2. "The data was divided up into regional sections (e.g. 113-121 in.) and the position of the minimum (hole) for each run was determined. The lack of a defect within a region was obvious, so no adjustments were made for these regions." [8]

3. "The average position of the minimum was calculated." [8]

4. "The position of each data point for a particular run within that region was adjusted by adding a constant. The constant equaled the difference between the 
position of the average minimum and the position of the minimum of that particular run within the region." [8]

"Each data point was normalized by subtracting the minimum capacitance for that particular run in that particular region from the absolute value of capacitance of that point." [8]

"Battelle initially requested that the volume and diameter of the defect should also be determined. An algorithm for determining these values had not been determined at the time of the test. The output of the probe was not linear with respect to volume of a defect. A small void close to the probe produced the same output as a larger void further from the probe due to the nature of electrical fields. However, an attempt was made to determine volumes using a linear algorithm. No attempt was made to determine diameters." [8]

"The calibration hole was used as a standard. The normalized values for ten points on either side of the minimum were summed. These values were then summed to yield a single value. In the case of the calibration defect, the value was 237809 , which corresponded to a volume of 0.028 in. ${ }^{3}$. An identical procedure was performed on the regions where defects were detected. For example, the value for the defect at $25 \mathrm{in}$. was 327371 , and the actual volume was 0.044 in. $^{3}$. Assuming the ratio of calibration defect volume to the single value calibration number is equal to the ratio of a particular defect volume to the single value number of that defect, the defect volume can be determined using Equation 2. The volume of the defect at $25 \mathrm{in}$. was determined to be $0.039 \mathrm{in}^{3}$. However, the calculation of the volumes of other defects was not as accurate. The algorithm requires further refinement." [8]

$$
V_{\text {defect }}=V_{c a l} * \frac{N_{\text {def }}}{N_{c a l}}
$$

"The detection of defects during this test was highly successful. All defects were identified and there were no false positives." [8]

"The Battelle testing results show that the capacitive sensor simulation and designed accurately detected all defects along the pipeline." [8]

As stated above, the capacitive sensor was successful in detecting all defects in the pipe, and the FEA simulations proved successful as a tool that can be used in simulation of capacitive sensors. 


\section{CHAPTER 4 CONCLUSION}

\subsection{Conclusion of Finale Sensor Size based on FEA simulations}

Based on the results of the previous experiments, a sensor will detect objects half the distance of the size of the active electrode. With this being our baseline, we will start with an active and guard electrode size of .5 inches in diameter. If a defect is $\sim .25$ inches in depth, this will achieve a change in capacitance with our pipe having a .5 inch wall thickness. To ensure as much of the defect is encapsulated by the electric field, the active electrode will be increased to a size of .6. This will also allow for deeper penetration without having too much sacrifice resolution. Previous studies show that a larger guard will also improve penetration depth. The guard electrode will then be increase to a size of .75 as previous studies show that a guard that is 1.25 times the length of the active is optimal for detection. The peripheral distance test indicates that an active electrode of 0.6 inch and a guard electrode of. 75 inch will detect a defect of .25 inches in depth. To better increase the penetration depth, spacers will be shortened so that the length of the spacers do not exceed the electrode plate size that lies above it. A circular design will also be used to cut down on sharp edges and corners. This will allow for a more even distribution of electric field across the sensor.

\subsection{Conclusion of Battelle Testing Experiment}

The concept of incorporating the capacitance parameter in a probe to detect abnormalities in polyethylene natural gas distribution lines is a viable alternative to "gas sniffer". This study has shown that the detection of abnormalities on the outside of dielectric materials is successful. The detection of abnormalities inside of the dielectric or on the non-probe side can be accomplished but requires greater effort. The penetration depth of the probe is dependent on probe geometry and other factors. The farther away a defect is from a single probe and the smaller the defect is, the more difficult it is to detect, though it is possible. It has been demonstrated that small defects within dielectric material can be detected using the capacitance method. Further research will allow this method to be refined.

\subsection{Future Work}

Since the sensor outperformed the standard and detected objects on the outside of the pipe, this shows that the FEA software can be better characterized so that more accurate size sensors can be built. More simulation can be conducted to get an optimal active and guard ratio chart. 
1. Capacitive Sensor for Detection of Defects in Polyethylene Natural Gas Distribution Lines. Prepared By: James Spenik; REM Engineering Services Chris Condon; REM Engineering Services; Travis Kirby; West Virginia University; Bill Fincham; Parsons. pp 31-34, pp 36-40 February 14, 2006.

2. Finite element method. Retrieved March 28, 2009 from Wikipedia: http://en.wikipedia.org/wiki/Finite element method.

3. Franklin, R., et. al. (1978). Electronic Wall Stud Sensor. US Patent 4,099,118.

4. Fringing fields. Retrieved March 28, 2009 from: http://www.answers.com/topic/fringing-fields.

5. Mahandra, M., Monazam, E., Spenik, J., Condon, C. (2004). Development of Capacitance Probe Sensor for Plastic Pipeline Integrity Assessment. Paper presented at the Natural Gas Technology II Conference - Ingenuity and Innovation. Section 10 - Gas Industry Forum. February $8-11,2004$. Phoenix, AZ.

6. Li, X.B.; Kato, C.; Zyuzin, A.S.; Mamishev, A.V.; 19-22 Sept. 2004 Page(s):410 - 413 Design of multichannel fringing electric field sensors for imaging. Part II. Numerical examples. Proceeding of the Electrical Insulation, 2004. Conference Record of the 2004 IEEE International Symposium

7. Midkiff, Jason. Theory of Finite Element Analysis. Retrieved March 28, 2009 from: http://www.sv.vt.edu/classes/MSE2094 NoteBook/97ClassProj/num/midkiff/theory.html.

8. Pipeline \& Hazardous Materials Safety Administration (2006); Pipeline Inspection Technologies; Demonstration Report; Pipeline Safety Research \& Development Program.

9. Vawter, Richard. Parallel Plate Capacitors. Retrieved March 28, 2009 from: http://www.ac.wwu.edu/ vawter/PhysicsNet/Topics/Capacitors/ParallCap.html.

10. Vranish, J., McConnell, R.. (1992). Driven Shield Proximity Sensor. US Patent 5,166,679. Reissued 2000. Re. 36,772. 
Table 1: Guard Electrode Radius vs. Field Intensities

\begin{tabular}{|c|c|c|c|c|c|c|c|c|c|}
\hline \multicolumn{10}{|c|}{ Change in guard plate } \\
\hline \multicolumn{10}{|c|}{ Active default radius value $=0.170 \mathrm{in}$. } \\
\hline \multicolumn{10}{|c|}{ Test done on RZ plane (asymmetric) } \\
\hline \multicolumn{10}{|c|}{ Radius values } \\
\hline \multirow{2}{*}{\multicolumn{10}{|c|}{$\begin{array}{l}\text { Field Intensities are on a scale of } 0 \text { to } 250 \mathrm{~V} / \mathrm{m} \\
\text { Field Intensities values are }+0.12 \text { higher in value }\end{array}$}} \\
\hline & & & & & & & & & \\
\hline \multicolumn{10}{|c|}{ Field Intensities $(\mathrm{V} / \mathrm{m})$} \\
\hline $\begin{array}{c}\text { Guard } \\
\text { radius (in.) }\end{array}$ & 25 & 50 & 75 & 125 & 150 & 175 & 200 & 225 & 250 \\
\hline 0.01 & 0.4729 & 0.3557 & 0.3046 & 0.2637 & 0.1972 & 0.1580 & & & \\
\hline 0.05 & 0.4726 & 0.3561 & 0.3055 & 0.2633 & 0.1975 & 0.1581 & & & \\
\hline 0.1 & 0.4733 & 0.3565 & 0.3048 & 0.2641 & 0.1971 & 0.1572 & & & \\
\hline 0.15 & 0.4708 & 0.3581 & 0.3049 & 0.2626 & 0.1950 & 0.1530 & & & \\
\hline 0.17 & 0.4707 & 0.3568 & 0.3032 & 0.2623 & 0.1964 & 0.1562 & & & \\
\hline 0.2 & 0.4841 & 0.3647 & 0.3051 & 0.2589 & 0.1800 & & & & \\
\hline 0.25 & 0.5044 & 0.3752 & 0.3044 & 0.2437 & & & & & \\
\hline 0.3 & 0.5167 & 0.3770 & 0.2897 & 0.2038 & & & & & \\
\hline 0.35 & 0.5506 & 0.3639 & 0.2536 & 0.1291 & & & & & \\
\hline 0.4 & 0.5448 & 0.3340 & 0.1758 & & & & & & \\
\hline 0.45 & 0.5136 & 0.2597 & & & & & & & \\
\hline 0.5 & 0.4343 & & & & & & & & \\
\hline
\end{tabular}

Table 2: Active Electrode Radius vs. Field Intensities

Change in active plate

Guard default radius value $=0.170 \mathrm{in}$.

Test done on RZ plane (asymmetric)

Lengths are radius values

Field Intensities are on a scale of 0 to $250 \mathrm{~V} / \mathrm{m}$ kField Intensities values are +0.12 higher in value

\begin{tabular}{lccccccccc}
\hline \multicolumn{10}{c}{ value } \\
\hline $\begin{array}{c}\text { Active } \\
\text { radius (in.) }\end{array}$ & 25 & 50 & 75 & 125 & & 150 & 200 & 225 & 250 \\
\hline 0.01 & 0.4425 & 0.3331 & 0.2789 & 0.2399 & 0.1875 & 0.1679 & 0.1524 & 0.1443 & 0.1388 \\
0.05 & 0.4488 & 0.3368 & 0.2880 & 0.2483 & 0.2013 & 0.1811 & 0.1652 & 0.1484 & 0.1306 \\
0.1 & 0.4520 & 0.3422 & 0.2954 & 0.2569 & 0.2049 & 0.1827 & 0.1544 & & \\
0.15 & 0.4567 & 0.3532 & 0.3022 & 0.2626 & 0.1975 & 0.1613 & & & \\
0.17 & 0.4707 & 0.3568 & 0.3032 & 0.2623 & 0.1964 & 0.1562 & & &
\end{tabular}




\begin{tabular}{llllll}
0.2 & 0.4916 & 0.3729 & 0.3066 & 0.2571 & 0.1611 \\
0.25 & 0.5137 & 0.3829 & 0.3039 & 0.2297 & \\
0.3 & 0.5314 & 0.3846 & 0.2780 & 0.1646 & \\
0.35 & 0.5631 & 0.3675 & 0.2222 & & \\
0.4 & 0.5546 & 0.3253 & & & \\
0.45 & 0.5208 & 0.2095 & & & \\
0.5 & 0.4515 & & & & \\
\hline
\end{tabular}

Table 3: Polarity vs. Field Intensities

\begin{tabular}{|c|c|c|c|c|c|c|c|c|c|c|}
\hline & & $(1,1)$ & $(1,1)$ & $(1,-1)$ & $(-1,1)$ & & $(1,1)$ & $(1,1)$ & $(1,-1)$ & $(-1,1)$ \\
\hline & & $s+r+$ & $s+r+$ & $s+r-$ & S-r+ & & $s+r+$ & $s+r+$ & $s+r-$ & s-rt+ \\
\hline \multicolumn{11}{|l|}{$1 \mathrm{~V}$} \\
\hline $.05-.06$ & WF & 0.3383 & 0.3383 & 0.2929 & 0.2929 & SF & 0.1746 & 0.1746 & 0.1761 & 0.1761 \\
\hline $.05-.085$ & WF & 0.3613 & 0.3613 & 0.2632 & 0.2632 & SF & 0.172 & 0.172 & 0.1782 & 0.1782 \\
\hline $.05-.15$ & WF & 0.4203 & 0.4203 & 0.2451 & 0.2451 & SF & 0.1477 & 0.1477 & 0.1824 & 0.1824 \\
\hline $25 \mathrm{~V}$ & & $(25,1)$ & $(1,25)$ & $(1,-25)$ & $(-25,1)$ & & $(25,1)$ & $(1,25)$ & $(1,-25)$ & $(-25,1)$ \\
\hline $.05-.06$ & WF & 0.7532 & 0.6276 & 0.5939 & 0.7444 & SF & 0.3988 & 0.2853 & 0.1815 & 0.3955 \\
\hline $.05-.085$ & WF & 0.7465 & 0.7725 & 0.7498 & 0.7308 & SF & 0.3942 & 0.3732 & 0.3577 & 0.388 \\
\hline $.05-.15$ & WF & 0.7383 & 1.0667 & 1.1445 & 0.6953 & SF & 0.3956 & 0.5233 & 0.5275 & 0.3777 \\
\hline $50 \mathrm{~V}$ & & $(50,1)$ & $(1,50)$ & $(1,-50)$ & $(-50,1)$ & & $(50,1)$ & $(1,50)$ & $(1,-50)$ & $(-50,1)$ \\
\hline $.05-.06$ & WF & 0.9462 & 0.738 & 0.7236 & 0.9404 & SF & 0.4866 & 0.3649 & 0.3489 & 0.4836 \\
\hline $.05-.085$ & WF & 0.9241 & 0.9564 & 0.9472 & 0.9144 & SF & 0.4753 & 0.4669 & 0.4621 & 0.4706 \\
\hline $.05-.15$ & WF & 0.9211 & 1.3234 & 1.3187 & 0.8798 & SF & 0.4741 & 0.6517 & 0.6486 & 0.4573 \\
\hline
\end{tabular}

Table 4: Guard Electrode Voltage vs. Field Intensities

Change in guard plate

Test done on RZ plane (asymmetric)

Active radius value $=0.05$ in.

Guard radius value $=0.15 \mathrm{in}$.

Field Intensities are on a scale of 0 to $250 \mathrm{~V} / \mathrm{m}$

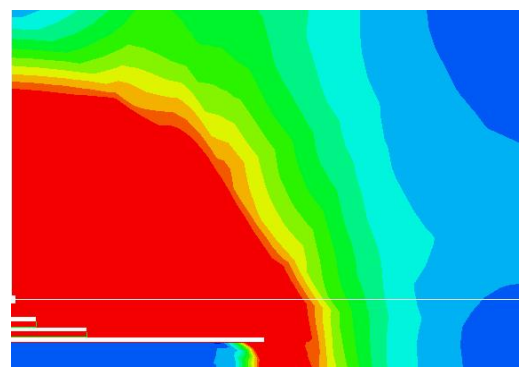

Field Intensities values are +0.12 higher in value

\begin{tabular}{|c|c|c|c|c|c|c|c|c|c|}
\hline \multicolumn{10}{|c|}{ Field Intensities (V/m) } \\
\hline & 25 & 50 & 75 & 125 & & & 200 & 225 & 250 \\
\hline \multicolumn{10}{|l|}{ Voltage } \\
\hline 1 & 0.4033 & 0.3234 & 0.2744 & 0.2426 & 0.2083 & 0.1920 & 0.1797 & 0.1699 & 0.1593 \\
\hline 2 & 0.4747 & 0.3733 & 0.3243 & 0.2875 & 0.2296 & 0.1916 & 0.0000 & 0.0000 & 0.0000 \\
\hline 3 & 0.5305 & 0.4242 & 0.3640 & 0.3256 & 0.2680 & 0.2449 & 0.1275 & 0.1225 & 0.0000 \\
\hline 4 & 0.5739 & 0.4605 & 0.3987 & 0.3586 & 0.3025 & 0.2772 & 0.2567 & 0.1485 & 0.1466 \\
\hline 5 & 0.6071 & 0.4889 & 0.4310 & 0.3849 & 0.3318 & 0.3081 & 0.2857 & 0.2656 & 0.2502 \\
\hline
\end{tabular}




\begin{tabular}{llllllllll}
10 & 0.7595 & 0.6017 & 0.5349 & 0.4832 & 0.4228 & 0.3988 & 0.3774 & 0.3623 & 0.3471 \\
15 & 0.8358 & 0.6934 & 0.6010 & 0.5525 & 0.4813 & 0.4616 & 0.4404 & 0.4207 & 0.4041 \\
20 & 0.9585 & 0.7411 & 0.6781 & 0.6293 & 0.5458 & 0.5127 & 0.4796 & 0.4528 & 0.4402 \\
25 & 1.0470 & 0.7832 & 0.7120 & 0.6373 & 0.5713 & 0.5505 & 0.5244 & 0.5018 & 0.4827 \\
30 & 1.1050 & 0.8498 & 0.7450 & 0.6862 & 0.5998 & 0.5760 & 0.5539 & 0.5355 & 0.5190 \\
35 & 1.1550 & 0.9128 & 0.7730 & 0.7238 & 0.6175 & 0.5958 & 0.5781 & 0.5604 & 0.5426 \\
40 & 1.2000 & 0.9632 & 0.7947 & 0.7510 & 0.6595 & 0.6137 & 0.5971 & 0.5804 & 0.5659 \\
45 & 1.2340 & 1.0080 & 0.8486 & 0.7686 & 0.6907 & 0.6456 & 0.6128 & 0.5944 & 0.5821 \\
50 & 1.2630 & 1.0450 & 0.8890 & 0.7833 & 0.7085 & 0.6755 & 0.6336 & 0.6116 & 0.5984 \\
\hline
\end{tabular}

Table 5: Active Electrode Voltage vs. Field Intensities

Change in active plate

Test done on RZ plane (asymmetric)

Active radius value $=0.05 \mathrm{in}$.

Guard radius value $=0.15 \mathrm{in}$.

Field Intensities are on a scale of 0 to $250 \mathrm{~V} / \mathrm{m}$

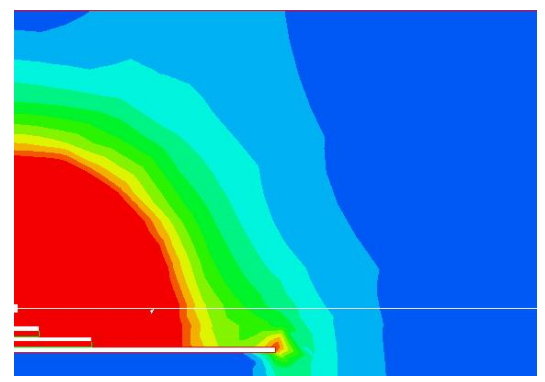

Field Intensities values are +0.12 higher in value

\begin{tabular}{|c|c|c|c|c|c|c|c|c|c|}
\hline \multicolumn{10}{|c|}{ Field Intensities (V/m) } \\
\hline & 25 & 50 & 75 & 125 & 150 & 175 & 200 & 225 & 250 \\
\hline \multicolumn{10}{|l|}{ Voltage } \\
\hline 1 & 0.4033 & 0.3234 & 0.2744 & 0.2426 & 0.2083 & 0.1970 & 0.1797 & 0.1699 & 0.1593 \\
\hline 2 & 0.4370 & 0.3680 & 0.3181 & 0.2826 & 0.2528 & 0.2394 & 0.2298 & 0.2212 & 0.2145 \\
\hline 3 & 0.4579 & 0.3817 & 0.3406 & 0.3115 & 0.2763 & 0.2659 & 0.2539 & 0.2500 & 0.2383 \\
\hline 4 & 0.4983 & 0.4062 & 0.3576 & 0.3316 & 0.2939 & 0.2813 & 0.2712 & 0.2620 & 0.2545 \\
\hline 5 & 0.5211 & 0.4246 & 0.3714 & 0.3493 & 0.3125 & 0.2978 & 0.2841 & 0.2758 & 0.2675 \\
\hline 10 & 0.5956 & 0.4926 & 0.4370 & 0.4061 & 0.3628 & 0.3474 & 0.3350 & 0.3226 & 0.3144 \\
\hline 15 & 0.6553 & 0.5461 & 0.4810 & 0.4442 & 0.4012 & 0.3822 & 0.3675 & 0.3581 & 0.3465 \\
\hline 20 & 0.7108 & 0.5809 & 0.5231 & 0.4754 & 0.4298 & 0.4132 & 0.3976 & 0.3843 & 0.3698 \\
\hline 25 & 0.7473 & 0.6091 & 0.5538 & 0.5117 & 0.4469 & 0.4336 & 0.4204 & 0.4072 & 0.3964 \\
\hline 30 & 0.7744 & 0.6369 & 0.5750 & 0.5321 & 0.4715 & 0.4501 & 0.4362 & 0.4248 & 0.4147 \\
\hline 35 & 0.8074 & 0.6705 & 0.5944 & 0.5543 & 0.4948 & 0.4685 & 0.4492 & 0.4395 & 0.4284 \\
\hline 40 & 0.8454 & 0.6988 & 0.6077 & 0.5721 & 0.5151 & 0.4909 & 0.4681 & 0.4496 & 0.4411 \\
\hline 45 & 0.8783 & 0.7221 & 0.6317 & 0.5873 & 0.5342 & 0.5098 & 0.4869 & 0.4683 & 0.4511 \\
\hline 50 & 0.9087 & 0.7393 & 0.6524 & 0.6012 & 0.5485 & 0.5243 & 0.5029 & 0.4830 & 0.4659 \\
\hline
\end{tabular}

Table 6: Spacer Size vs. Field Intensities

\begin{tabular}{lccccccccc}
\hline & \multicolumn{8}{c}{ Field Intensities $(\mathrm{V} / \mathrm{m})$} \\
& 25 & 50 & 75 & 125 & 150 & 175 & 200 & 225 & 250 \\
\hline Default & 0.4188 & 0.3295 & 0.2799 & 0.2484 & 0.204 & 0.1876 & 0.1742 & 0.1619 & 0.1497 \\
Decreased & 0.4129 & 0.3213 & 0.2741 & 0.2458 & 0.2004 & 0.1891 & 0.1778 & 0.1664 & 0.1555 \\
length & 0.422 & 0.324 & 0.2732 & 0.2442 & 0.1993 & 0.1855 & 0.1729 & 0.1611 & 0.1498
\end{tabular}


thickness

Decreased

thickness

$\begin{array}{lllllllll}0.4204 & 0.3328 & 0.2857 & 0.2567 & 0.2086 & 0.1925 & 0.1775 & 0.1625 & 0.1459\end{array}$

Table 7: Spacer Size Results vs. Field Intensities Results

\begin{tabular}{lcc}
\hline & $\begin{array}{c}\text { Change in weaker field heights } \\
(\mathrm{AVG})\end{array}$ & $\begin{array}{c}\text { Change in stronger field heights } \\
\text { (AVG) }\end{array}$ \\
\hline Default & 0 & 0 \\
Decreased length & -0.0261 & 0.0118 \\
Increased thickness & -0.0179 & -0.0088 \\
Decreased thickness & 0.0236 & 0.0096 \\
\hline
\end{tabular}

Table 8: Sensor Specifications

\begin{tabular}{lccc}
\hline & $\begin{array}{c}\text { Plate radius size } \\
\text { (in.) }\end{array}$ & $\begin{array}{c}\text { Plate thickness size } \\
\text { (in.) }\end{array}$ & $\begin{array}{c}\text { Polarity/voltage } \\
\text { (V) }\end{array}$ \\
\hline Active electrode & 0.1 & 0.01 & 1 \\
Guard electrode & 0.2 & 0.01 & 1 \\
Ground electrode & 0.504 & 0.01 & 0 \\
Polystyrene spacers & 0.5 & 0.03 & N/A \\
\hline
\end{tabular}

Table 9: Sensor Specifications

\begin{tabular}{|c|c|c|c|c|c|}
\hline Electrodes & Size (in.) & Thickness (in.) & $\begin{array}{l}\text { Polarity } \\
\text { and } \\
\text { voltage } \\
\text { (V) }\end{array}$ & Shape & Notes \\
\hline Active size & 0.3 & 0.01 & 1 & Square & \multirow{7}{*}{$\begin{array}{l}\text { Simulation was conducted in } \\
2-D X-Y \text { plane. }\end{array}$} \\
\hline Reflector size & 0.375 & 0.01 & 1 & Square & \\
\hline Ground size & 0.50 & 0.01 & 0 & Square & \\
\hline Polystyrene & $\mathrm{N} / \mathrm{A}$ & $\mathrm{N} / \mathrm{A}$ & & & \\
\hline \multicolumn{5}{|l|}{ Pipe } & \\
\hline Length & 1.0 & & & & \\
\hline Thickness & 0.5 & & & & \\
\hline \multicolumn{6}{|l|}{ Defect size } \\
\hline Width & 0.25 & & & & \multirow{4}{*}{$\begin{array}{l}\text { Defect was moved along the } \\
\text { horizontal axis in increments of } \\
0.5 \text { in. }\end{array}$} \\
\hline Depth & 0.25 & & & & \\
\hline Sensor $D$ from pipe & 0.01 & & & & \\
\hline Defect location & OP & & & & \\
\hline \multirow[t]{2}{*}{ Scale } & & & & & $250 \mathrm{~V} / \mathrm{m}$ \\
\hline & & & & & ND=No defect \\
\hline
\end{tabular}


Table 10: Sensor Specifications

Voltage $=1 \mathrm{~V}$

Ground electrode radius $=0.504 \mathrm{in}$.

Guard electrode radius $=0.15 \mathrm{in}$.

Active electrode sensor surface area $=0.00785 \mathrm{in}$.

Polarity $=s+r+$

\begin{tabular}{lcccccccccc}
\hline & \multicolumn{10}{c}{ Field Intensities $(\mathrm{V} / \mathrm{m})$} \\
& 22.5 & 25 & 50 & 75 & 125 & 150 & 175 & 200 & \multicolumn{1}{c}{225} & \multicolumn{1}{c}{250} \\
\hline Triangular & 0.4217 & 0.3274 & 0.2789 & 0.2484 & 0.2248 & 0.2033 & 0.188 & 0.1735 & 0.1603 & 0.1478 \\
Circular & 0.4203 & 0.3283 & 0.2807 & 0.2469 & 0.2238 & 0.204 & 0.189 & 0.1746 & 0.1625 & 0.15 \\
Square & 0.4151 & 0.3277 & 0.2791 & 0.2483 & 0.2235 & 0.2047 & 0.1891 & 0.1744 & 0.1617 & 0.1501 \\
\hline
\end{tabular}

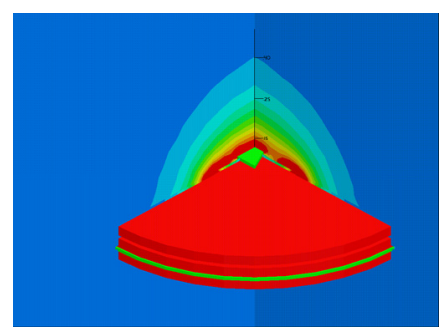

Triangular

Circular

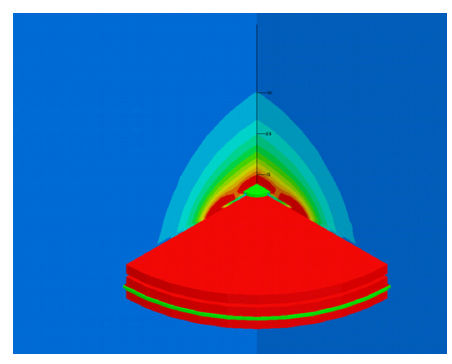

Square

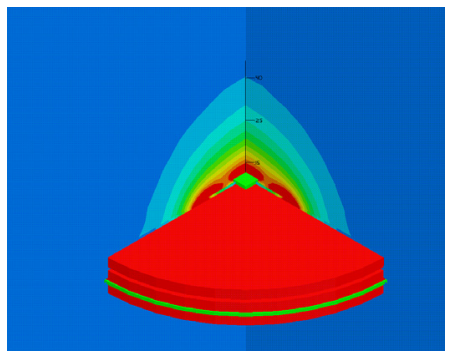

Table 11: Battelle Testing Results

\begin{tabular}{|c|c|c|c|c|c|c|c|c|}
\hline \multirow[b]{2}{*}{$\begin{array}{l}\text { Defect } \\
\quad \#\end{array}$} & \multirow[b]{2}{*}{$\begin{array}{l}\text { Search } \\
\text { region } \\
\text { (in.) }\end{array}$} & \multicolumn{4}{|c|}{ Benchmark } & \multicolumn{3}{|c|}{ NETL } \\
\hline & & $\begin{array}{l}\text { Defect } \\
\text { location } \\
\text { (in.) }\end{array}$ & $\begin{array}{c}\text { Volume } \\
\text { ratio }\end{array}$ & $\begin{array}{c}\text { Defect } \\
\text { volume } \\
\text { (in. }^{3} \text { ) }\end{array}$ & $\begin{array}{l}\text { Defect } \\
\text { diameter } \\
\text { (in.) }\end{array}$ & $\begin{array}{l}\text { Defect } \\
\text { location } \\
\text { (in.) }\end{array}$ & $\begin{array}{l}\text { Volume } \\
\text { ratio }\end{array}$ & $\begin{array}{l}\text { Defect } \\
\text { volume } \\
{\left.\text { (in. }{ }^{3}\right)}^{\text {a }}\end{array}$ \\
\hline D1 & $21-27$ & 25 & 1.57 & 0.044 & 0.375 & 25.1 & 1.38 & 0.039 \\
\hline $\mathrm{D} 2$ & $28-34$ & & & & & & & \\
\hline D3 & $35-41$ & & & & & & & \\
\hline D4 & $42-48$ & 46 & 0.79 & 0.022 & 0.25 & 45.6 & 0.99 & 0.028 \\
\hline D5 & $49-55$ & 53 & 0.89 & 0.025 & $\begin{array}{l}1 / 8 \text { in. wide, } \\
1 \text { in. cut }\end{array}$ & 52.6 & 1.31 & 0.037 \\
\hline D6 & $56-62$ & & & & & & & \\
\hline D7 & $62-70$ & 67 & 1.57 & 0.044 & 0.375 & 66.4 & 1.15 & 0.033 \\
\hline D8 & $70-76$ & & & & & & & \\
\hline D9 & $77-83$ & & & & & & & \\
\hline D10 & $84-90$ & 88 & 0.61 & 0.017 & 0.25 & 87.2 & 0.43 & 0.012 \\
\hline D11 & $91-97$ & & & & & & & \\
\hline D12 & $98-104$ & 102 & 1.43 & 0.040 & $\begin{array}{l}1 / 8 \text { in. wide, } \\
1 \text { in. long cut }\end{array}$ & 101.0 & 1.61 & 0.045 \\
\hline D13 & $105-111$ & 109 & 1.43 & 0.040 & 0.75 & 107.8 & 0.71 & 0.02 \\
\hline D14 & $112-118$ & 116 & 0.54 & 0.015 & 0.375 & 114.8 & 0.57 & 0.16 \\
\hline D15 & $119-125$ & $123-123.5$ & 0.61 ea. & 0.017 ea. & 0.25 ea. & 121.9 & 0.74 & 0.74 \\
\hline
\end{tabular}




\begin{tabular}{llcllllll}
$\mathrm{D} 16$ & $126-132$ & & & & & & & \\
$\mathrm{D} 17$ & $132-138$ & & & & & & & \\
$\mathrm{D} 18$ & $138-144$ & 140 & 1.25 & 0.035 & 0.75 & 138.3 & 1.13 & 0.032 \\
$\mathrm{D} 19$ & $144-150$ & 148 & 1.11 & 0.031 & 0.75 & 146.8 & 0.71 & 0.020 \\
\hline
\end{tabular}




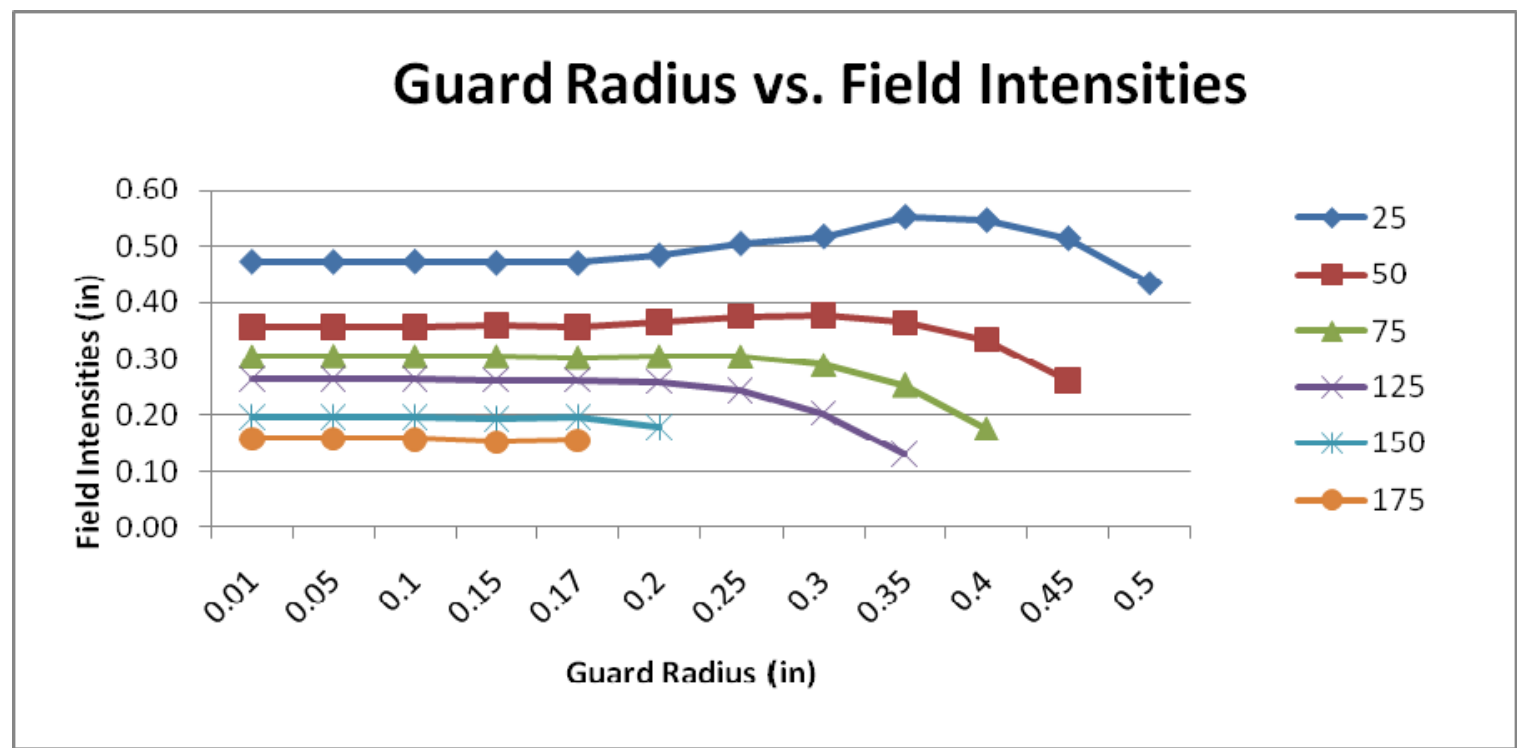

Figure 1. Guard Electrode Radius vs. Field Intensities

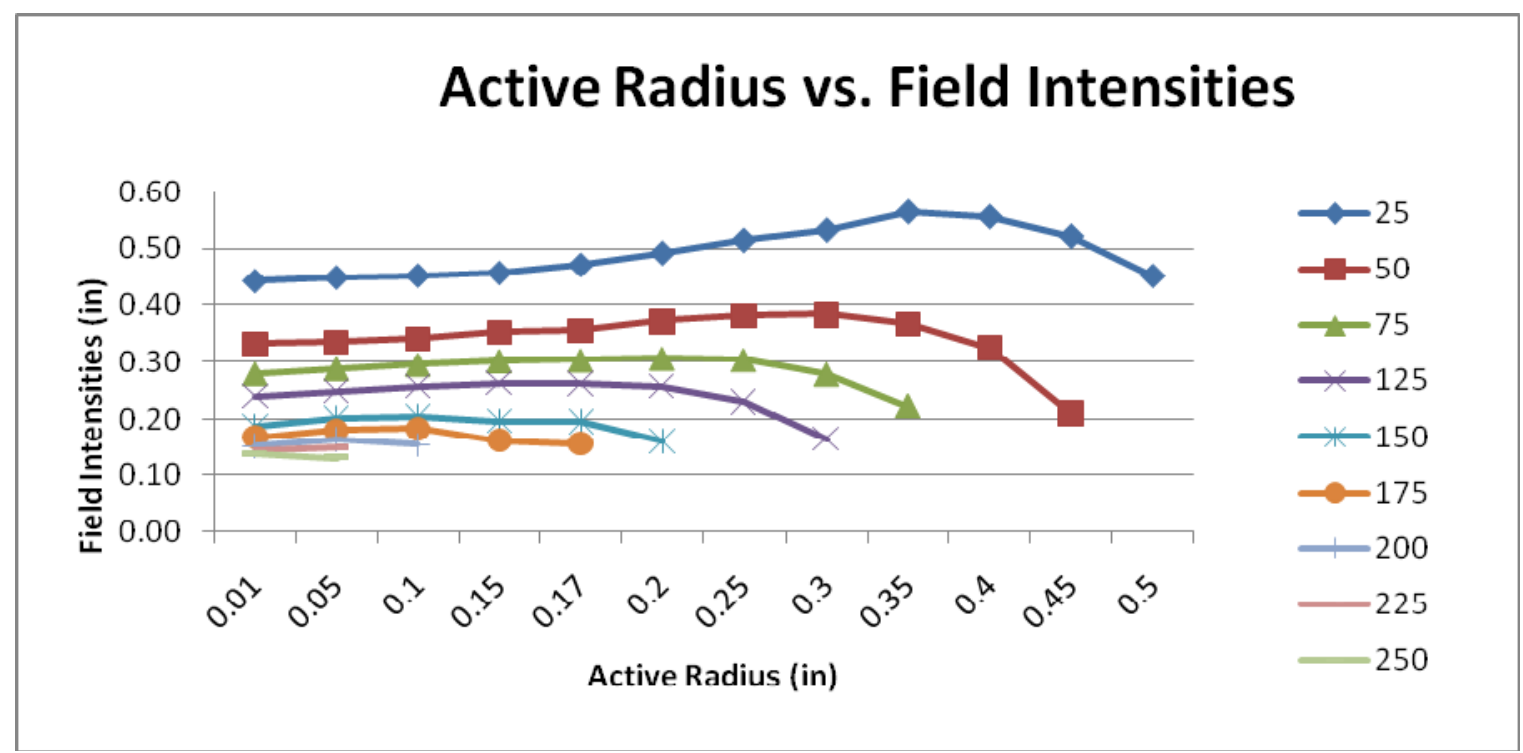

Figure 2. Active Electrode Radius vs. Field Intensities 


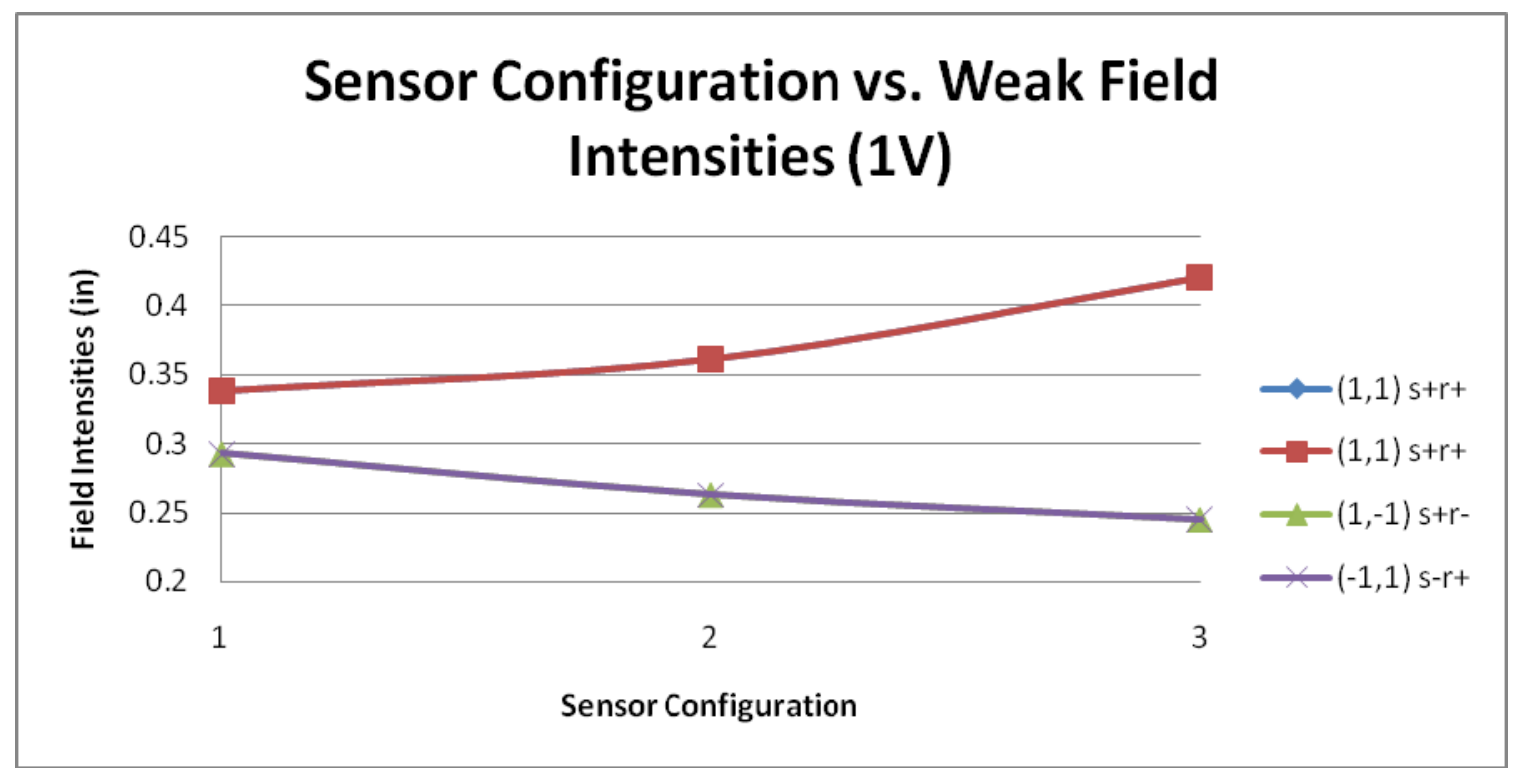

Figure 3. Plate Sizes Combination vs. Weak Field Intensities (1V)

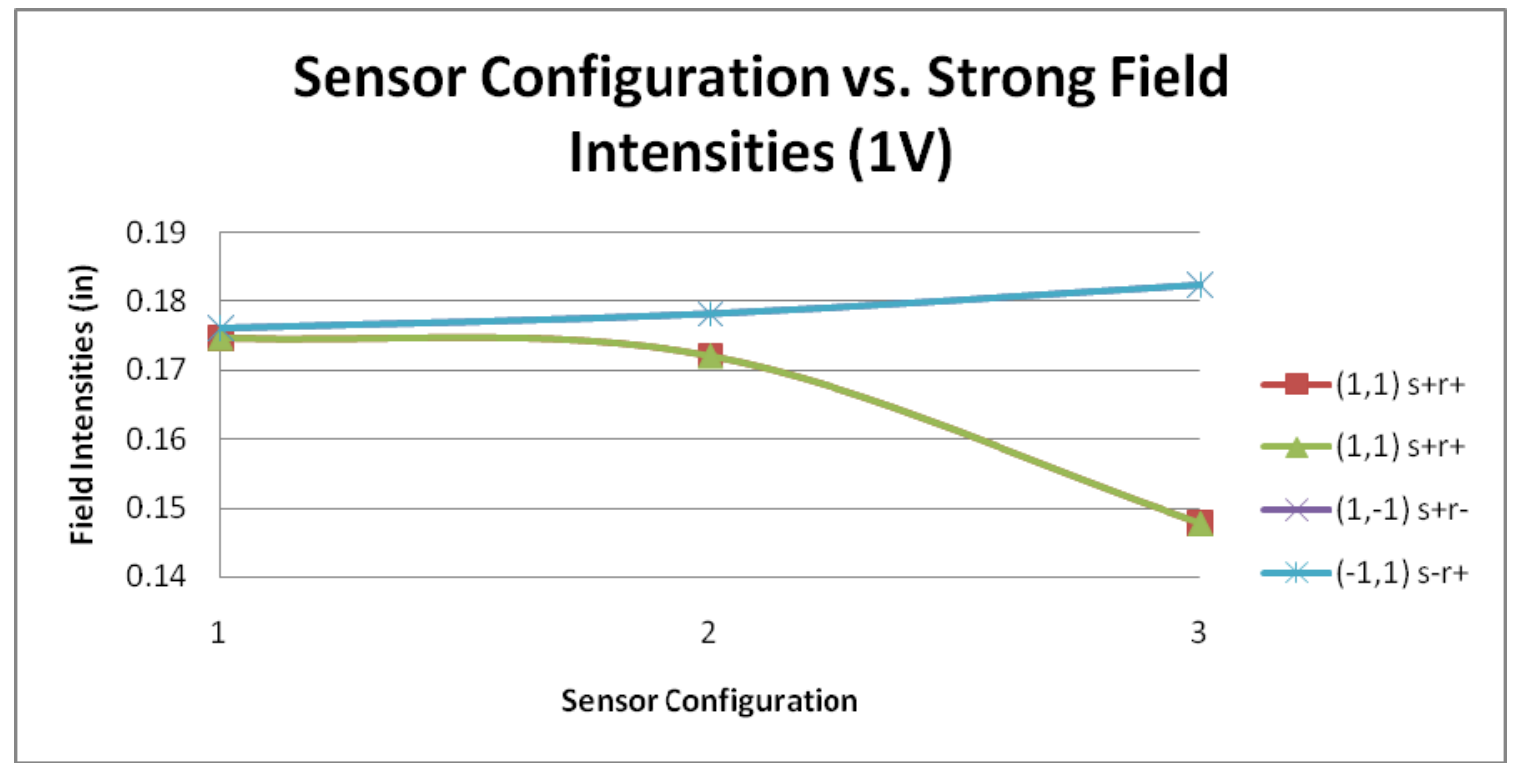

Figure 4. Plate Sizes Combination vs. Strong Field Intensities (1V) 


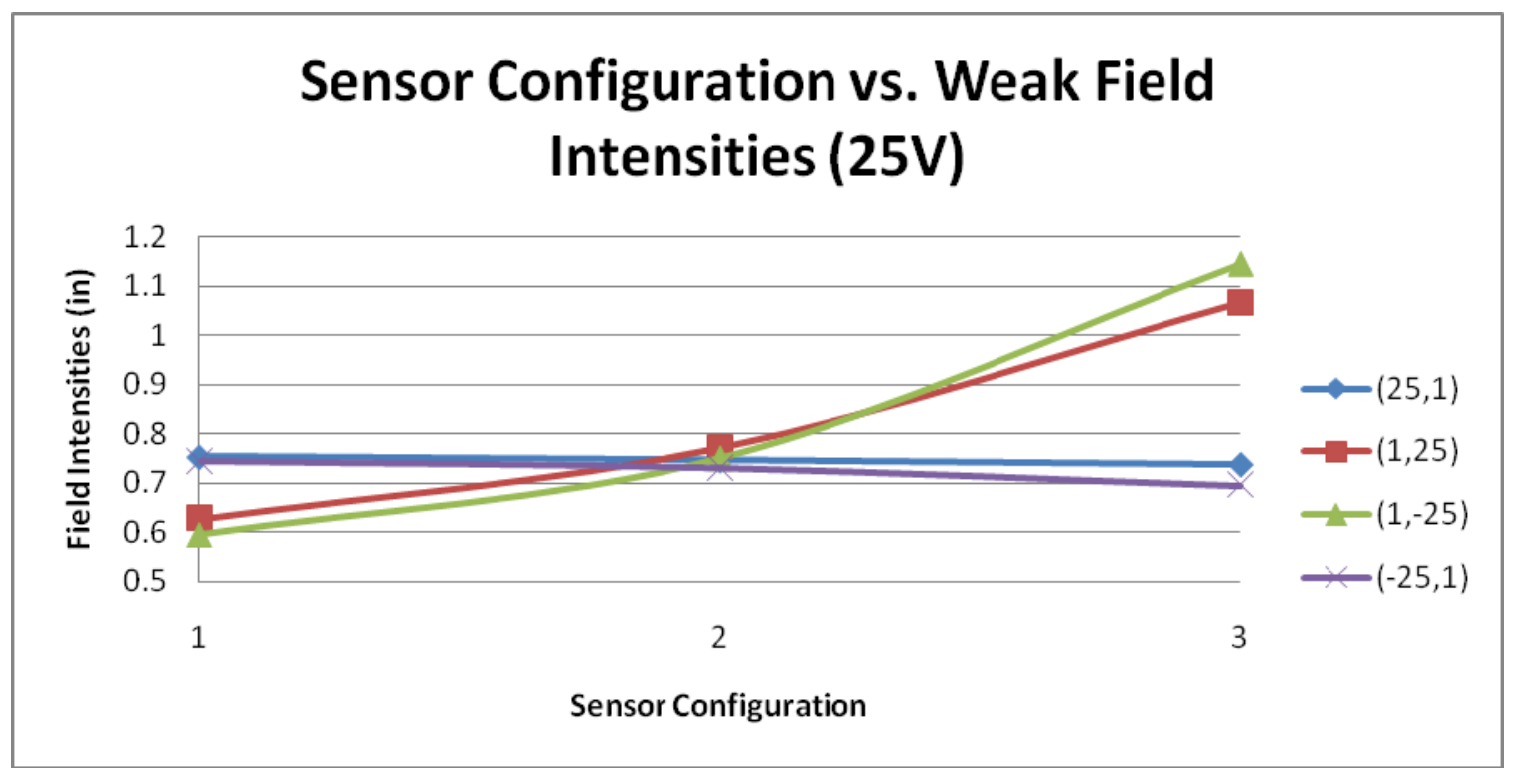

Figure 5. Plate Sizes Combination vs. Weak Field Intensities (25V)

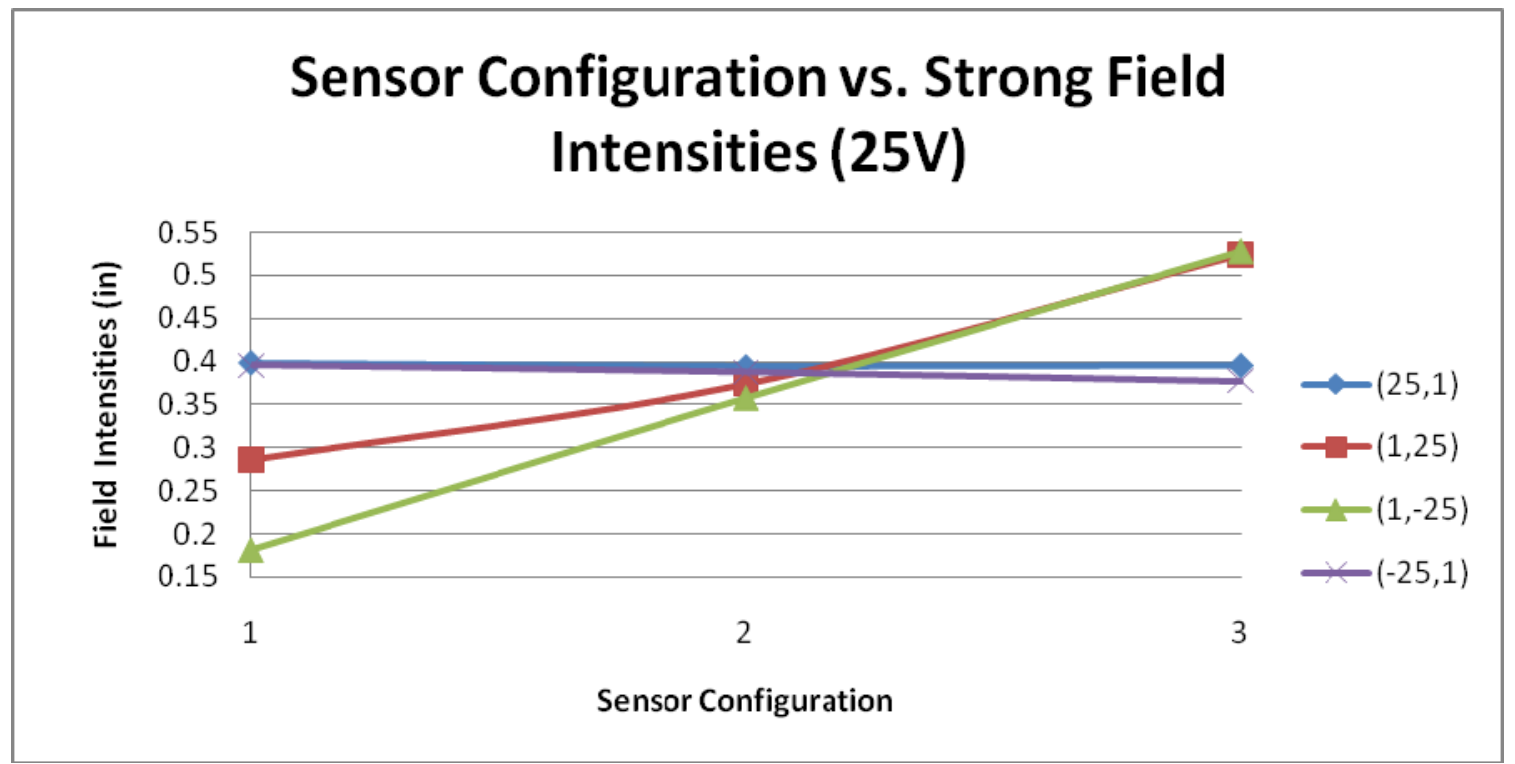

Figure 6. Plate Sizes Combination vs. Strong Field Intensities (25V) 


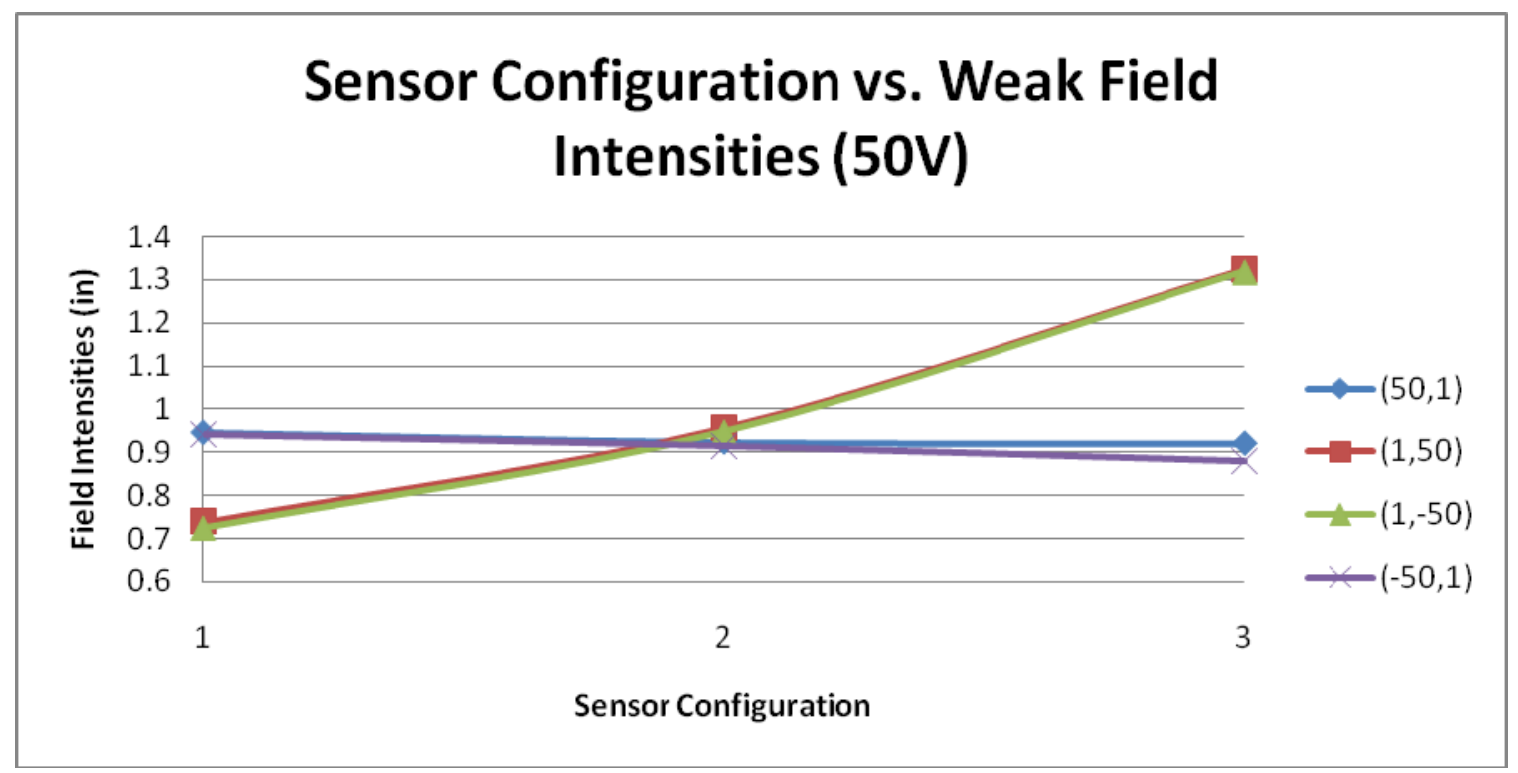

Figure 7. Plate Sizes Combination vs. Weak Field Intensities (50V)

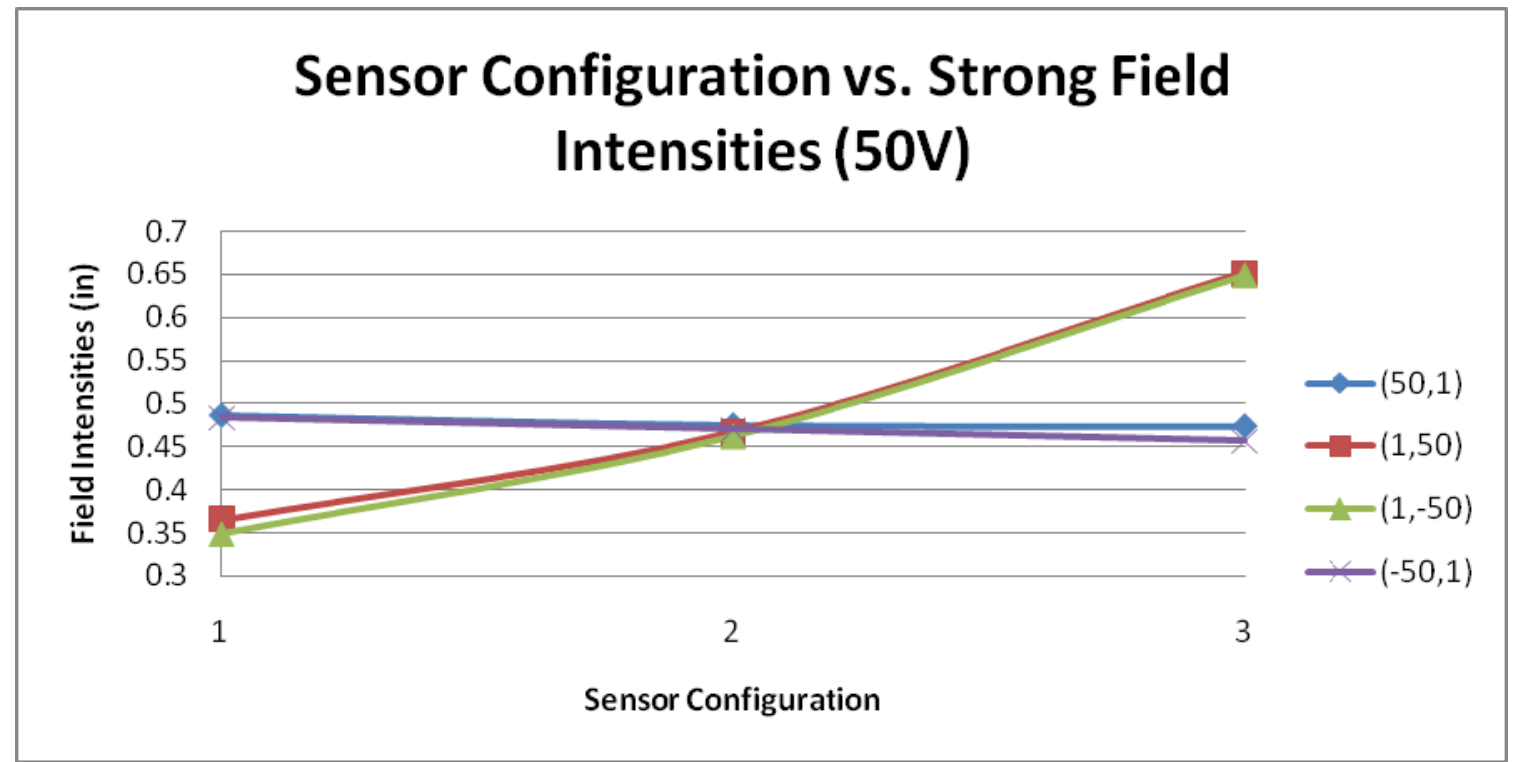

Figure 8. Plate Sizes Combination vs. Strong Field Intensities (50V) 


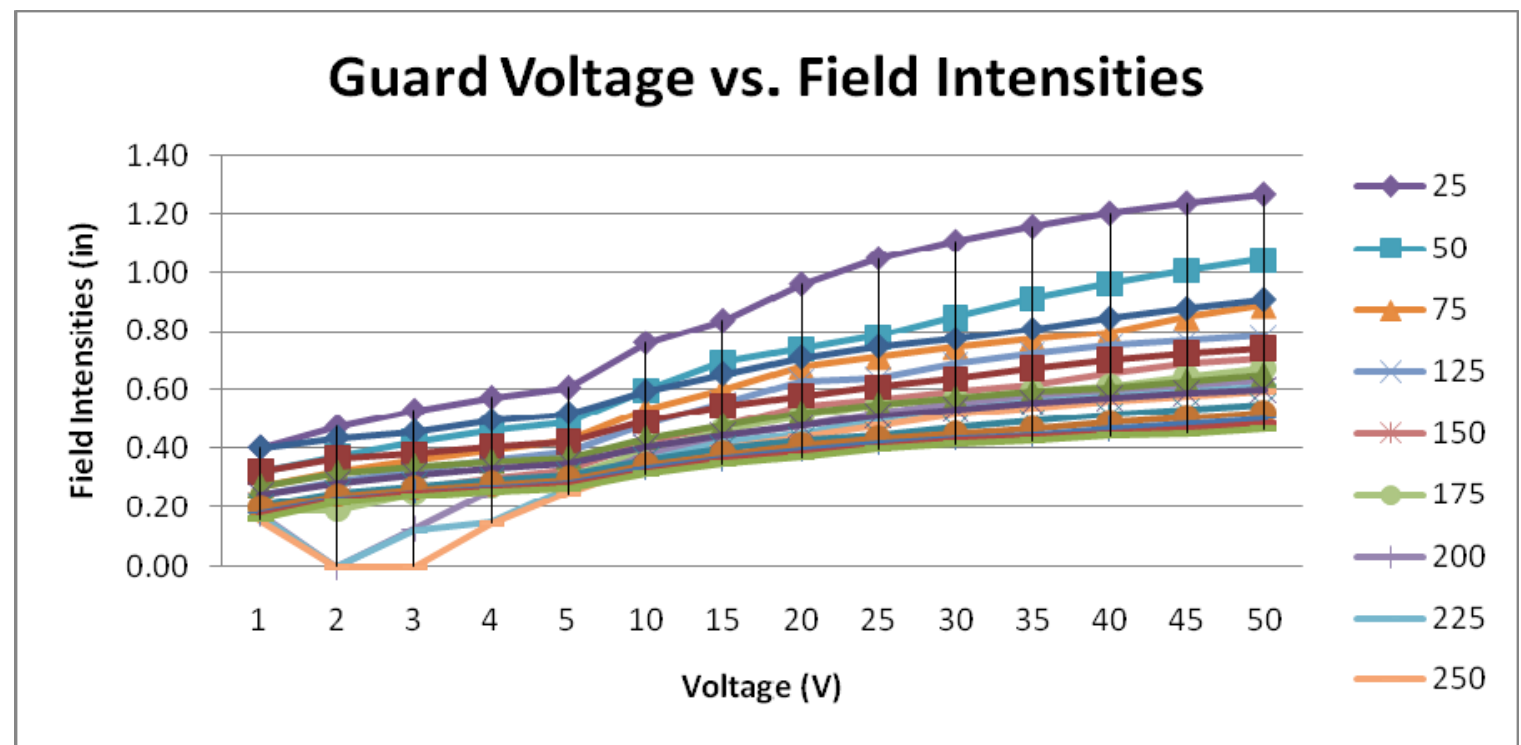

Figure 9. Guard Electrode Voltage vs. Field Intensities

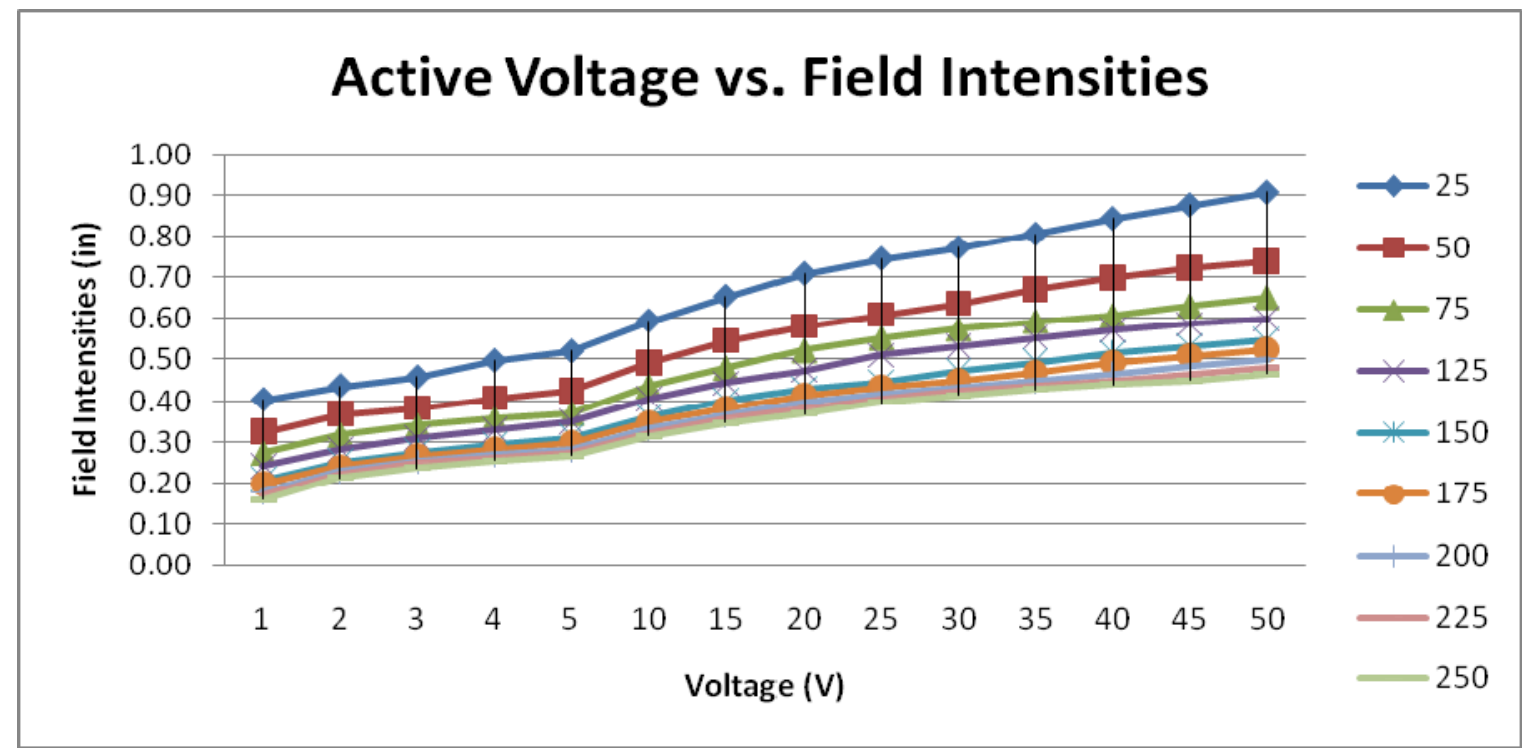

Figure 10. Active Electrode Voltage vs. Field Intensities 


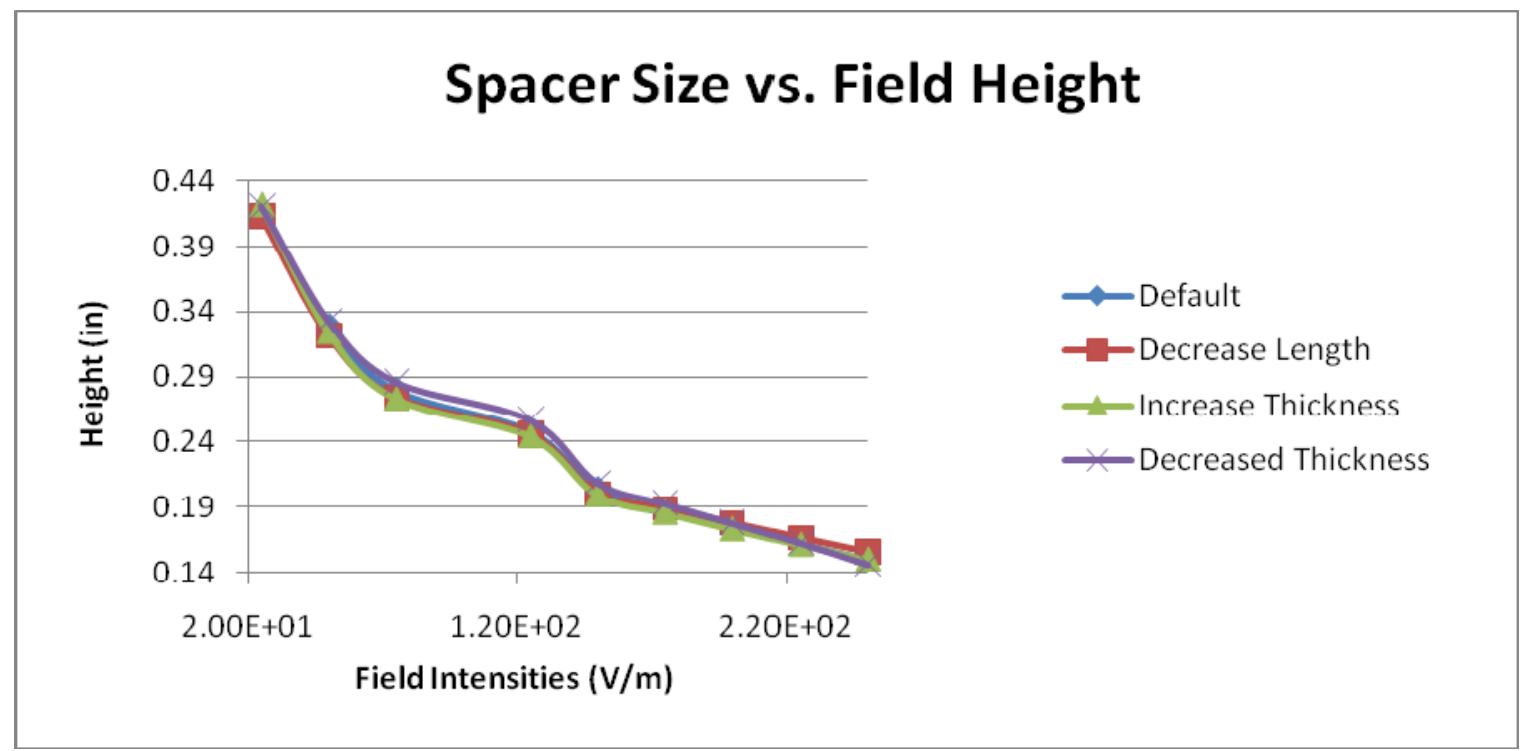

Figure 11. Spacer Size vs. Field Intensities

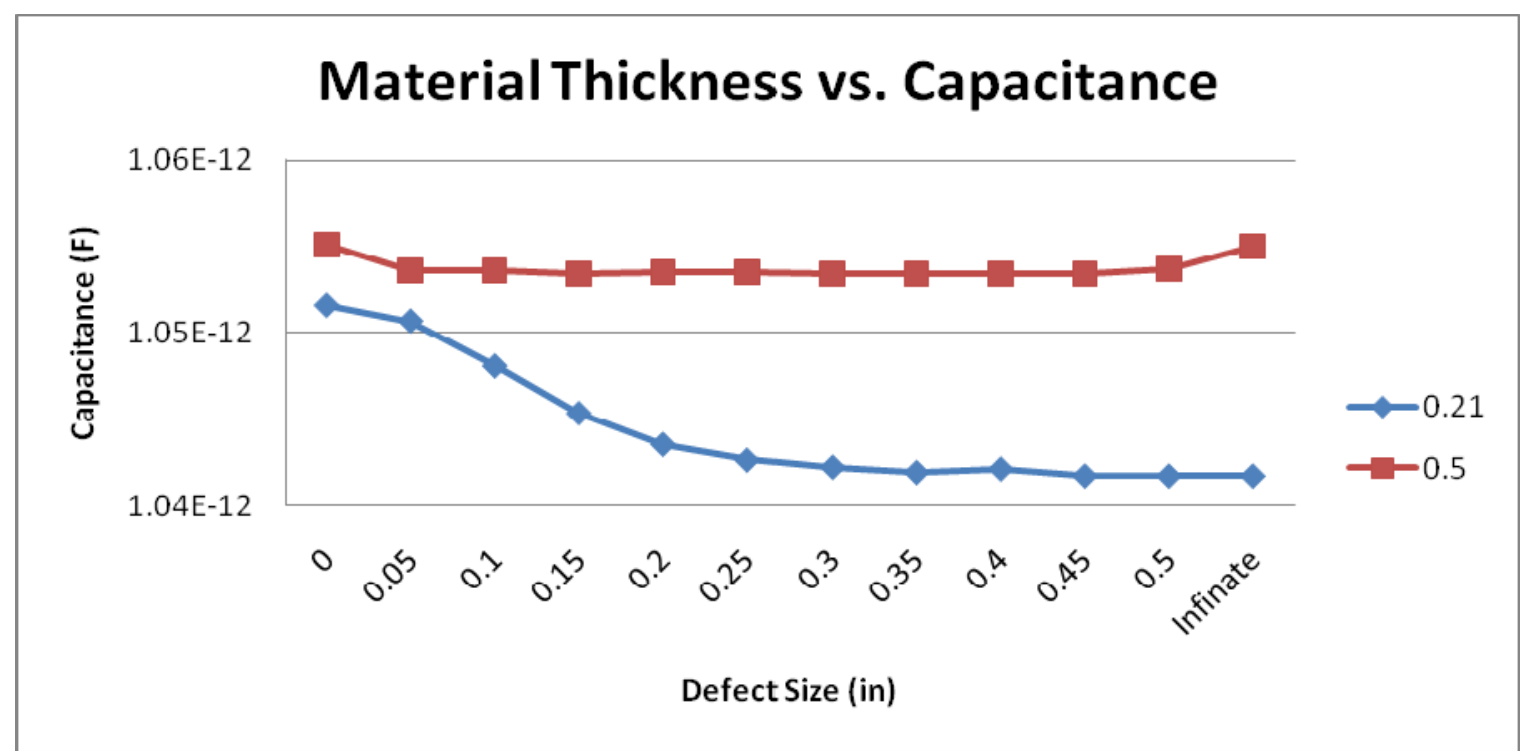

Figure 12. Defect Size vs. Capacitance 


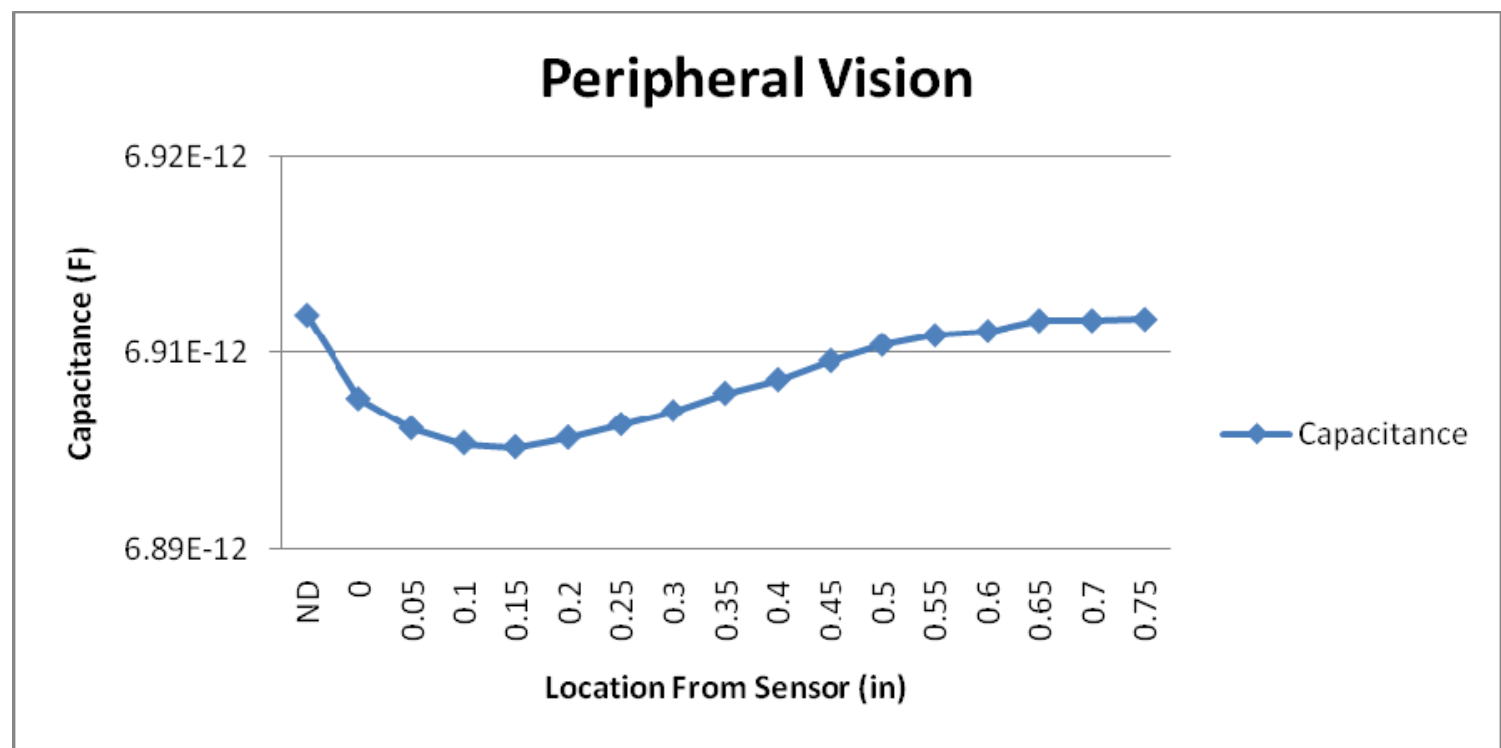

Figure 13. Defect Locations vs. Capacitance

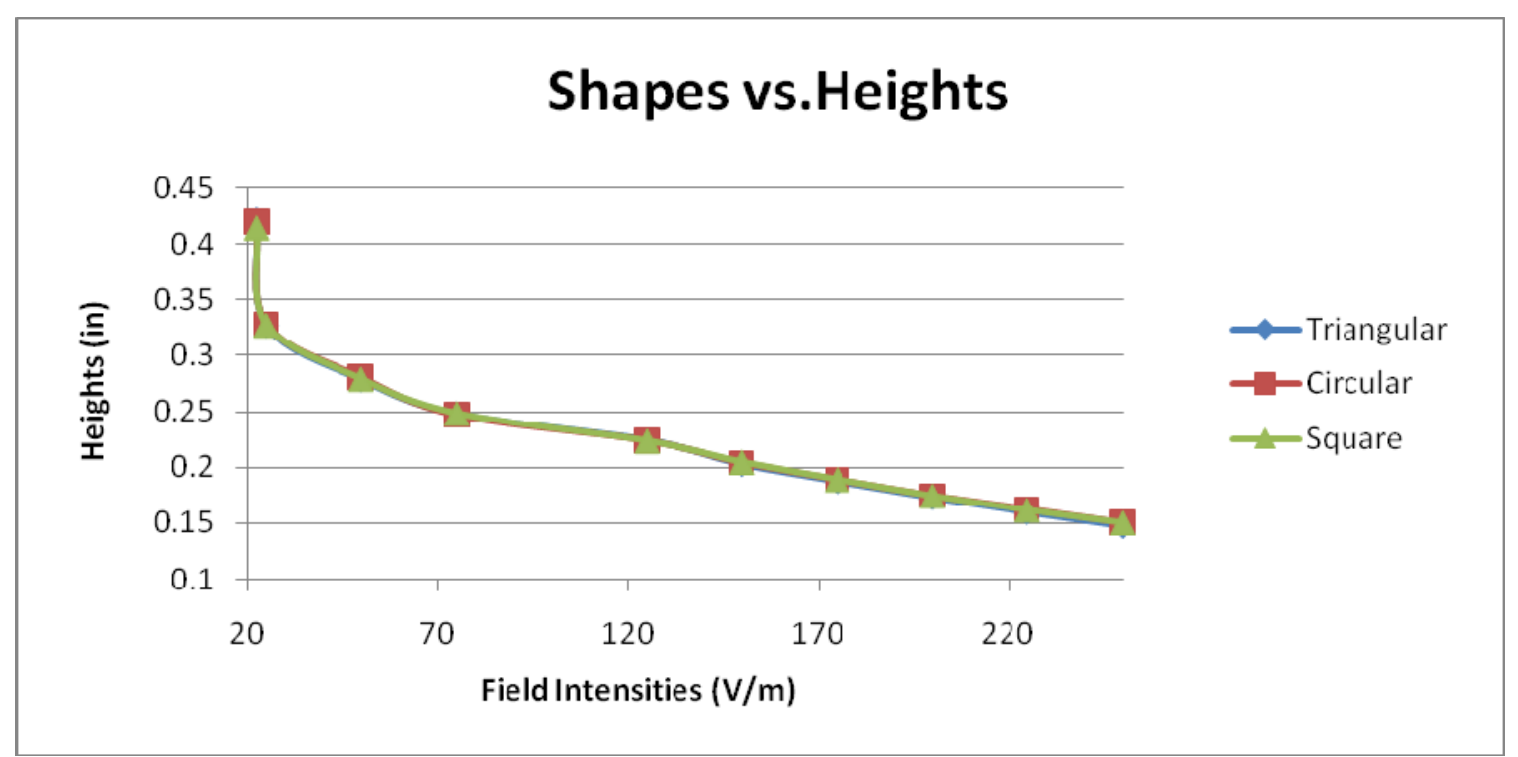

Figure 14. Field Intensities vs. Field Heights 


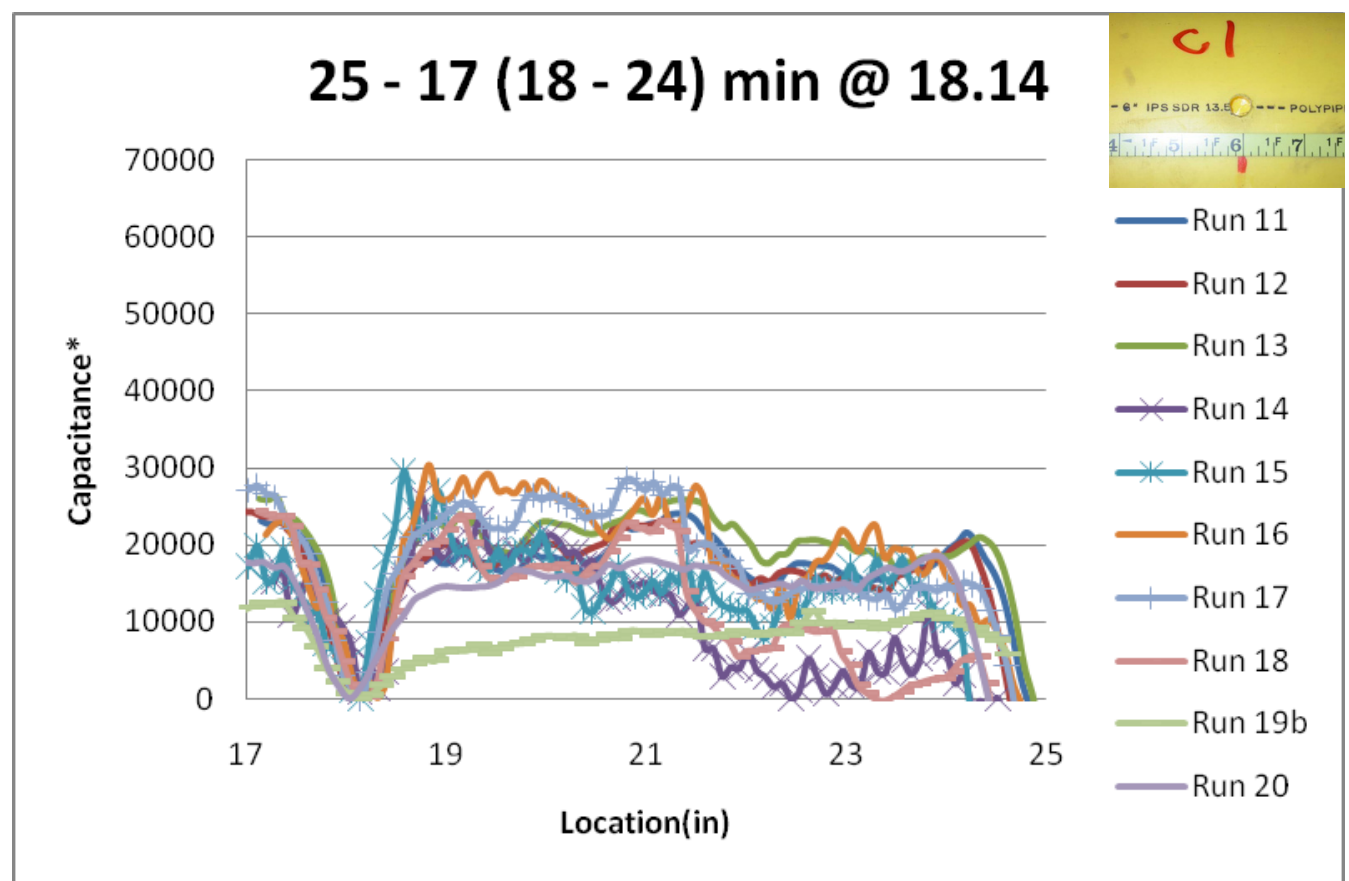

Figure 15. Battelle Testing Length 17"-25"

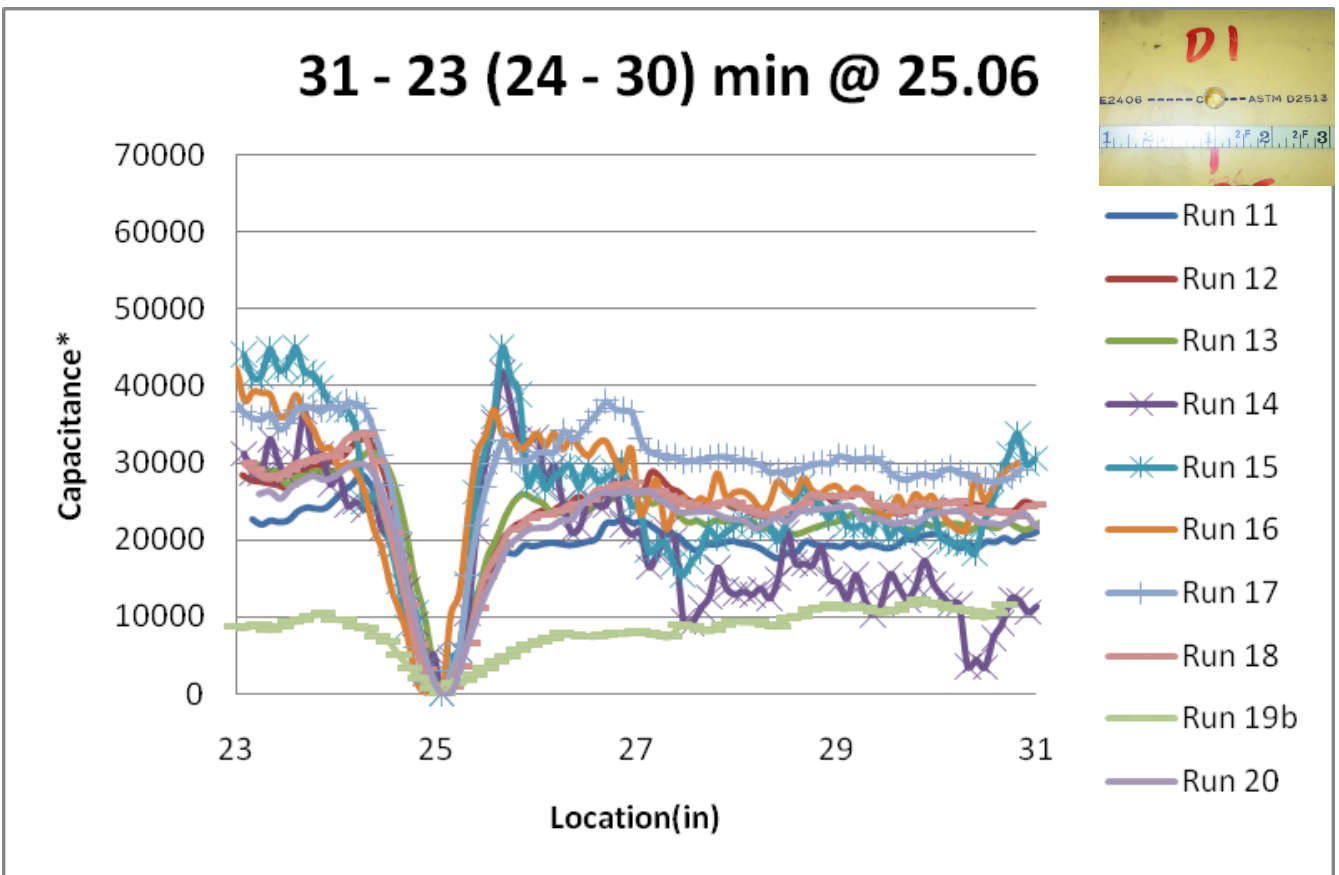

Figure 16. Battelle Testing Length 23"-31" 


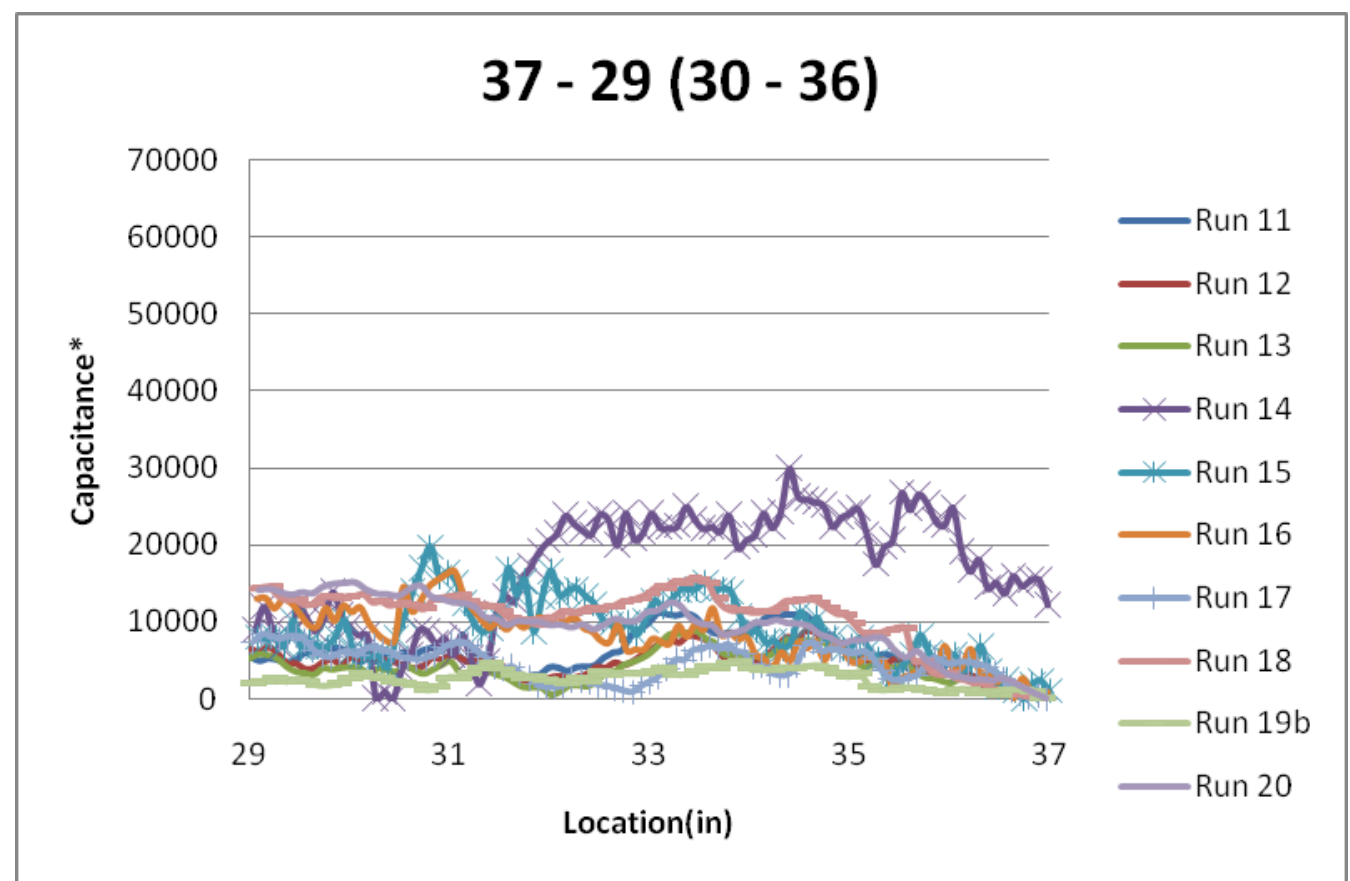

Figure 17. Battelle Testing Length 29"-37"

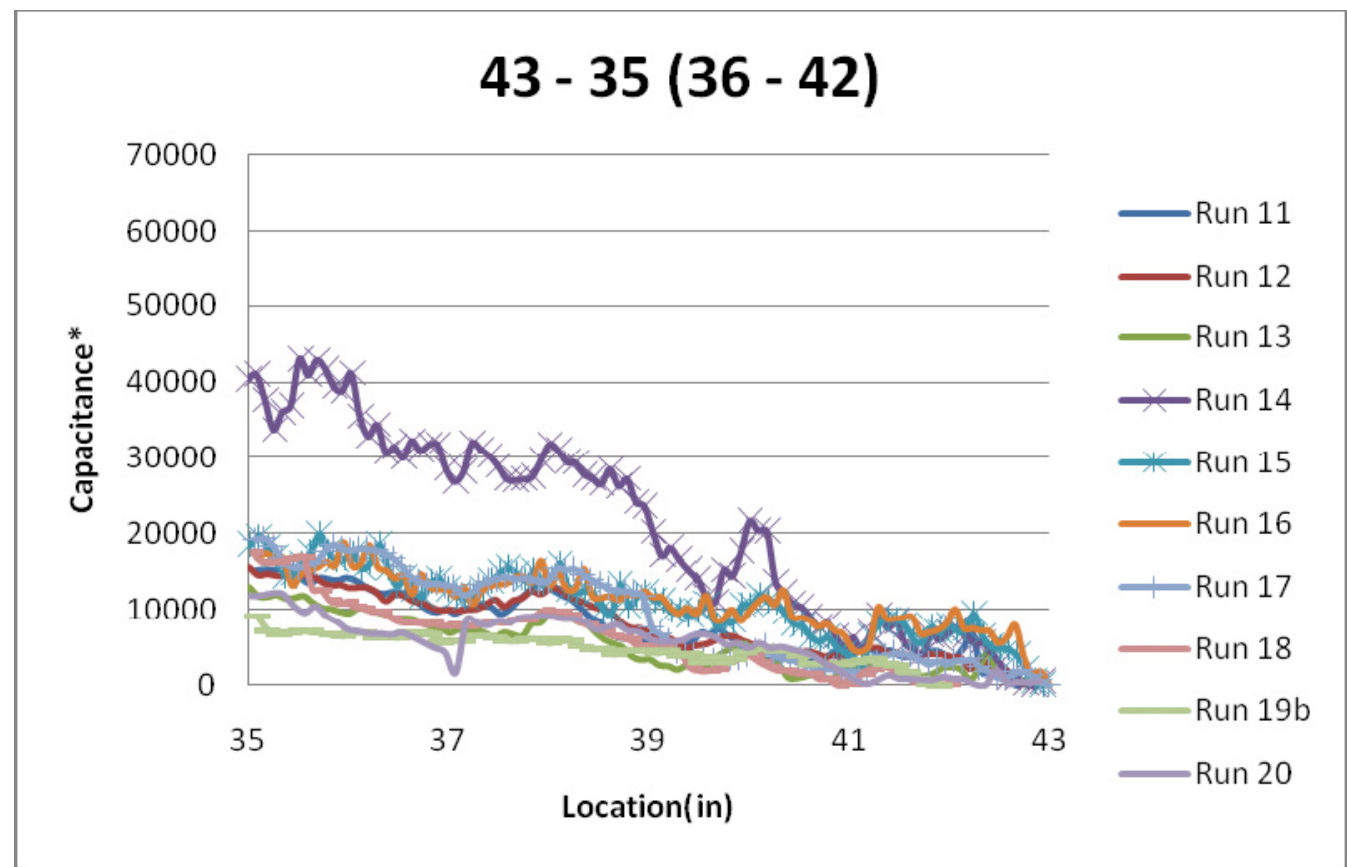

Figure 18. Battelle Testing Length 35"-43" 


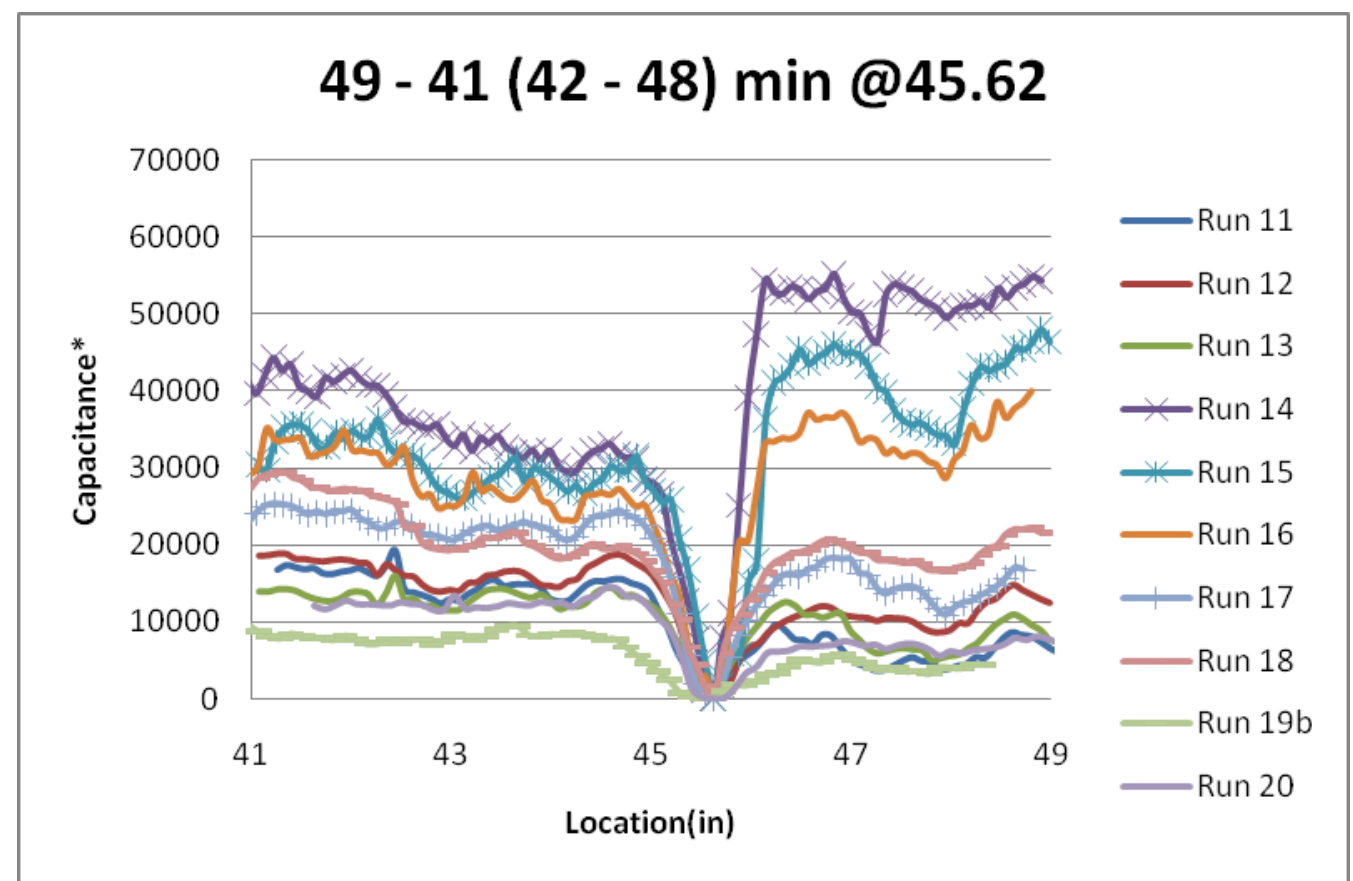

Figure 19. Battelle Testing Length 41"-49"

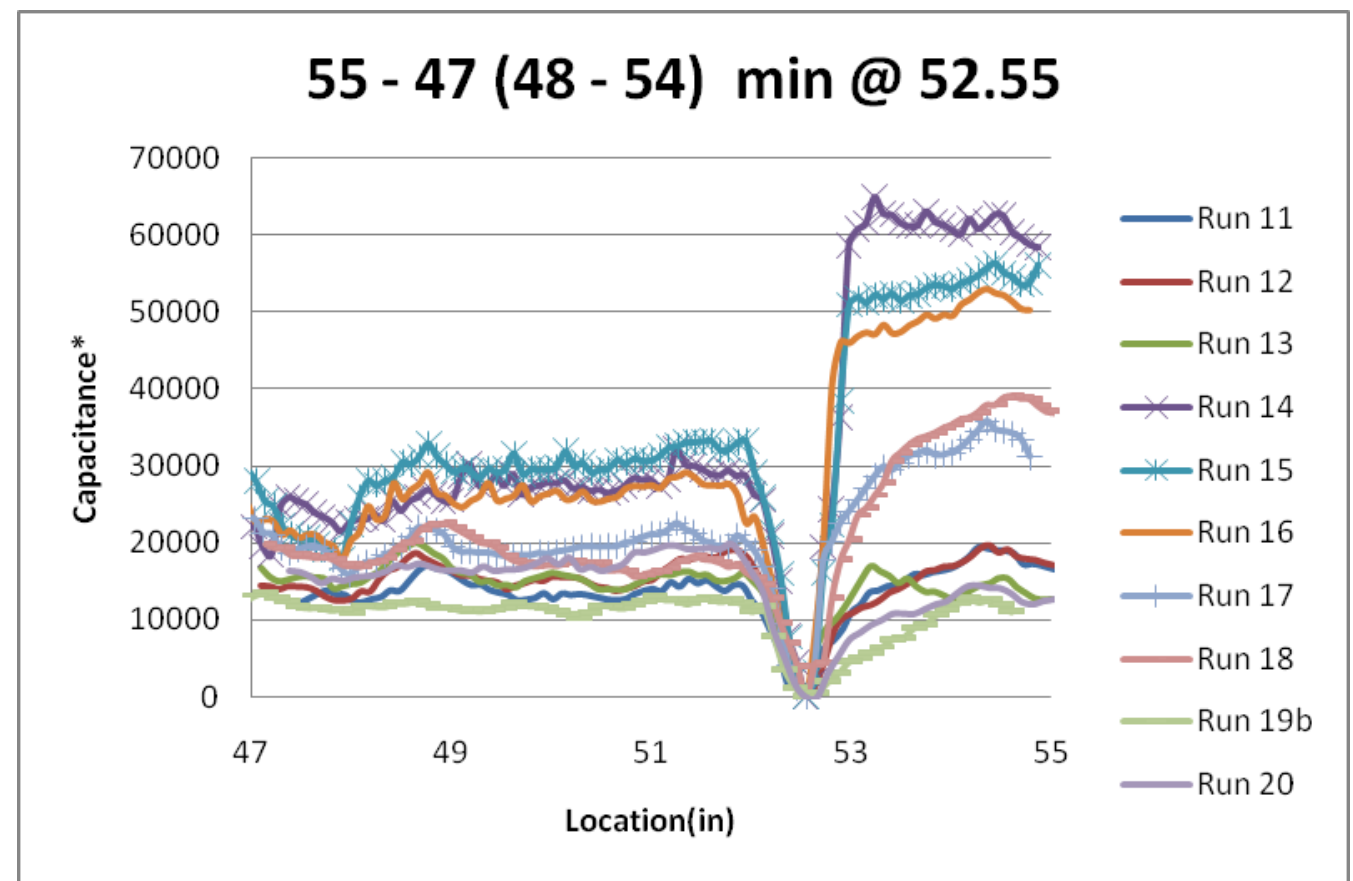

Figure 20. Battelle Testing Length 47"-55" 


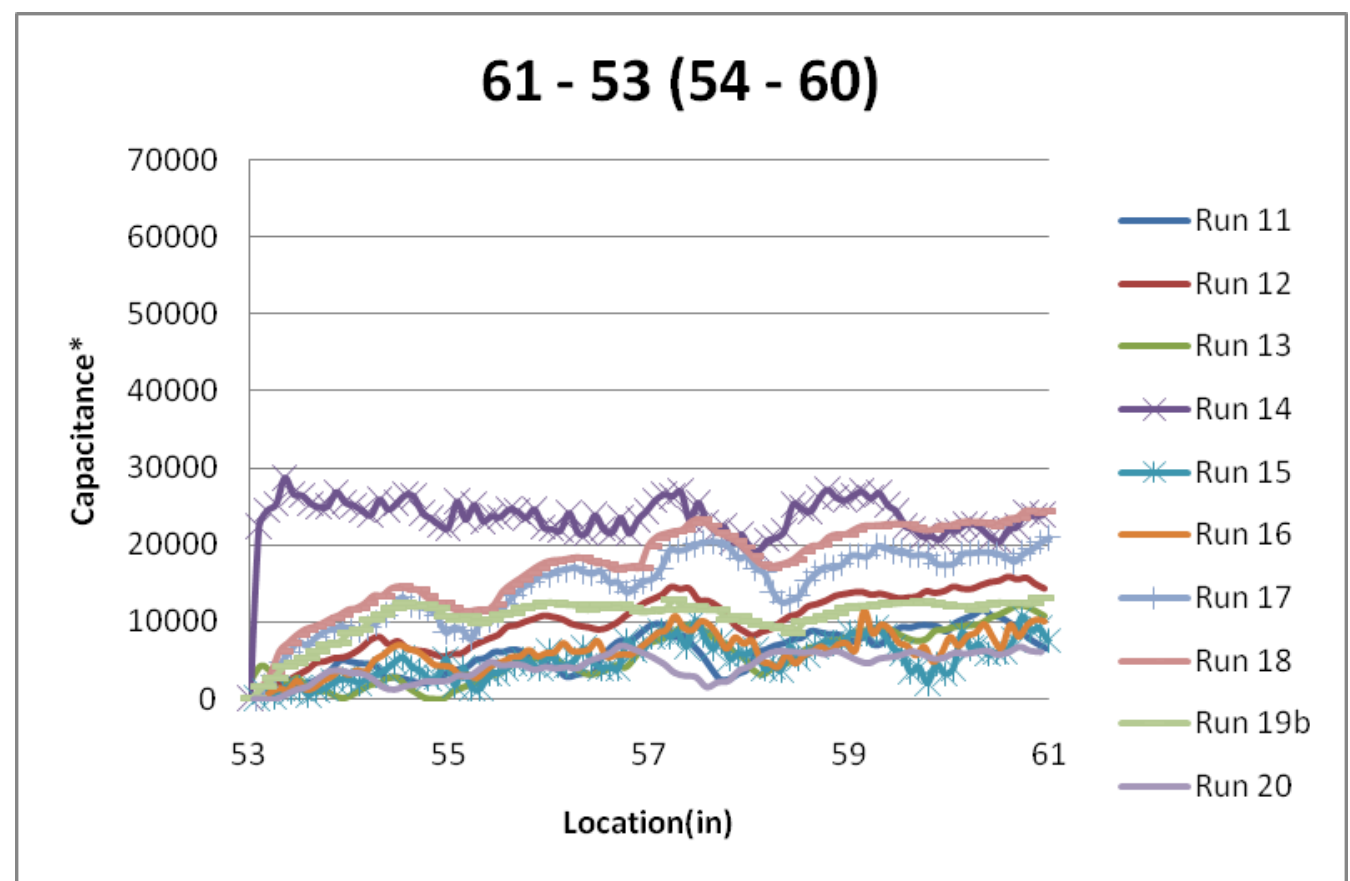

Figure 21. Battelle Testing Length 53"-61"

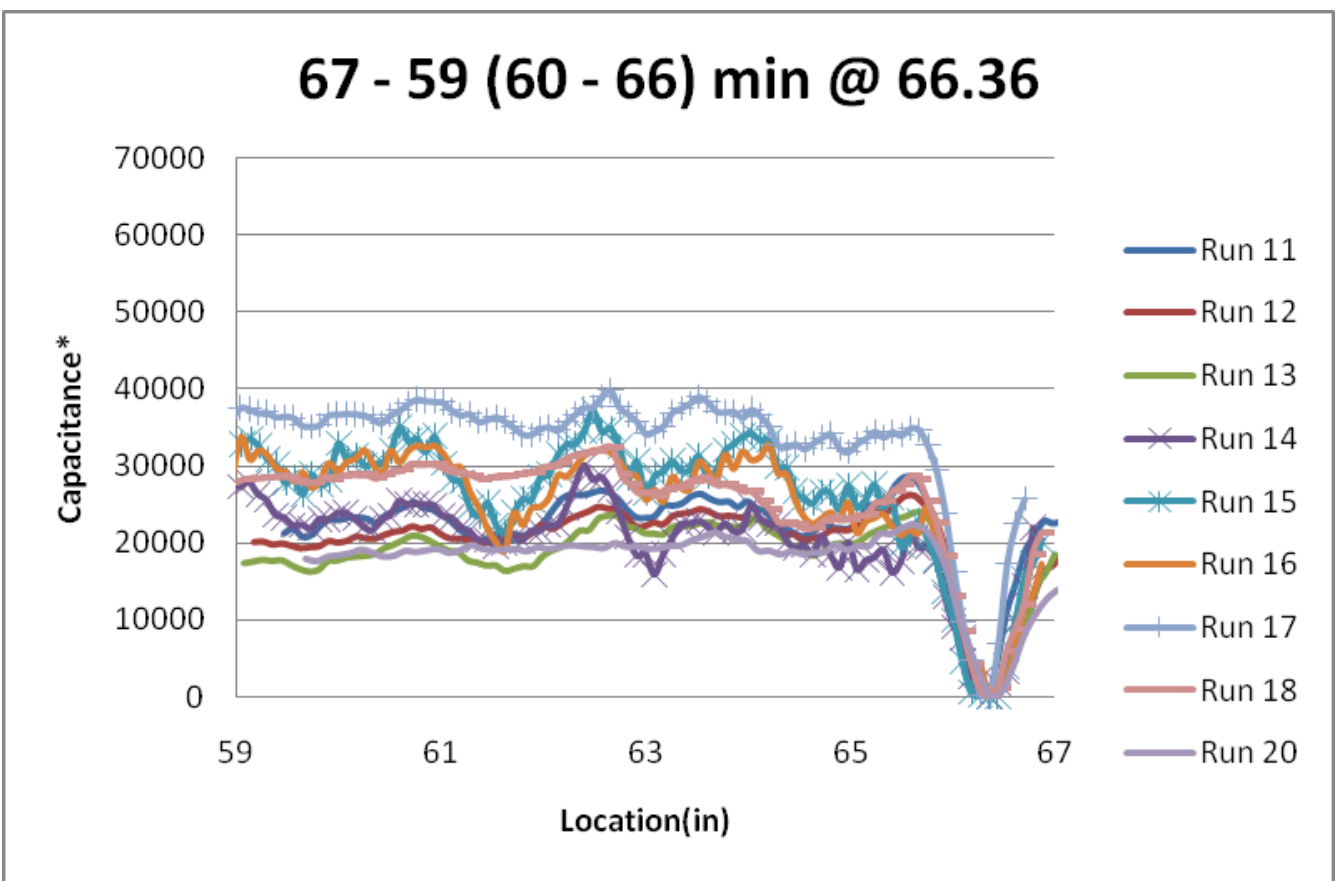

Figure 22. Battelle Testing Length 59"-67" 


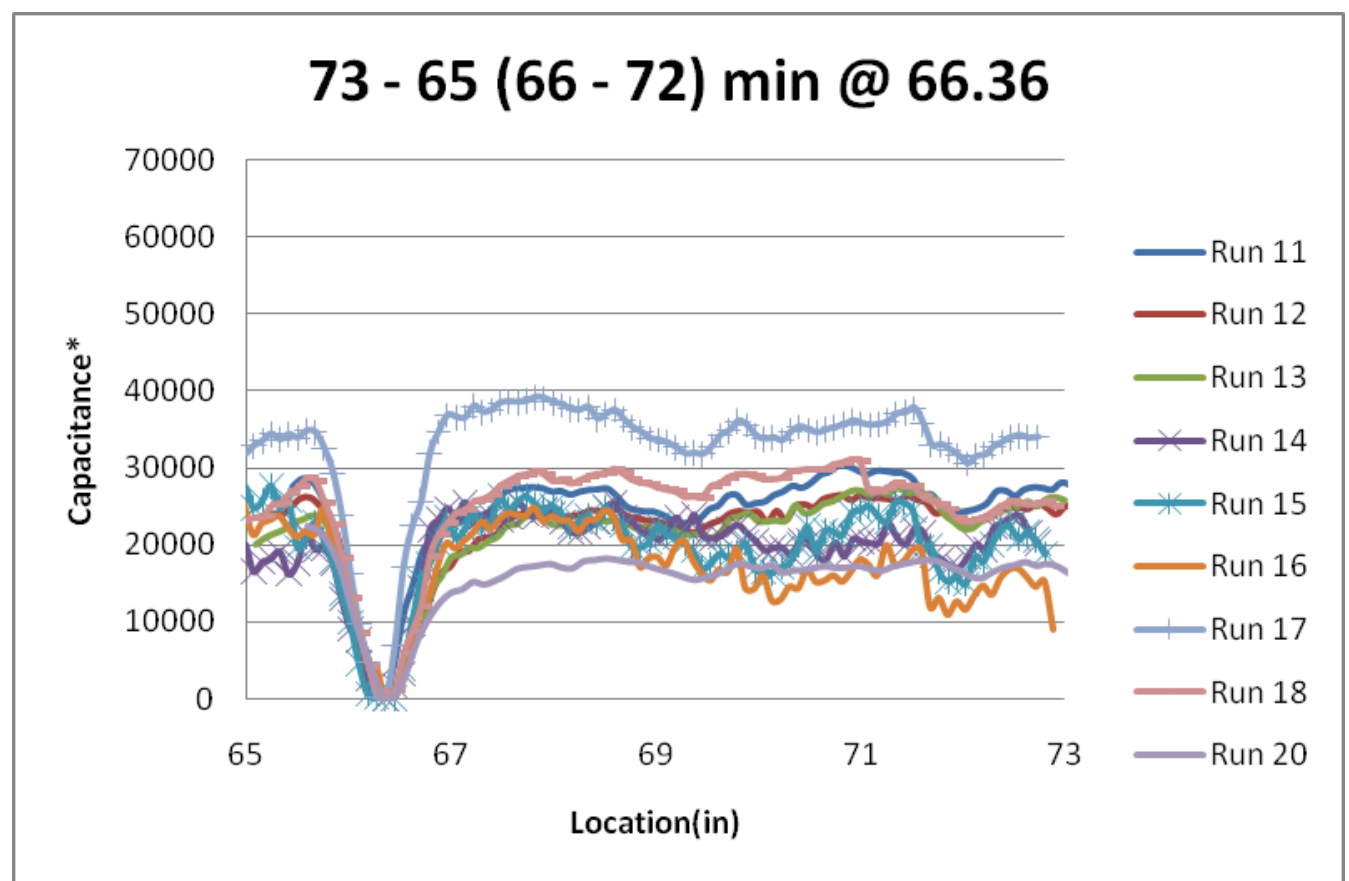

Figure 23. Battelle Testing Length 65"-73"

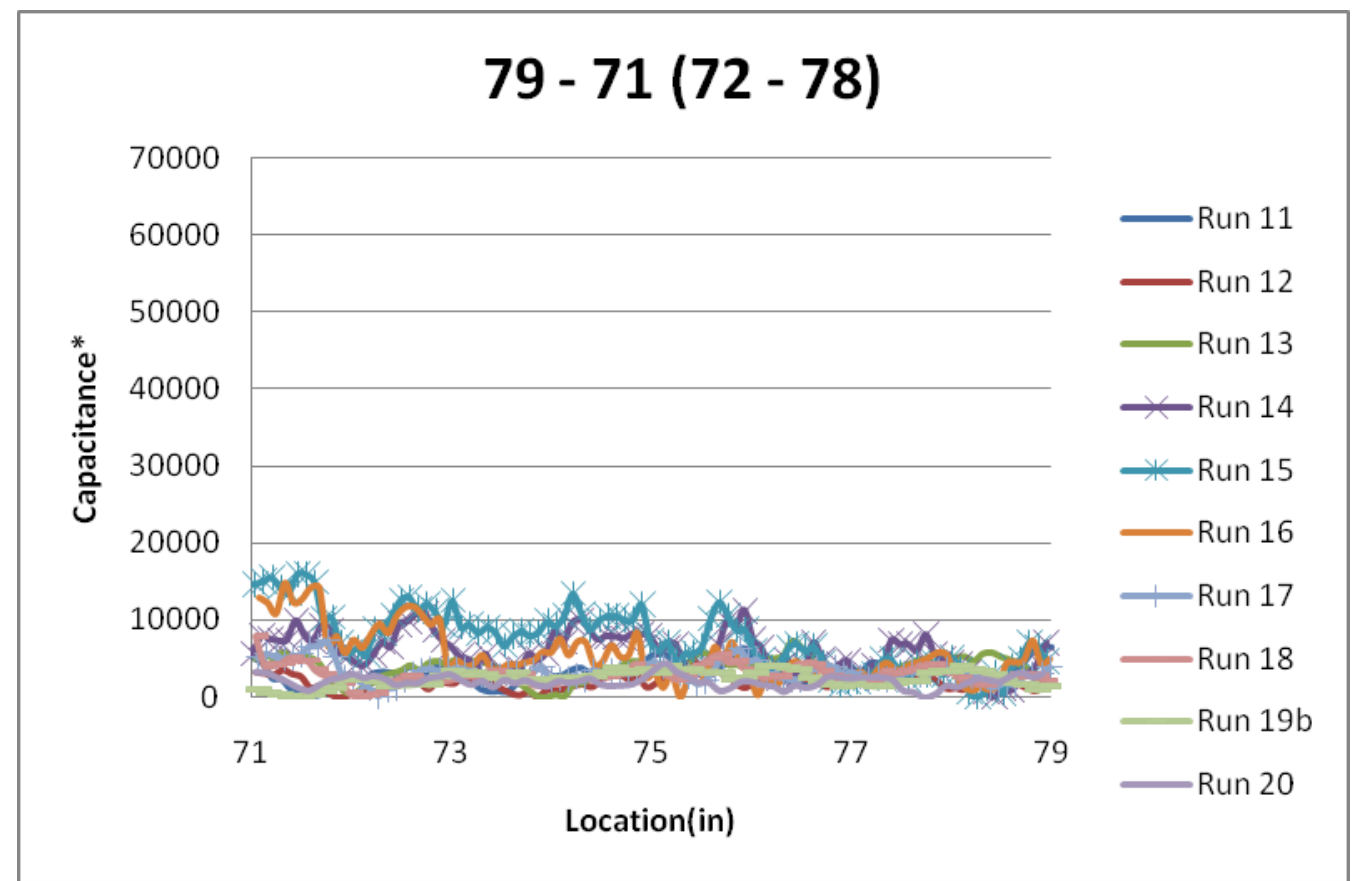

Figure 24. Battelle Testing Length 71"-79" 


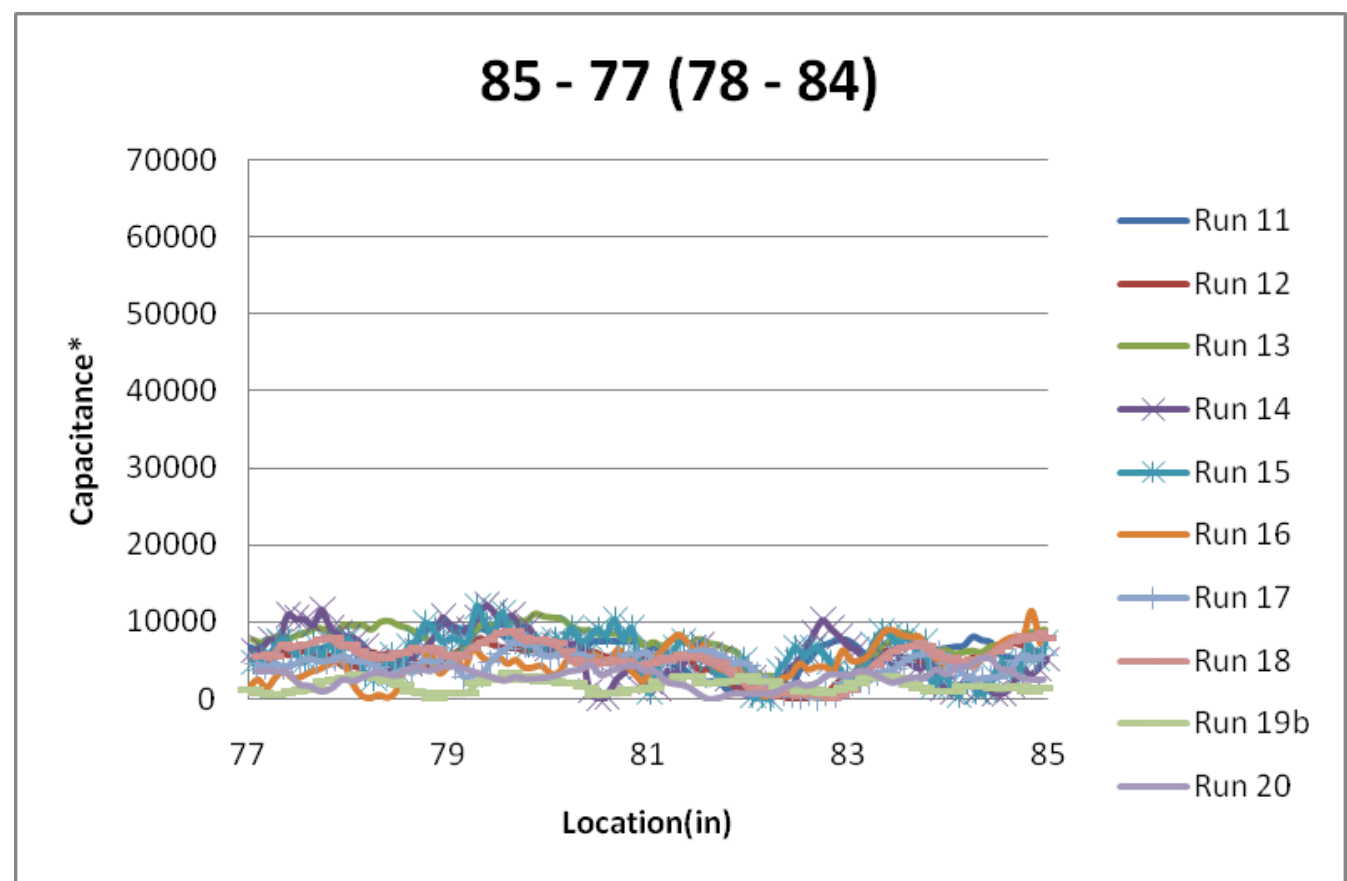

Figure 25. Battelle Testing Length 77"-85"

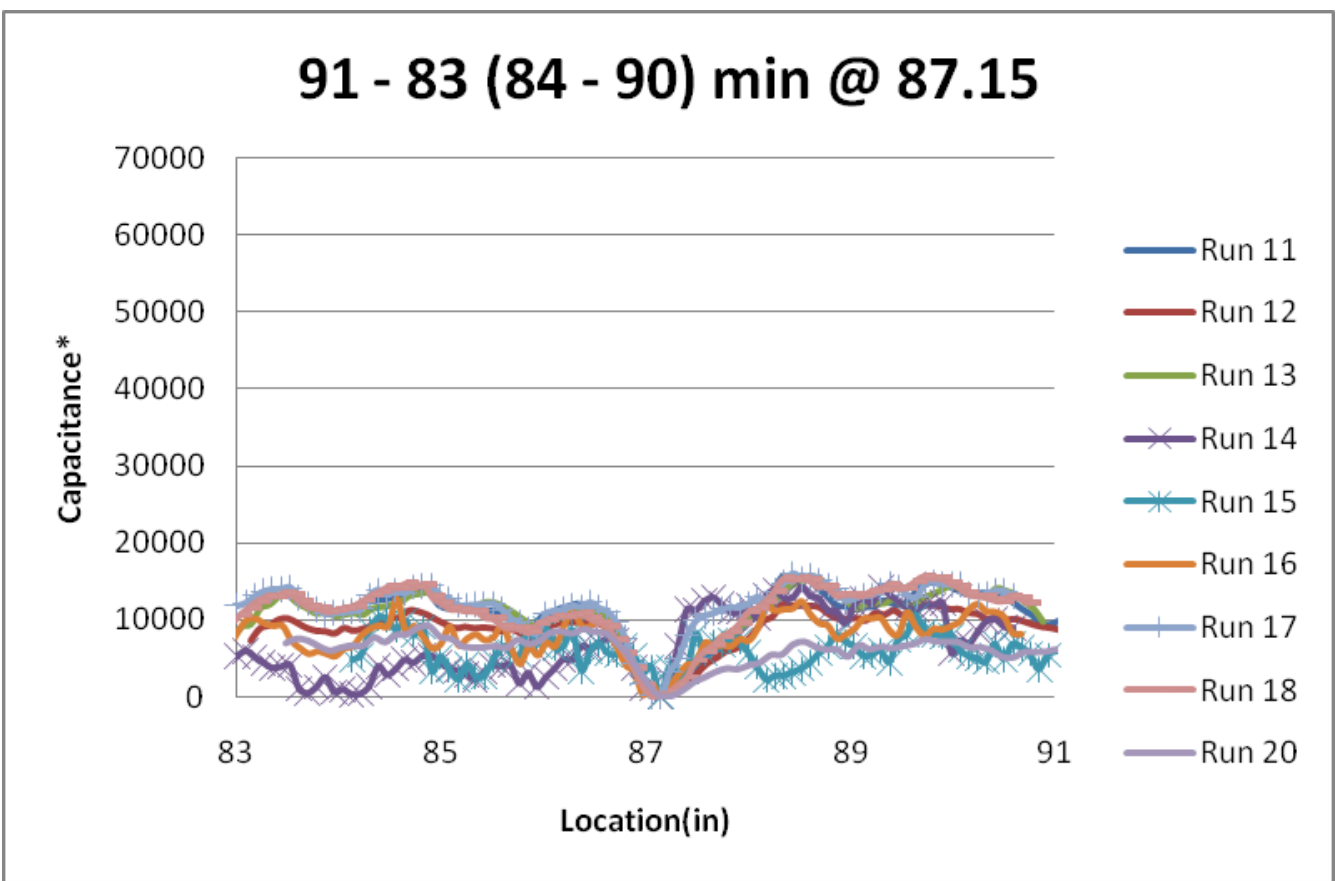

Figure 26. Battelle Testing Length 83"-91" 


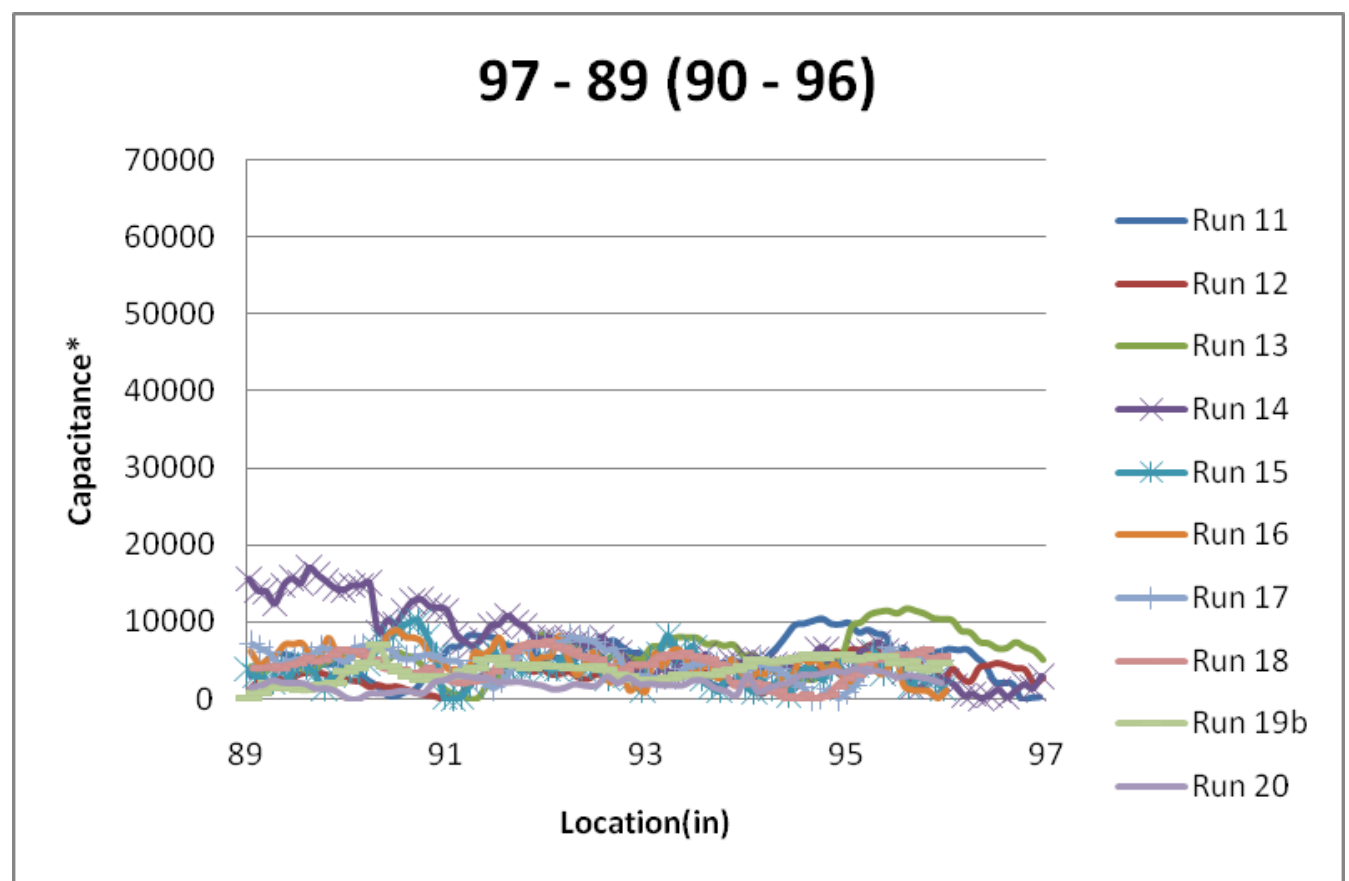

Figure 27. Battelle Testing Length 89"-97"

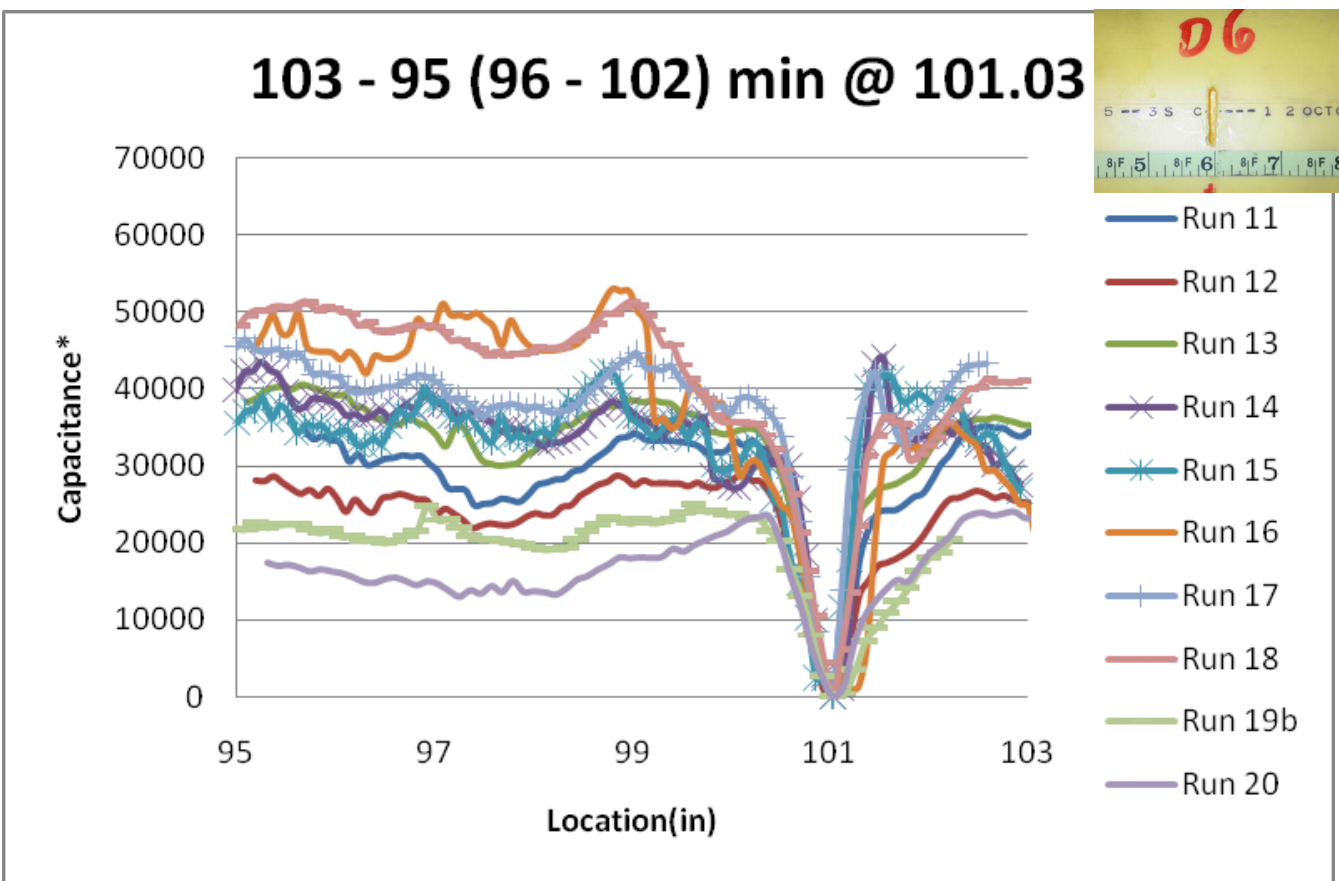

Figure 28. Battelle Testing Length 95"-103" 


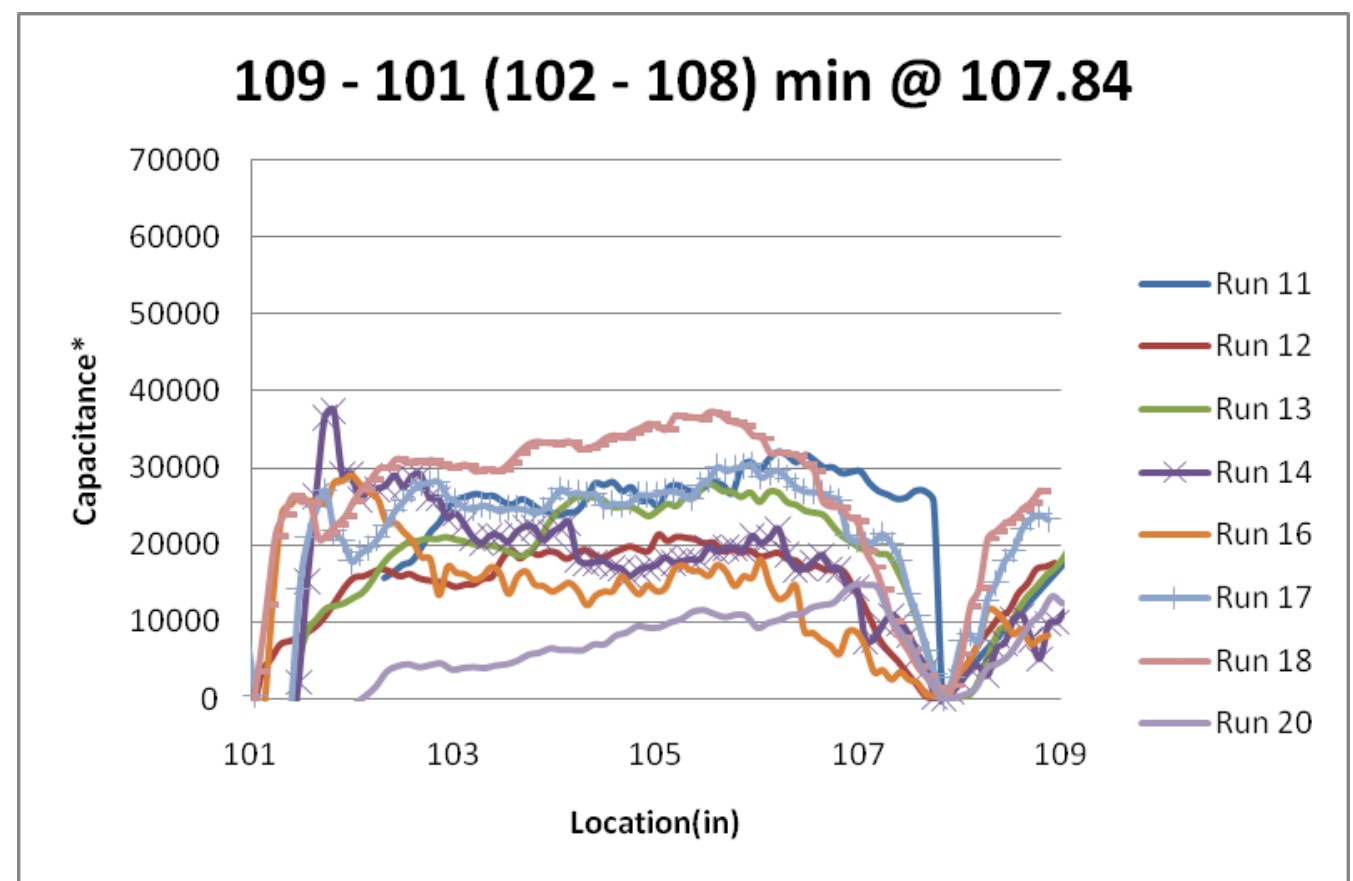

Figure 29. Battelle Testing Length 101"-109"

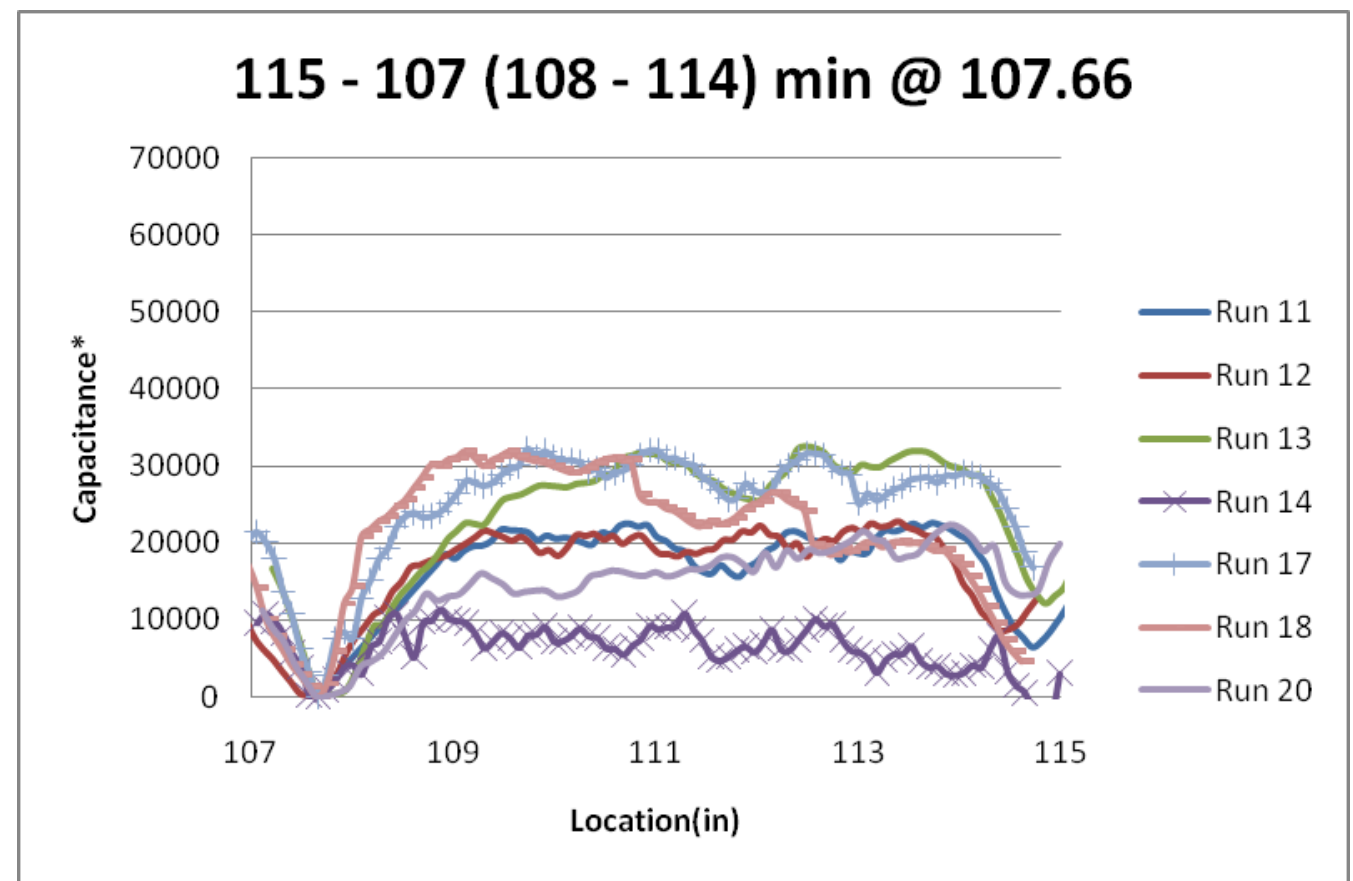

Figure 30. Battelle Testing Length 107"-115" 


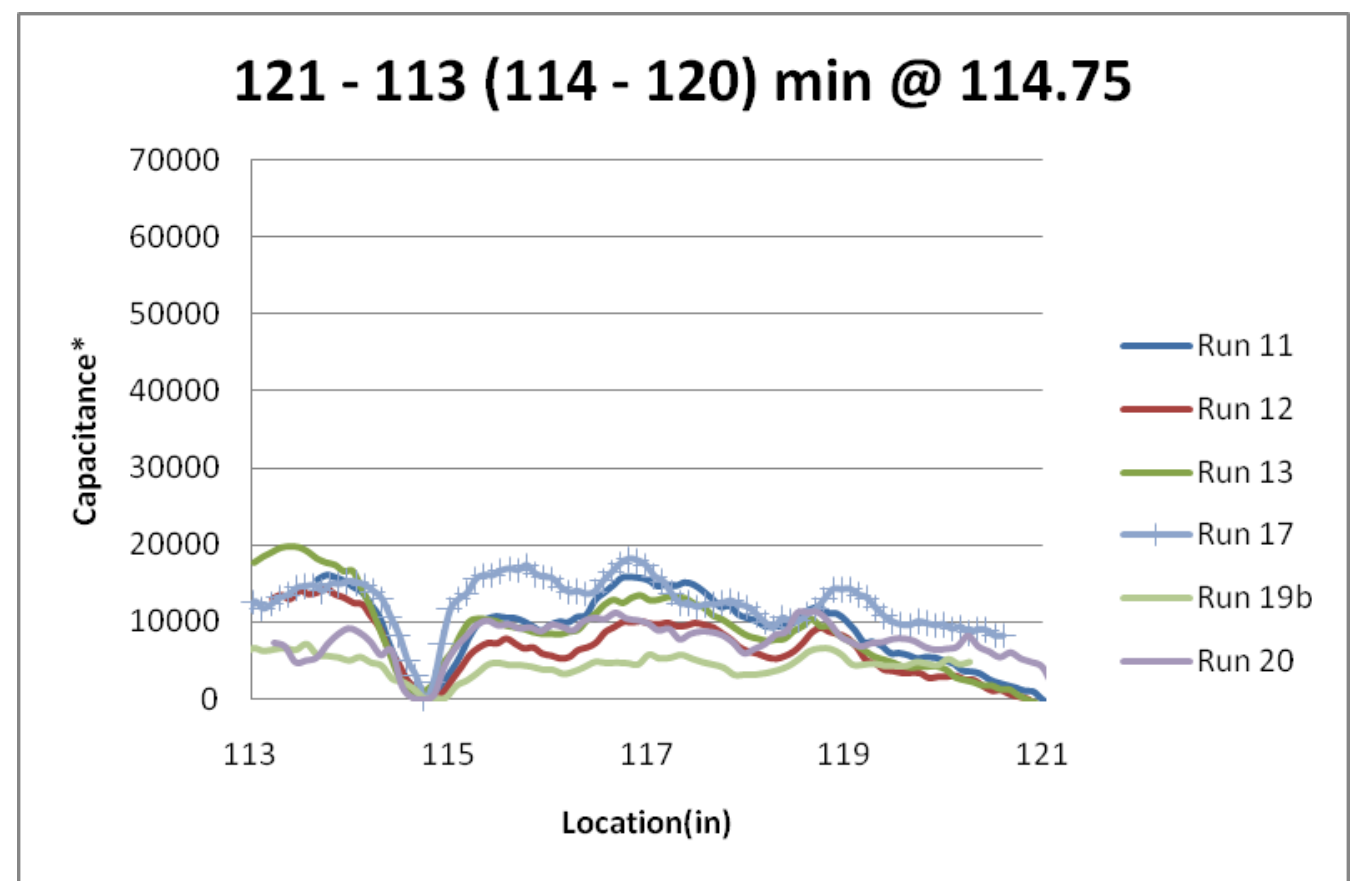

Figure 31. Battelle Testing Length 113"-121"

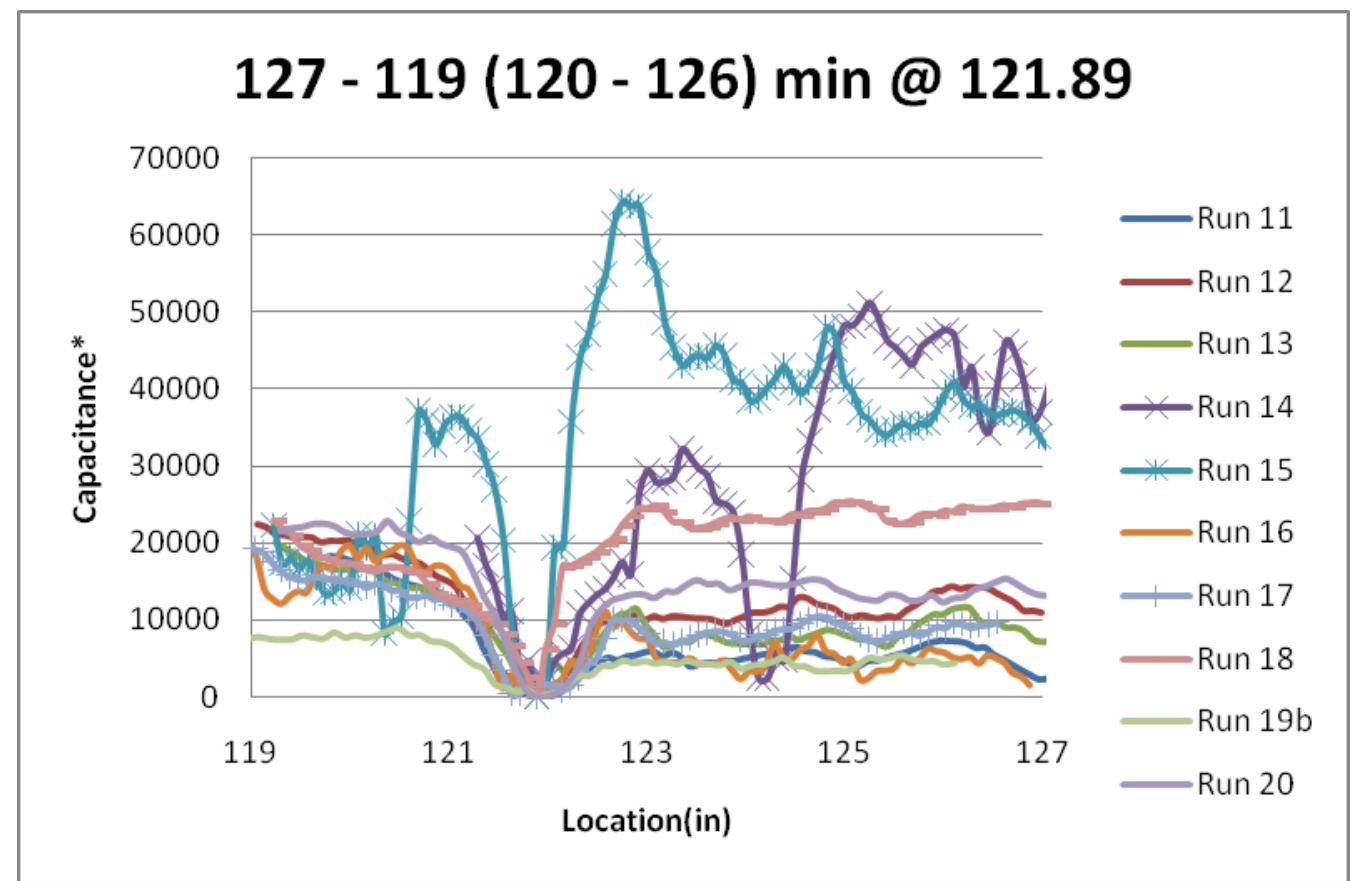

Figure 32. Battelle Testing Length 119"-127" 


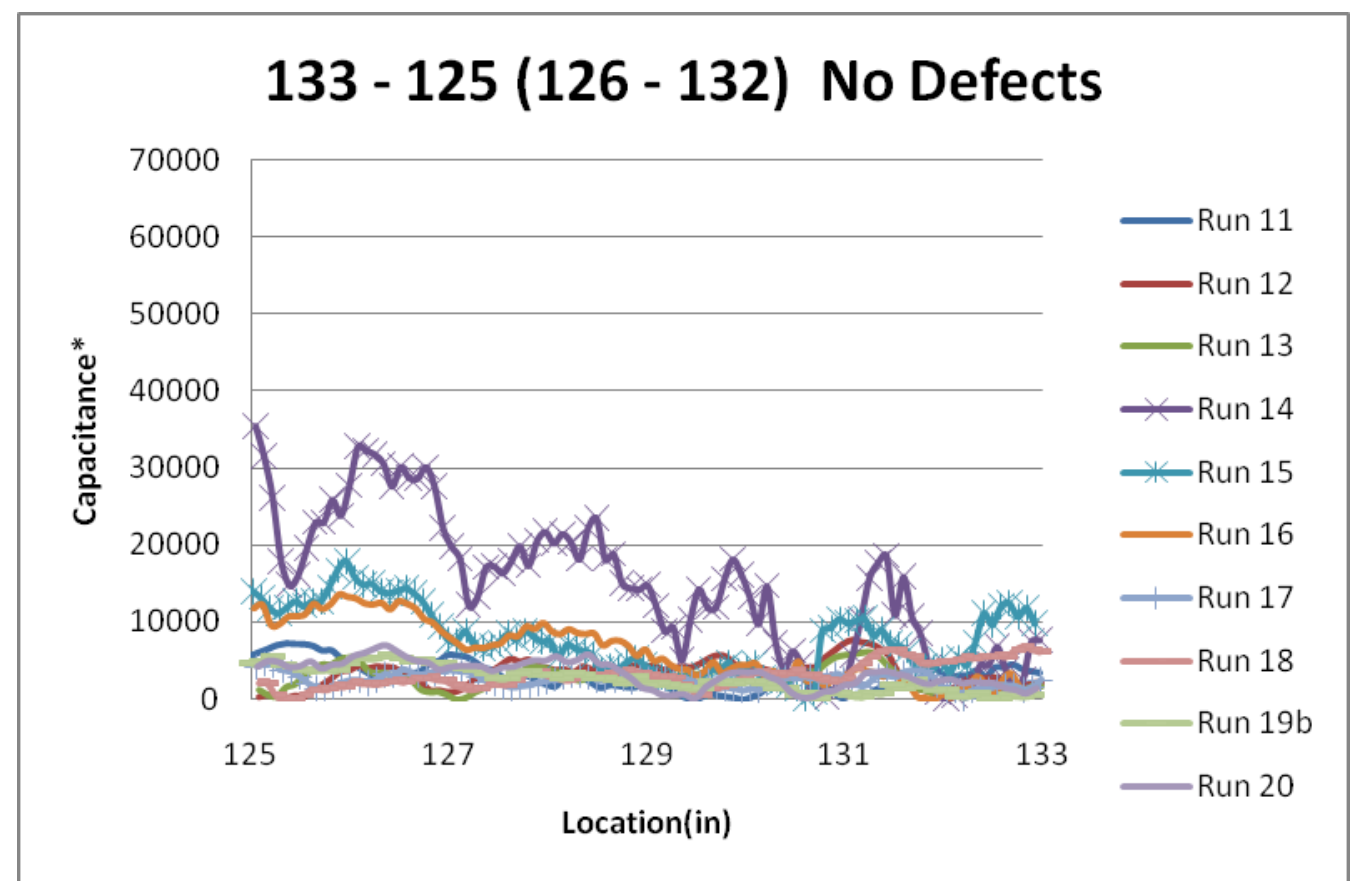

Figure 33. Battelle Testing Length 125"-133"

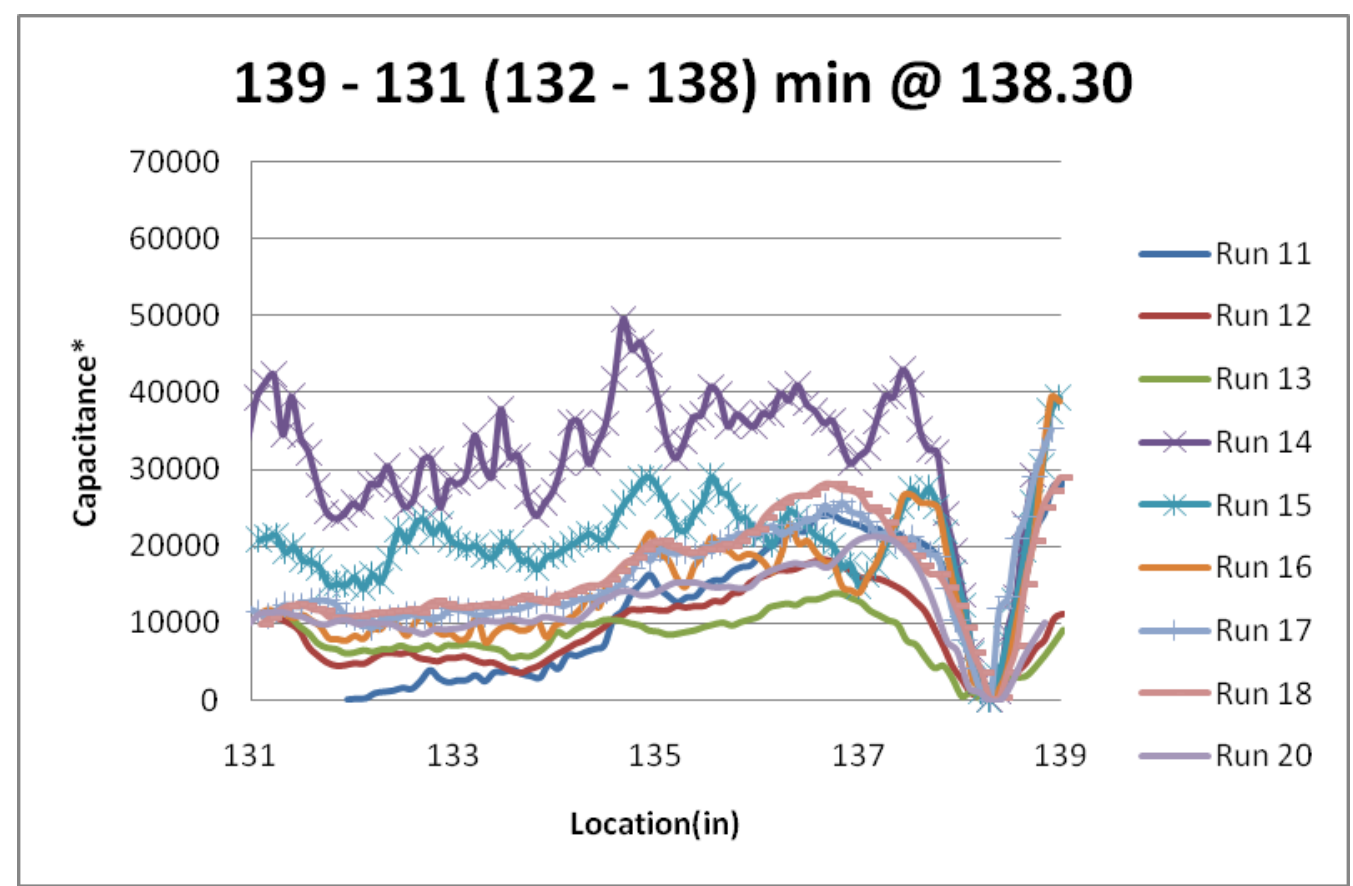

Figure 34. Battelle Testing Length 131"-139" 


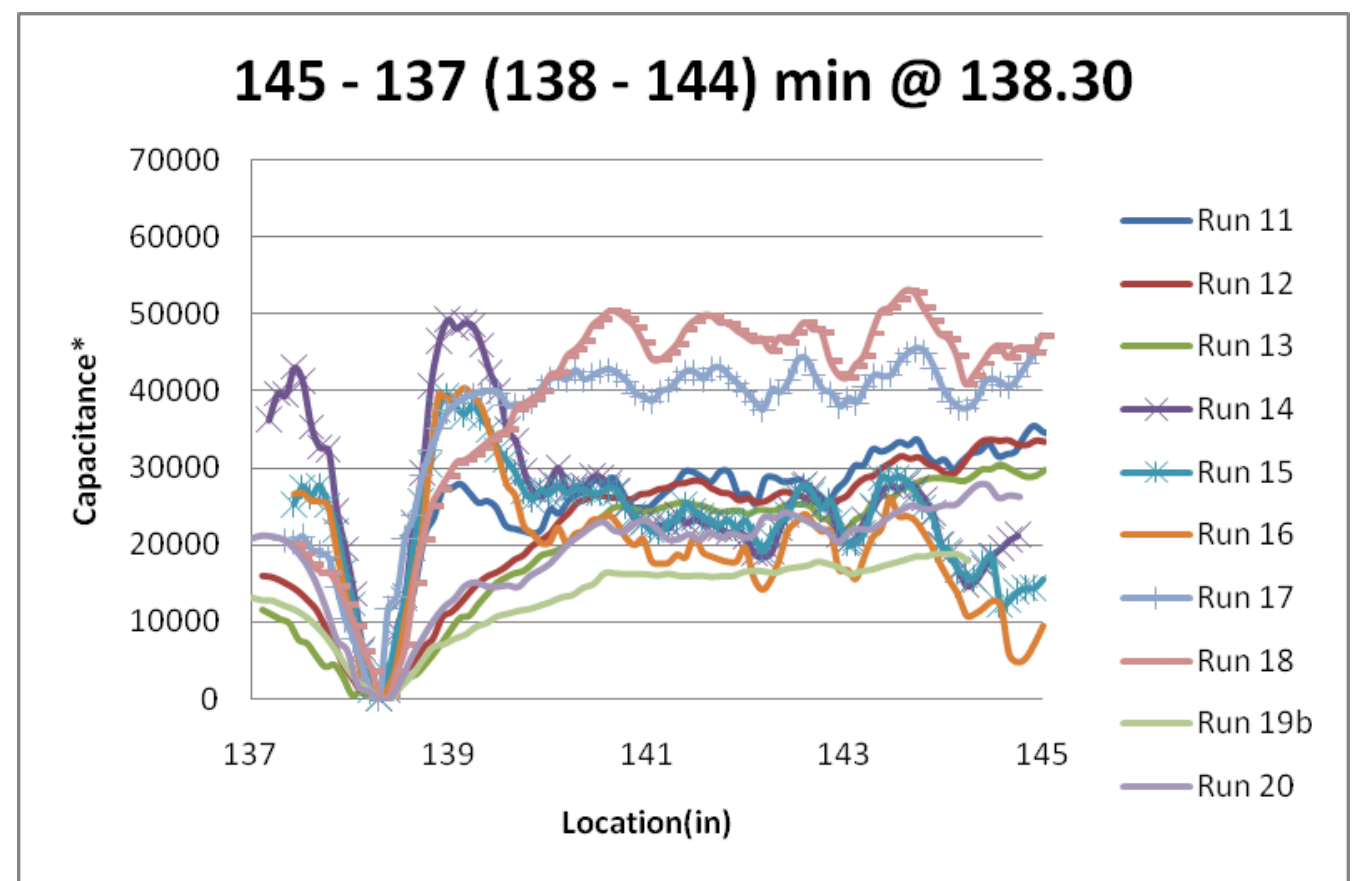

Figure 35. Battelle Testing Length 137"-145"

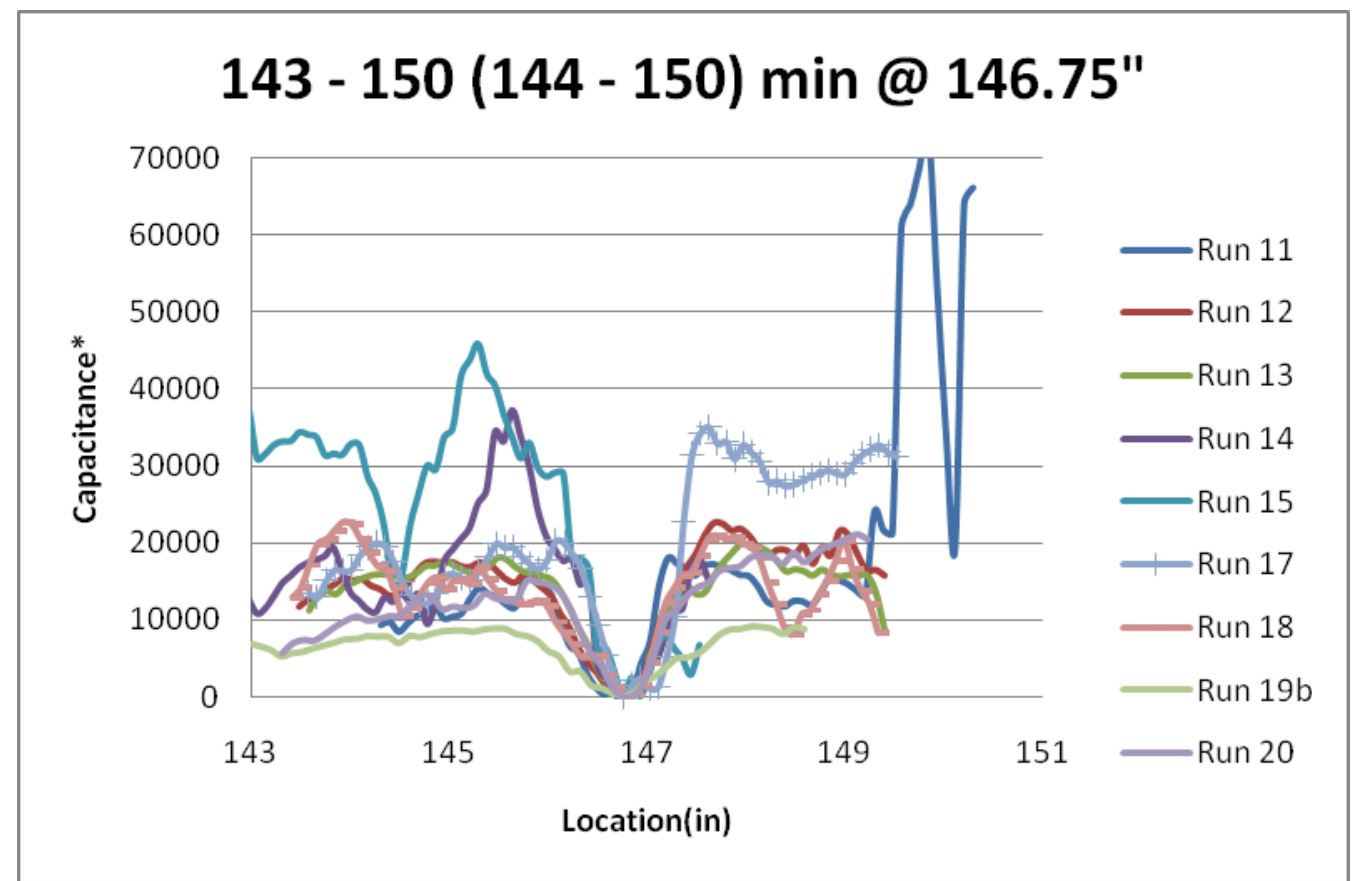

Figure 36. Battelle Testing Length 143"-150" 


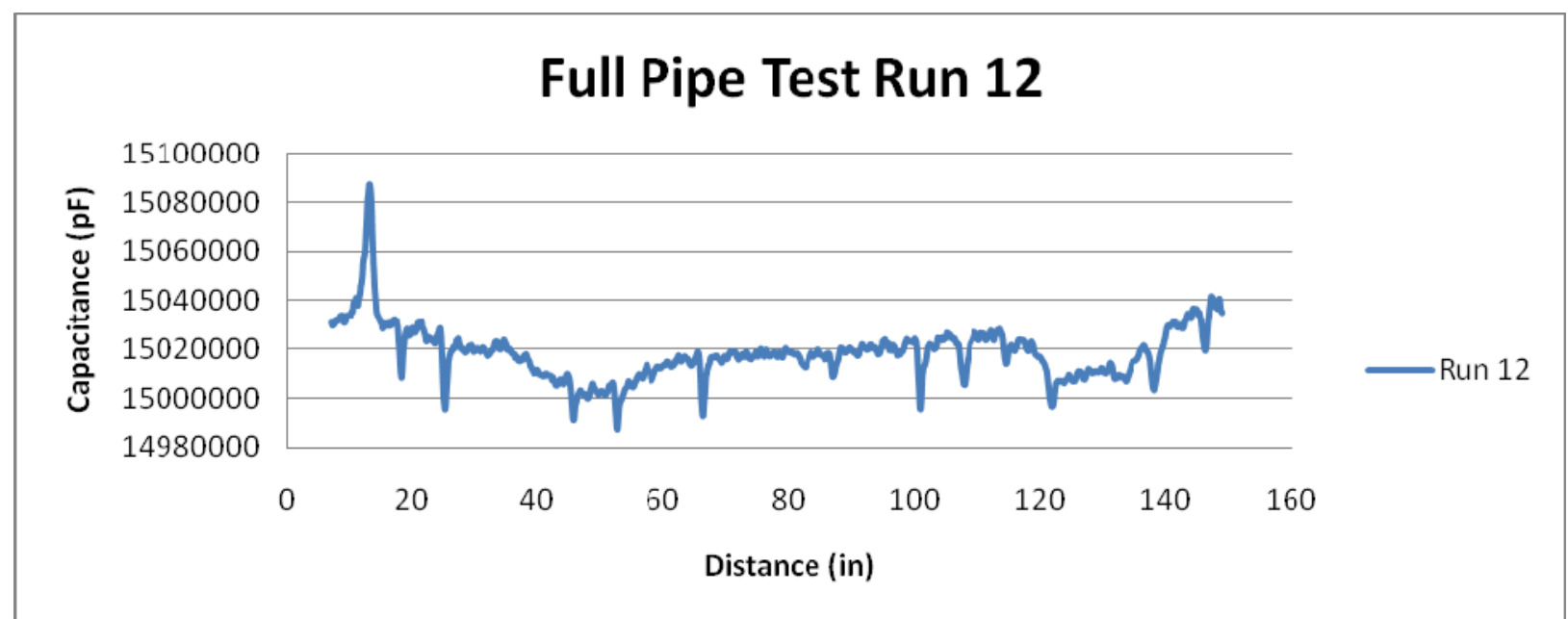

Figure 37: Full Pipe Test Run 12 
CURRICULUM VITAE

Travis Wayne Kirby 366 North Richhill St.

Waynesburg, PA, 15370

Email: travis.kirby@us.army.mil

\section{EDUCATION}

West Virginia University, Morgantown, WV 26505

MS, Electrical Engineering, Expected Graduation 2009

West Virginia University, Morgantown, WV 26505

BS, Electrical Engineering, May 2004

Alleghany College, Cumberland, MD

Welding Certificate, August 2000

Westmar High School, Lonaconing, MD 21539

May 1999

\section{TRAINING, AWARDS, AND CERTIFICATION}

- 140 hrs Arc Welding

- Medical - Combat Life Saver

- Bronze Star Medal for Service, Army Achievement Medal (4 Awards)

- Eta Kappa Nu (2004) and Sigma Phi Omega (2000) Honor Societies

Languages:

LabVIEW, Microsoft Office Macros

Software:

LabVIEW 7-8.6, Real Time and FPGA, MultiSIM, Electronic WorkBench, AutoCAD LT and 3D, MATLab, MathCAD, ALGOR, ANSOFT, Microsoft Office (Word, Excel, PowerPoint, Project), Microsoft Internet Explorer, Corel WordPerfect.

Hardware:

NI PCI, PXI, NI MXI-4, LabVIEW DAQCARD, CompactRIO

Programming:

In National Instruments LabVIEW:

Experience using LabVIEW Professional Development Suite, with real-time module and FPGA, used in the development of novel data acquisition and control systems for use with novel sensors and/or interfaced with custom designed electronic hardware with the main focus on development for research purposes. 
Experience in developing 2D and 3D designs for a multitude of force protection and general construction projects. Further AutoCAD 2D experience in developing electrical layout / floor plan for subordinate battalions. Successfully modified and implemented military construction standards to ensure consistency between 2 engineering battalions.

\section{KNOWLEDGE, SKILLS, AND ABILITIES}

Project Management Skills:

Experience providing support to the Department of Energy's, Energy System Dynamics Division as a project manager for the Advanced Power Systems Sensors and Controls Developments task. Experience with task personnel management, management of task funds within defined cost plan, developing comprehensive project reports for the DOE customer, reviewing and adjusting the DOE customer statement of work, supervising day to day project activities, and determining validity of project deliverables and or milestones. Experience with planning, organizing, and managing research, development, and demonstration (RD\&D) projects coupled with experience in the preparation of project progress and or budget documentation. Experience as a Military Contracting Officer Representative (COR), providing support to missions conducted by the MND-North. Experience with assisting management (Commanders, Senior Staff Officers, project leads, etc), in developing projects and or missions. Experience with rapidly expanding current knowledge skills and abilities to meet new and challenging tasks.

Engineering Skills:

Experience providing support to the Department of Energy's, Energy System Dynamics Division as a research engineer for the onsite support contract. Experience providing engineering research support to the development, design, construction, implementation and operations of new technology for both complex and small scale novel sensor and control systems utilized for testing and characterization.

Written and Oral Communication:

Experience in technical report writing, instruction and calibration manual development and R\&D design documentation for projects. Experience with the work requests / work order system and a good working knowledge of its function. Experience with technical report writing using various formats. Proficient in technical based presentations for research project deliverables. Also skilled at facilitating meetings with multiple engineering and technical disciplined teams. Prepared and briefed battle update briefs for the section to give the commander situational awareness of his area of operations.

\section{EXPERIENCE}

PARSONS - US DOE-NETL, Morgantown, WV

August 2008 to Present

Energy System Dynamics Division for Sensors and Controls Support

Title: Engineer 2

Currently supporting the Energy System Dynamics Division as both a project (task) manager and as a research engineer $(\mathrm{EE})$. Main engineering duties consist of designing control and data acquisition systems using National Instruments LabVIEW programming software. Program duties programs that efficiently captures, records, and analyzes data from the ICE Version 2 hardware that is effectively allowing the team to begin expanding on the hardware. Advanced knowledge of LabVIEW Real Time, FPGA, and 8.5 programming and have developed many new techniques/VI's that is allowing the ICEV2 to 
capture endless streams of data with no lag in the computer software. As part of the development and testing phase gained an extensive knowledge of the ICEV2 system, how it works, both hardware and software. Worked as software developer of the control system for the ICEV2 system. Extensive knowledge with circuit analysis techniques used for trouble shooting complex systems. Task manager of the project, worked with DOE project managers in development of cost plans for future funding of this task. Developed monthly cost management reports for DOE project managers and DOE division directors.

ORISE - US DOE-NETL, Morgantown, WV

May 2005 to May 2007

Gas Energy System Dynamics Division for Sensors and Controls

Title: Research Engineer/Research Associate

Supported research projects by designing LabVIEW programs that efficiently captured, recorded, and analyzed data from the ICEBOX hardware that effectively allowed the team to expand, design, and upgrade to a newer system. Advanced knowledge of LabVIEW programming and have developed many new techniques/VI's that allowed the ICEBOX to capture endless streams of data with no lag in the computer software, collected data over 24 hour period at $0.5 \mathrm{~T}$ byte $(500,000,000,000$ bytes $)$. As part of the development and testing phase gained an extensive knowledge of the ICEBOX system, how it works, both hardware and software. Worked as software developer of the control system for the ICEBOX system. Was a participating member of the implementation team for multiple locations testing of the ICEBOX system. Knowledge in circuit analysis and trouble shooting systems consisting of the combination of software and hardware using both off the shelf equipment and novel systems. Skilled in soldering methods and the use of both proto boards and breadboards for initial circuit design testing.

Engineering Research Division for Capacitance Probe Development Title: Engineering Student Intern

As part of a multifaceted team of engineers and scientists, researched and developed the capacitive sensor. My portion of the project was working directly with the project-engineering manager in the application of using Finite Element Analysis (FEA) simulations. Developed preliminary FEA reports weekly that assisted the team with important data that helped the sensor development and ultimately help lead to a successful. Was an active participant in an independent offsite testing of the Capacitance Probe. The test resulted in $99 \%$ sensor accuracy and lead to a successful contract deliverable.

WEST VIRGINIA ARMY NATIONAL GUARD

July 1999 to Present

West Virginia National Guard, Eleanor, WV

Technical Chief (1st Lieutenant)

June 2007- Present

Participated in Operation Iraqi Freedom (OIF 7) as Technical Chief for design section specialized in force protection (Over 30 missions completed). Conducted electrical missions throughout northern Iraq providing soldiers with reliable, safe electricity that allowed them to continue operations (14 electrical missions completed). Provided leadership and guidance to the section in lieu of the Design Engineer absents, a position that is 3 echelons above current rank.

Provided expertise to 4 Brigade Combat Team Engineers in force protections, vertical, and horizontal construction. Successfully managed over 100 design packets valued at a total of 10 Million dollars. During a mission, demonstrated valor during combat by performing aid to a wounded soldier, and assuming gunner position in the convoy while under attack.

West Virginia National Guard, Kingwood, WV

Platoon Leader/Detachment Commander (2nd/1st Lieutenant) 
July 1998 - May 2007

Worked with the military school to ensure that the soldiers met their standard requirements by prompting physical activities. Wrote training schedules and appointed men to instruct other soldiers in activities involving Army Engineering. Managed and supervised detachment size element as well as equipment that values over $\$ 1,000,000$

West Virginia University Army ROTC, Institute, WV

Gold Bar Recruiter (2nd Lieutenant)

May 2004 - Dec 2004

Coordinated recruitment efforts among High Schools and Universities. Reviewed, selected and nominated multiple qualified individuals to receive ROTC scholarships and waivers. Enhanced oral communication and public relation skills by distributing ROTC information. Oversaw department in recruitment efforts, devoting extra hours to ensure recruitment goals. Recognized for demonstrating professionalism, competence, and initiative in Officer Evaluation Report and awarded an Army Achievement Medal. 